Florida International University FIU Digital Commons

$11-14-2013$

\title{
Rapid Inline Derivatization of Primary and Secondary Amine Containing Drugs by Capillary Electrophoresis with Laser-Induced Fluorescence
}

Britt E. Turnquest

Florida International University, britt.turnquest@gmail.com

DOI: $10.25148 /$ etd.FI13120614

Follow this and additional works at: https://digitalcommons.fiu.edu/etd

Part of the Analytical Chemistry Commons

\section{Recommended Citation}

Turnquest, Britt E., "Rapid Inline Derivatization of Primary and Secondary Amine Containing Drugs by Capillary Electrophoresis with Laser-Induced Fluorescence" (2013). FIU Electronic Theses and Dissertations. 998.

https://digitalcommons.fiu.edu/etd/998 


\title{
FLORIDA INTERNATIONAL UNIVERSITY
}

Miami, Florida

\section{RAPID INLINE DERIVATIZATION OF PRIMARY AND SECONDARY AMINE CONTAINING DRUGS BY CAPILLARY ELECTROPHORESIS WITH LASER- INDUCED FLUORESCENCE}

\author{
A dissertation submitted in partial fulfillment of \\ the requirements for the degree of \\ DOCTOR OF PHILOSOPHY \\ in \\ CHEMISTRY \\ by
}

Britt E. Turnquest 
To: Dean Kenneth G. Furton

College of Arts and Sciences

This dissertation, written by Britt E. Turnquest, and entitled Rapid Inline Derivatization of Primary and Secondary Amine Containing Drugs by Capillary Electrophoresis with Laser-Induced Fluorescence, having been approved in respect to style and intellectual content, is referred to you for judgment.

We have read this dissertation and recommend that it be approved.

Jose R. Almirall

Yong Cai

David C. Chatfield

Deodutta Roy

Bruce R. McCord, Major Professor

Date of Defense: November 14, 2013

The dissertation of Britt E. Turnquest is approved.

Dean Kenneth G. Furton

College of Arts and Sciences

Dean Lakshmi N. Reddi

University Graduate School

Florida International University, 2013 
C Copyright 2013 by Britt E. Turnquest

All rights reserved. 


\section{DEDICATION}

I dedicate this dissertation to my mother and my brother, Noel. Without your support I never would have made it here. Even though you had no idea what I was talking about most of the time, you've always listened and that's meant more to me than words can express. I love you both. 


\section{ACKNOWLEDGMENTS}

I wish to thank the members of my committee, in particular my advisor Dr. Bruce R. McCord, for their continuous support and encouragement during this entire process. Every one of you has contributed something vital to this experience, from grammatical advice to general good humor, and I am more appreciative of those contributions than words can express. Thank you as well, Dr. Quirke and Dr. Blanes for your assistance during the course of this work.

I would also like to thank the department of Chemistry and Biochemistry at Florida International University for funding me via a teaching assistantship for the majority of my time here and as the Latin American and Caribbean graduate fellow for my final semester of study. Not only did it make this endeavor financially possible, it also provided me with invaluable practical experience for the real world.

My final acknowledgment is to the contributions of the various other members of the McCord research. Though the group composition has changed over the years, the support has been steadfast and instrumental in my making it through this. Nowhere in the world is there another group of people who will ever understand me as you all do. 


\section{ABSTRACT OF THE DISSERTATION \\ RAPID INLINE DERIVATIZATION OF PRIMARY AND SECONDARY AMINE CONTAINING DRUGS BY CAPILLARY ELECTROPHORESIS WITH LASER- INDUCED FLUORESCENCE}

by

Britt E. Turnquest

Florida International University, 2013 Miami, Florida

Professor Bruce R. McCord, Major Professor

Despite the ongoing "war on drugs" the seizure rates for phenethylamines and their analogues have been steadily increasing over the years. The illicit manufacture of these compounds has become big business all over the world making it all the more attractive to the inexperienced "cook". However, as a result, the samples produced are more susceptible to contamination with reactionary byproducts and leftover reagents. These impurities are useful in the analysis of seized drugs as their identities can help to determine the synthetic pathway used to make these drugs and thus, the provenance of these analytes. In the present work two fluorescent dyes, 4-fluoro-7-nitrobenzofurazan and 5-(4,6-dichlorotriazinyl)aminofluorescein, were used to label several phenethylamine analogues for electrophoretic separation with laser-induced fluorescence detection.

The large scale to which law enforcement is encountering these compounds has the potential to create a tremendous backlog. In order to combat this, a rapid, sensitive method capable of full automation is required. Through the utilization of the inline derivatization method developed whereby analytes are labeled within the capillary 
efficiently in a minimum span of time, this can be achieved. The derivatization and separation parameters were optimized on the basis of a variety of experimentally determined factors in order to give highly resolved peaks in the fluorescence spectrum with limits of detection in the low $\mu \mathrm{g} / \mathrm{mL}$ range. 


\section{TABLE OF CONTENTS}

CHAPTER

PAGE

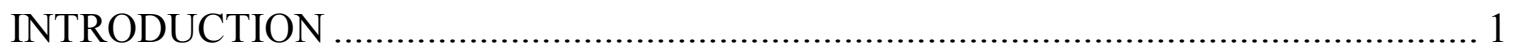

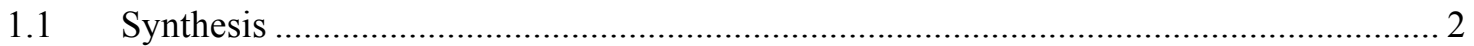

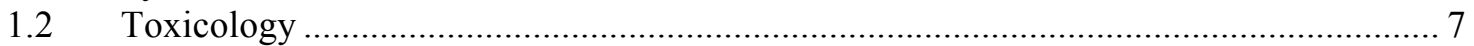

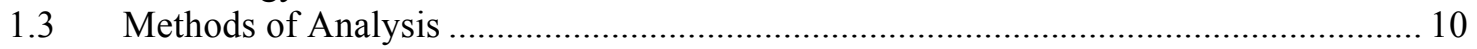

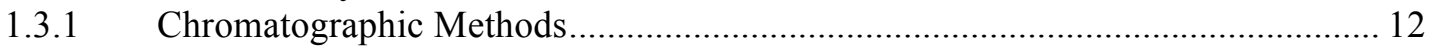

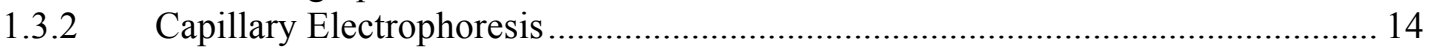

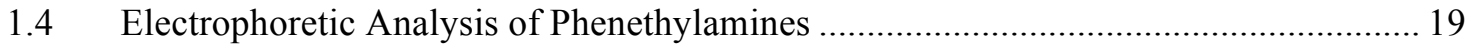

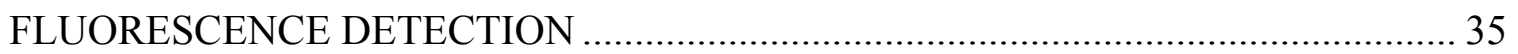

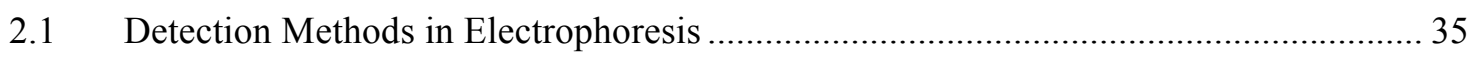

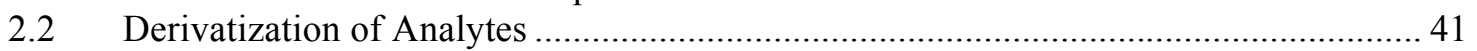

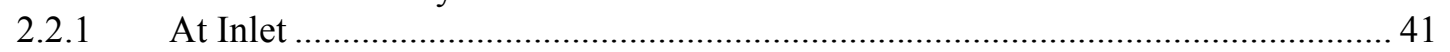

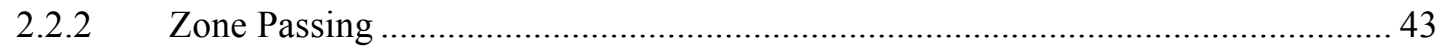

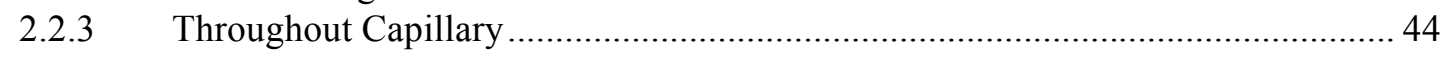

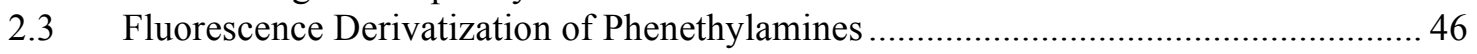

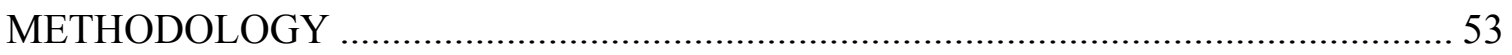

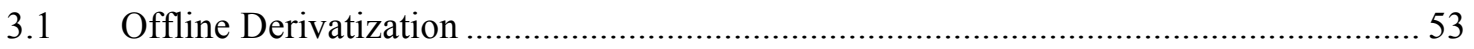

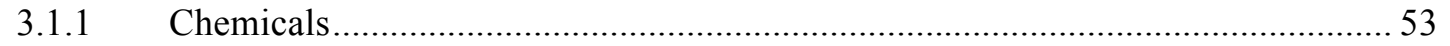

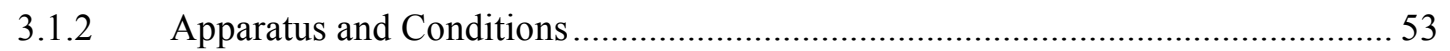

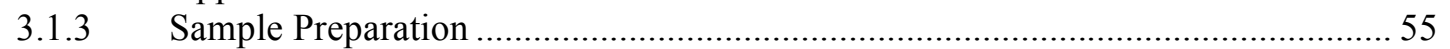

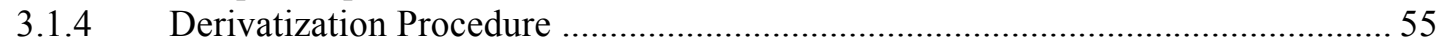

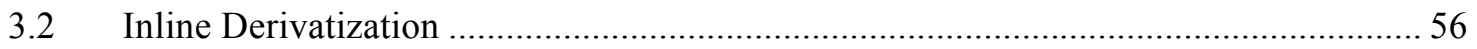

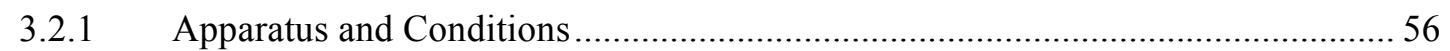

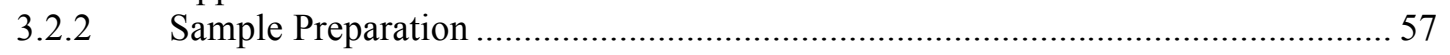

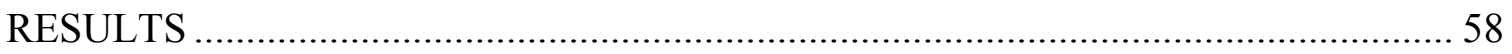

4.1 Analysis of Pre-capillary Labeled NBD-Derivatives.................................................. 58

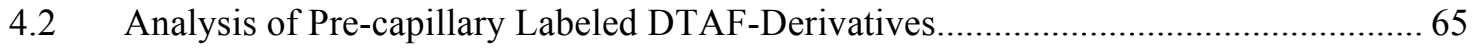

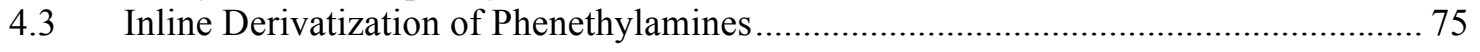

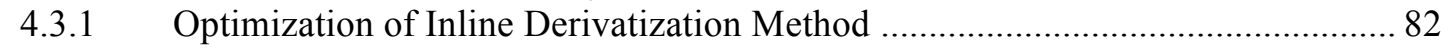

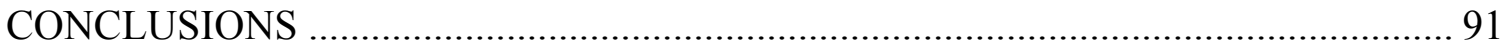

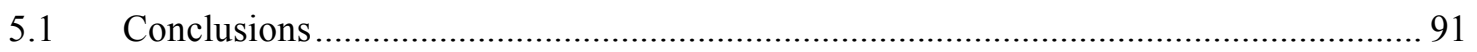

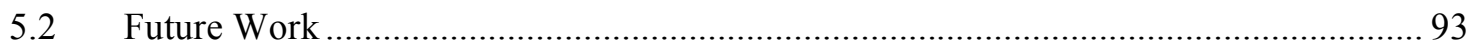

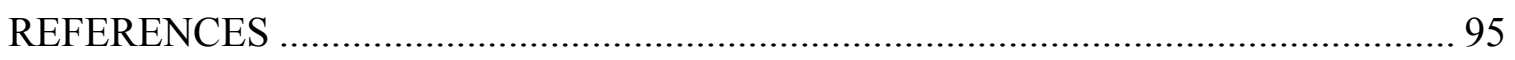

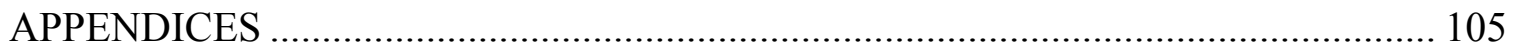

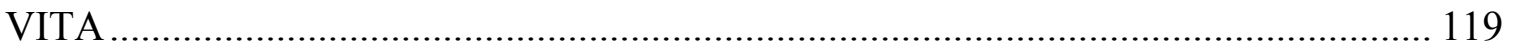




\section{LIST OF FIGURES}

\section{FIGURE}

Figure 1: Bar chart showing trends in global seizures of ATS from the year 2002 to 2011. Total includes seized amphetamine, "ecstasy"-type substances, methamphetamine, nonspecified amphetamine-type stimulants, other stimulants and prescription stimulants. For the categories of other stimulants and prescription stimulants, seizures reported by weight or volume only are included. Adapted from [92].

Figure 2: Synthetic routes for converting ephedrine (or pseudoephedrine) to dmethamphetamine. (a) Emde method (b) Modified Birch reduction/"Nazi" method (c) Nagai method $[2,75,102]$

Figure 3: Conversion of safrole to generic methylenedioxyphenethylamine. The actual product generated is dependent on the structure of the $\mathrm{R}_{1}$ substituent. $\mathrm{R}_{1}=\mathrm{H}, 3,4-$ methylenedioxyamphetamine (MDA); $\mathrm{R}_{1}=\mathrm{CH}_{3}, 3$,4-methylenedioxy- $N$ methamphetamine (MDMA); $\mathrm{R}_{1}=\mathrm{CH}_{2} \mathrm{CH}_{3}, 3$,4-methylenedioxy- $N$-ethylamphetamine (MDEA).[2, 75, 102]

Figure 4: Synthesis of amphetamine-type stimulant through Leuckart reductive amination of phenyl-2-propanone. $[2,75,102]$

Figure 5: Synthesis of ATS from benzaldehyde in the presence of nitroethane. [2, 75, $102]$

Figure 6: Simplified metabolic pathway for methamphetamine with relative amounts of each product from a single dose. Adapted from [44].

Figure 7: Simplified schematic of a capillary electrophoresis system........................... 15

Figure 8: Diagram of the electric bilayer formed on the walls of silica capillaries in electrophoresis

Figure 9: Simplified Jablonski diagram illustrating energy deactivation routes. 37

Figure 10: Schematic of LIF detection system coupled to CE. ................................... 38

Figure 11: Excitation and emission fluorescence spectrum for fluorescein isothiocyanate using a $488 \mathrm{~nm}$ laser. 39

Figure 12: Workflow diagram for pre-capillary derivatization. 40

Figure 13: Schematic of coaxial sheathed capillary reactor for post-capillary derivatization. [41] 
Figure 14: Schematic of at inlet method of inline derivatization. (a) Several plugs of the fluorescent tag and analyte are injected in alternating order. (b) During a set waiting period, diffusion between the zones starts to take place. (c) Plugs have completely mixed and derivatization reaction has gone to completion leaving the fluorescent derivatives of the analytes of interest to be separated. 42

Figure 15: Schematic of zone passing method of inline derivatization. (a) Plugs of analyte and fluorescent tag are injected sequentially into a buffer filled capillary (with faster moving plug injected second). (b) Potential is applied generating an electric field. Faster moving zone begins to move through preceding zone allowing the two to mix. (c) As derivatization reaction takes place, fluorescent derivatives produced are separated.... 44

Figure 16: Schematic of throughout capillary method of inline derivatization. (a) Analyte is injected into capillary filled with run buffer spiked with fluorescent dye. (b) Electric field is generated causing sample to migrate towards the detector, mixing with the fluorescent label in the bulk solution. (c) Fully derivatized sample moves towards the detector while being separated into individual components.

Figure 17: Derivatization mechanism for NBD-F via an $\mathrm{S}_{\mathrm{N}} 2$ reaction scheme. The nucleophilic amine group of the analyte attacks at the fluorine bound carbon site prompting the migration of electrons from the double bond eventually resulting in the fluorine and a hydrogen atom being ejected from the molecule [33].

Figure 18: Derivatization mechanism for reaction of 5-DTAF with generic amine via an $\mathrm{S}_{\mathrm{N}} 2$ reaction. The nucleophilic amine group of the analyte attacks at one of the chlorine bound carbon sites prompting the migration of electrons from the double bond eventually resulting in a chlorine and a hydrogen atom being ejected from the molecule. [33]....... 51

Figure 19: Chemical structures of several analytes of interest. 52

Figure 20: Reaction between NBD-F and primary amine containing MDA to give NBDderivative.

Figure 21: Derivatization products of NBD-F.

Figure 22: ESI mass spectrum of directly infused NBD-OH. Analyte $\mathrm{m} / \mathrm{z}$ is observed at $182.0190 \mathrm{amu}$ which is representative of the target analyte with an extra hydrogen atom.

Figure 23: Emission spectrum of NBD-OH following excitation at 480nm wavelength. Peak fluorescence was observed at $562 \mathrm{~nm}$ with a maximum intensity of 17,015 cps (counts per second).

Figure 24: ESI mass spectrum for NBD-MDA. Fragment for sodium adduct of analyte is observed at $365 \mathrm{amu}$. 
Figure 25: Emission spectrum of NBD-MDA following excitation at 480nm wavelength.

Fluorescence maximum observed at $557 \mathrm{~nm}$ at a value of 16,444 cps. 62

Figure 26: ESI mass spectrum for NBD-norephedrine. Fragments for the sodium adduct of the derivative (m/z $337 \mathrm{amu})$, underivatized analyte (m/z $152 \mathrm{amu})$, and dehydroxylated underivatized analyte $(\mathrm{m} / \mathrm{z} 134 \mathrm{amu})$ were observed. Dehydroxylated underivatized analyte peak is largest fragment produced further supporting the hypothesis that the derivatization method is not efficiently labeling the analytes..... 63

Figure 27: Emission spectrum of NBD-norephedrine following excitation at 480nm wavelength. Emission spectrum peak maximum at $550 \mathrm{~nm}$ and $352,150 \mathrm{cps}$.

Figure 28: Separation of $1.0 \mu \mathrm{g} / \mathrm{mL}$ mixture of norephedrine, ephedrine, MDA, and MDMA. Conditions: Fused silica capillary, $75 \mu \mathrm{m}$ I.D., $40 \mathrm{~cm}$ length, $30 \mathrm{~cm}$ effective length; capillary temperature, $25^{\circ} \mathrm{C}$; fluorescent tag, $20 \mathrm{mM} \mathrm{NBD}-\mathrm{F}$ in ethanol; buffer, $50 \mathrm{mM}$ sodium borate, $\mathrm{pH} 8.5 / 10 \mathrm{mM}$ SDS; offline derivatization, 10 minutes at $60^{\circ} \mathrm{C}$. . 65

Figure 29: Reversible formation of guest-host complex between fluorescently-labeled derivatives and $\beta$-cyclodextrin.

Figure 30: Effect of concentration of secondary $\beta$-cyclodextrins in combination with $15 \mathrm{mM}$ native $\beta$-cyclodextrin on analysis of 5-DTAF labeled ephedrine at $100 \mathrm{ug} / \mathrm{mL} \ldots . .68$

Figure 31: Comparison of three selectivity modifiers in 50mM borate, $\mathrm{pH} 9.5 / 15 \mathrm{mM} \beta-$ CD buffer on separation of $100 \mu \mathrm{g} / \mathrm{mL}$ drug mixture labeled with $0.5 \mathrm{mM}$ 5-DTAF. (a) $40 \mathrm{mM}$ Brij-35 (b) $10 \mathrm{mg} / \mathrm{mL}$ S- $\beta-C D$ (c) $10 \mathrm{mg} / \mathrm{mL}$ DM- $\beta-C D$. Brij is a nonionic surfactant that forms micelles, while the cyclodextrins form guest/host complexes.

Figure 32: Effect of increasing acetonitrile concentration in running buffer $(50 \mathrm{mM}$ borate, $\mathrm{pH} 9.5 / 15 \mathrm{mM} \beta-\mathrm{CD} / 10 \mathrm{mg} / \mathrm{mL} \mathrm{DM}-\beta-\mathrm{CD}$ on resolution between peaks of DTAFlabeled $100 \mu \mathrm{g} / \mathrm{mL}$ drug mixture.

Figure 33: Typical electropherogram of $100 \mathrm{ug} / \mathrm{mL}$ mixture of five phenethylamines derivatized pre-capillary. Conditions: Fused silica capillary, $50 \mu \mathrm{m}$ I.D., $60 \mathrm{~cm}$ length, 50 $\mathrm{cm}$ effective length; capillary temperature, $35^{\circ} \mathrm{C}$; fluorescent tag, $0.5 \mathrm{mM}$-DTAF in ethanol/1,2-dichloroethane (9:1); buffer, $50 \mathrm{mM}$ sodium borate, $\mathrm{pH} 9.5 / 15 \mathrm{mM} \beta$ $\mathrm{CD} / 10 \mathrm{mg} / \mathrm{mL} \mathrm{DM}-\beta-\mathrm{CD} / 15 \%$ acetonitrile. All other conditions same as table 3 with the exception that steps 3 and 4 were consolidated into a single injection at $0.5 \mathrm{psi}$ for $5.0 \mathrm{sec}$.

Figure 34: Typical electropherograms for $100 \mathrm{ug} / \mathrm{mL}$ mixture of five phenethylamines labeled with varying concentrations of 5-DTAF pre-capillary. Conditions: Fused silica capillary, $50 \mu \mathrm{m}$ I.D., $60 \mathrm{~cm}$ length, $50 \mathrm{~cm}$ effective length; capillary temperature, $35^{\circ} \mathrm{C}$; buffer, $50 \mathrm{mM}$ sodium borate, $\mathrm{pH} 9.5 / 15 \mathrm{mM} \beta-\mathrm{CD} / 10 \mathrm{mg} / \mathrm{mL} \mathrm{DM}-\beta-\mathrm{CD} / 15 \%$ acetonitrile. All other conditions same as table 3; steps 3 and 4 consolidated into a single injection at $0.5 \mathrm{psi}$ for $5.0 \mathrm{sec}$. 
Figure 35: Typical electropherogram of $100 \mathrm{ug} / \mathrm{mL}$ mixture of five phenethylamines labeled with 5.0mM 5-DTAF. Conditions: Fused silica capillary, $50 \mu \mathrm{m}$ I.D., $60 \mathrm{~cm}$ length, $50 \mathrm{~cm}$ effective length; capillary temperature, $35^{\circ} \mathrm{C}$; buffer, $50 \mathrm{mM}$ sodium borate, $\mathrm{pH} 9.5 / 15 \mathrm{mM} \beta-\mathrm{CD} / 10 \mathrm{mg} / \mathrm{mL}$ DM- $\beta-\mathrm{CD} / 15 \%$ acetonitrile. All other conditions same as table 3 ; steps 3 and 4 consolidated into a single injection at $0.5 \mathrm{psi}$ for $5.0 \mathrm{sec} . \ldots \ldots \ldots \ldots . . . . . .73$

Figure 36: Calibration curves for online-derivatized analytes using 5-DTAF................ 74

Figure 37: Schematic representation of inline derivatization method. (a) Plugs of sample, 5-DTAF, and background electrolyte (BGE) are injected into capillary filled with more BGE. (b) Voltage is applied generating small electric field for a short time. (c) Capillary is allowed to stand for set time frame with no electric field. (d) Separation potential is applied and fluorescent derivatives separate as they approach the detector window...... 75

Figure 38: Typical electropherogram of $100 \mathrm{ug} / \mathrm{mL}$ mixture of five phenethylamines labeled via inline electrokinetic mixing with $20 \mu \mathrm{L}$ of $5.0 \mathrm{mM} 5$-DTAF. Conditions: Fused silica capillary, $50 \mu \mathrm{m}$ I.D., $60 \mathrm{~cm}$ length, $50 \mathrm{~cm}$ effective length; capillary temperature, $35^{\circ} \mathrm{C}$; buffer, $50 \mathrm{mM}$ sodium borate, $\mathrm{pH} 9.5 / 15 \mathrm{mM} \beta-\mathrm{CD} / 10 \mathrm{mg} / \mathrm{mL}$ DM- $\beta-\mathrm{CD} / 15 \%$ acetonitrile. All other conditions same as table 3.

Figure 39: Typical electropherogram of $100 \mathrm{ug} / \mathrm{mL}$ mixture of five phenethylamines labeled via inline electrokinetic mixing with $40 \mu \mathrm{L}$ of $5.0 \mathrm{mM} 5$-DTAF. Conditions: Fused silica capillary, $50 \mu \mathrm{m}$ I.D., $60 \mathrm{~cm}$ length, $50 \mathrm{~cm}$ effective length; capillary temperature, $35^{\circ} \mathrm{C}$; buffer, $50 \mathrm{mM}$ sodium borate, $\mathrm{pH} 9.5 / 15 \mathrm{mM} \beta-\mathrm{CD} / 10 \mathrm{mg} / \mathrm{mL}$ DM- $\beta-\mathrm{CD} / 15 \%$ acetonitrile. All other conditions same as table 3.

Figure 40: Typical electropherogram of $100 \mathrm{ug} / \mathrm{mL}$ mixture of five phenethylamines labeled via inline electrokinetic mixing with $40 \mu \mathrm{L}$ of $5.0 \mathrm{mM} 5$-DTAF. Conditions: Fused silica capillary, $50 \mu \mathrm{m}$ I.D., $60 \mathrm{~cm}$ length, $50 \mathrm{~cm}$ effective length; capillary temperature, $35^{\circ} \mathrm{C}$; buffer, $50 \mathrm{mM}$ sodium borate, $\mathrm{pH} 9.5 / 15 \mathrm{mM} \beta-\mathrm{CD} / 10 \mathrm{mg} / \mathrm{mL} \mathrm{DM}-\beta-\mathrm{CD} / 15 \%$ acetonitrile. Injection order, ( $5 \mathrm{sec}$ at $0.5 \mathrm{psi})$ analyte, tag, analyte; all other conditions same as table 3 .

Figure 41: Electropherogram of $100 \mathrm{ug} / \mathrm{mL}$ mixture of five phenethylamines labeled via inline electrokinetic mixing with $40 \mu \mathrm{L}$ of 5.0mM 5-DTAF. Conditions: Fused silica capillary, $50 \mu \mathrm{m}$ I.D., $60 \mathrm{~cm}$ length, $50 \mathrm{~cm}$ effective length; capillary temperature, $35^{\circ} \mathrm{C}$; buffer, $50 \mathrm{mM}$ sodium borate, $\mathrm{pH} 9.5 / 15 \mathrm{mM} \beta-\mathrm{CD} / 10 \mathrm{mg} / \mathrm{mL} \mathrm{DM}-\beta-\mathrm{CD} / 15 \%$ acetonitrile. Injection order, (5 sec at $0.5 \mathrm{psi})$ tag, analyte, tag; all other conditions same as table 3 .

Figure 42: Electropherogram of $100 \mathrm{ug} / \mathrm{mL}$ mixture of five phenethylamines labeled via inline electrokinetic mixing with $40 \mu \mathrm{L}$ of 5.0mM 5-DTAF. Conditions: Fused silica capillary, $50 \mu \mathrm{m}$ I.D., $60 \mathrm{~cm}$ length, $50 \mathrm{~cm}$ effective length; capillary temperature, $35^{\circ} \mathrm{C}$; buffer, $50 \mathrm{mM}$ sodium borate, $\mathrm{pH} 9.5 / 15 \mathrm{mM} \beta-\mathrm{CD} / 10 \mathrm{mg} / \mathrm{mL} \mathrm{DM}-\beta-\mathrm{CD} / 15 \%$ acetonitrile. Injection order, (5 sec at $0.5 \mathrm{psi}$ ) analyte, tag; all other conditions same as table 3 . 
Figure 43: Typical electropherogram of $100 \mathrm{ug} / \mathrm{mL}$ mixture of five phenethylamines labeled via inline electrokinetic mixing with $40 \mu \mathrm{L}$ of $5.0 \mathrm{mM}$ 5-DTAF. Conditions: Fused silica capillary, $50 \mu \mathrm{m}$ I.D., $60 \mathrm{~cm}$ length, $50 \mathrm{~cm}$ effective length; capillary temperature, $35^{\circ} \mathrm{C}$; buffer, $50 \mathrm{mM}$ sodium borate, $\mathrm{pH} 9.5 / 15 \mathrm{mM} \beta-\mathrm{CD} / 10 \mathrm{mg} / \mathrm{mL} \mathrm{DM}-\beta-\mathrm{CD} / 15 \%$ acetonitrile. Injection order, (5 sec at $0.5 \mathrm{psi})$ tag, analyte; all other conditions same as table 3 .

Figure 44: Two-dimensional and three-dimensional contour plots for amphetamine peak in $100 \mathrm{ug} / \mathrm{mL}$ mixture of five phenethylamines labeled via inline electrokinetic mixing with $40 \mu \mathrm{L}$ of $5.0 \mathrm{mM} 5$-DTAF. Conditions: Fused silica capillary, $50 \mu \mathrm{m}$ I.D., $60 \mathrm{~cm}$ length, $50 \mathrm{~cm}$ effective length; capillary temperature, $35^{\circ} \mathrm{C}$; buffer, $50 \mathrm{mM}$ sodium borate, $\mathrm{pH} 9.5 / 15 \mathrm{mM} \beta-\mathrm{CD} / 10 \mathrm{mg} / \mathrm{mL} \mathrm{DM}-\beta-\mathrm{CD} / 15 \%$ acetonitrile. Injection order, $(5 \mathrm{sec}$ at $0.5 \mathrm{psi}$ ) tag, analyte; all other conditions same as table 3 . Varying mix voltage and mix time values were plotted while holding wait time constant at $9.00 \mathrm{~min}$. The saddle shape generated indicates maximum labeling efficiency at the extremes of the mixing voltage range $(2-10 \mathrm{kV})$ particularly at the median mixing time value $(52.5 \mathrm{sec})$.

Figure 45: Two-dimensional and three-dimensional contour plots for amphetamine peak in $100 \mathrm{ug} / \mathrm{mL}$ mixture of five phenethylamines labeled via inline electrokinetic mixing with $40 \mu \mathrm{L}$ of $5.0 \mathrm{mM}$ 5-DTAF. Conditions: Fused silica capillary, $50 \mu \mathrm{m}$ I.D., $60 \mathrm{~cm}$ length, $50 \mathrm{~cm}$ effective length; capillary temperature, $35^{\circ} \mathrm{C}$; buffer, $50 \mathrm{mM}$ sodium borate, $\mathrm{pH} 9.5 / 15 \mathrm{mM} \beta-\mathrm{CD} / 10 \mathrm{mg} / \mathrm{mL} \mathrm{DM}-\beta-\mathrm{CD} / 15 \%$ acetonitrile. Injection order, $(5 \mathrm{sec}$ at $0.5 \mathrm{psi}$ ) tag, analyte; all other conditions same as table 3 . Varying mix time and wait time values were plotted while holding mix voltage constant at $6.00 \mathrm{kV}$. The bowl shape generated indicates maximum labeling efficiency at the wait time upper extreme value $(15.0 \mathrm{~min})$ and the mixing time lower extreme value $(30.0 \mathrm{sec})$.

Figure 46: Two-dimensional and three-dimensional contour plots for amphetamine peak in $100 \mathrm{ug} / \mathrm{mL}$ mixture of five phenethylamines labeled via inline electrokinetic mixing with $40 \mu \mathrm{L}$ of 5.0mM 5-DTAF. Conditions: Fused silica capillary, $50 \mu \mathrm{m}$ I.D., $60 \mathrm{~cm}$ length, $50 \mathrm{~cm}$ effective length; capillary temperature, $35^{\circ} \mathrm{C}$; buffer, $50 \mathrm{mM}$ sodium borate, $\mathrm{pH} 9.5 / 15 \mathrm{mM} \beta-\mathrm{CD} / 10 \mathrm{mg} / \mathrm{mL} \mathrm{DM}-\beta-\mathrm{CD} / 15 \%$ acetonitrile. Injection order, $(5 \mathrm{sec}$ at $0.5 \mathrm{psi}$ ) tag, analyte; all other conditions same as table 3 . Varying mix voltage and wait time values were plotted while holding mix time constant at $52.50 \mathrm{sec}$. The saddle shape generated indicates maximum labeling efficiency at the extremes of the mixing voltage range $(2-10 \mathrm{kV})$ particularly at the median wait time value $(9.00 \mathrm{~min})$........................ 88

Figure 47: Separation of $100 \mathrm{~g} / \mathrm{mL}$ mixture of five analytes derivatized on-capillary by 1.0mM 5-DTAF. Conditions: Fused silica capillary, $50 \mu \mathrm{m}$ I.D., $60 \mathrm{~cm}$ length, $50 \mathrm{~cm}$ effective length; capillary temperature, $35^{\circ} \mathrm{C}$; buffer, $50 \mathrm{mM}$ sodium borate, $\mathrm{pH}$ $9.5 / 15 \mathrm{mM} \beta-\mathrm{CD} / 10 \mathrm{mg} / \mathrm{mL} \mathrm{DM}-\beta-\mathrm{CD} / 15 \%$ acetonitrile; mixing voltage, $8 \mathrm{kV}$; mixing time, $33 \mathrm{sec}$; wait time, $9 \mathrm{~min}$; injection order, ( $5 \mathrm{sec}$ at $0.5 \mathrm{psi})$ tag, analyte; all other conditions same as table 3 


\section{LIST OF TABLES}

TABLE

PAGE

Table 1: Summary of positive responses for selected ATS with three common color tests. [91] 10

Table 2: Relative sensitivity of CE detection systems towards appropriate compounds.

Adapted from [59] 36

Table 3: Overview of selected fluorescent labels and their fluorescence properties.

Adapted from [33]

Table 4: Inline derivatization method parameters.

Table 5: Figures of merit for offline derivatization with 5-DTAF.

Table 6: Coded matrix for Doehlert optimization of electrokinetic mixing parameters... 83

Table 7: Uncoded matrix for Doehlert optimization of electrokinetic mixing parameters.

Table 8: Optimal parameter conditions for inline derivatization of each analyte in a mixture.

Table 9: Figures of merit for inline derivatization with 5-DTAF.... Error! Bookmark not defined. 


\section{CHAPTER 1: INTRODUCTION}

The term phenethylamine represents a large group of molecules all with a structural skeleton comprised of a benzene ring with an attached ethylamine group [14]. The presence and position of different substituents alters the pharmacological effects of these compounds giving them a wide variety of legitimate and illicit uses [44]. They can be found naturally in different plants or synthesized in a laboratory setting. It is these synthetic versions which are of greatest interest as they are primarily abused as psychostimulants [59].

According to the United Nations Office on Drugs and Crime (UNODC) in their world drug report for the year 2013, the seizures of amphetamine-type stimulants (ATS) increased by $66 \%$ in 2011 from the previous year's value of 74 tons (figure 1) [92]. These seizures were mostly in the form of methamphetamine which amounted to 31 tons being seized in Mexico alone.

It was been reported that in 2011, an estimated 33.8 million persons between the ages of 15 and 64 years admitted to using ATS in the preceding year globally. The increasing prevalence of these compounds is why a rapid, sensitive, selective, and inexpensive method of analysis of these drugs is needed. 


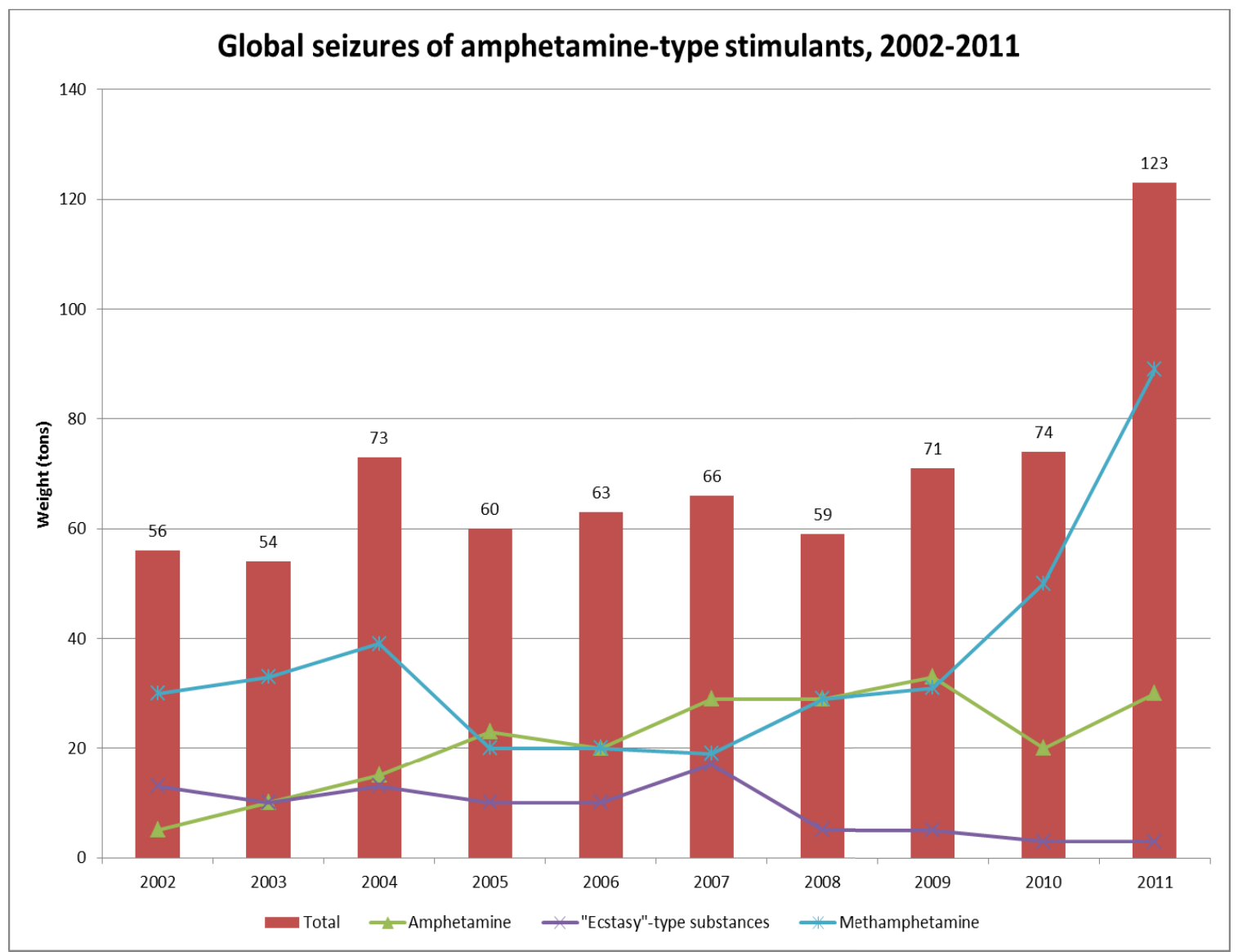

Figure 1: Bar chart showing trends in global seizures of ATS from the year 2002 to 2011 . Total includes seized amphetamine, "ecstasy"-type substances, methamphetamine, non-specified amphetamine-type stimulants, other stimulants and prescription stimulants. For the categories of other stimulants and prescription stimulants, seizures reported by weight or volume only are included. Adapted from [92].

\subsection{Synthesis}

There are a variety of synthetic pathways for the illicit manufacture of phenethylamines, most of which involve the conversion of non-controlled analogues via a reduction reaction [75]. These reduction reactions can be grouped into four main classifications; heterogeneous catalysis, dissolving metal reductions, metal hydride reductions, and non-metal reductions $[75,93]$. The method used is dependent not only on the starting materials available, but also the chemical knowledge of the manufacturer. 
Amphetamine precursors which can be used include safrole, ephedrine, pseudoephedrine, phenyl-2-propanone (P2P), and benzaldehyde [75].

Ephedrine and pseudoephedrine are diastereomers of the same molecule meaning they have the same formula but differ in configuration at one or more stereocenters without being mirror images of one another. As a result of these structural differences these diastereomers have different physical properties and reactivity [44]. They can be converted to ATS through a variety of methods as seen in figure 2 . By determining the synthetic pathway by which a precursor is converted into an illicit drug, one is able to track its location of origin and gain insight into how it was manufactured (home-based “cook" or large scale operation) $[75,102]$.

The conversion of ephedrine into methamphetamine via the reduction of a halogenated intermediate was first observed by Emde in the early 1900s [102]. The reaction targets the hydroxyl group of the (pseudo)ephedrine via an $\mathrm{S}_{\mathrm{N}} 2$ reaction with thionyl chloride to produce chloroephedrine. The chloroephedrine intermediate is subsequently reduced through catalytic hydrogenation. This method often produces a number of synthesis byproducts whose presence in a seized sample could indicate the synthesis method used. Some of these contaminants include chloroephedrine, methylephedrine, and $\mathrm{N}, \mathrm{O}$-diacetylephedrine. In a typical Birch reduction sodium and an alcohol are used, however, the more common "Nazi" method utilizes lithium which has greater reactivity. The final product is treated with muriatic acid in order to crystallize the hydrochloride salt form. 


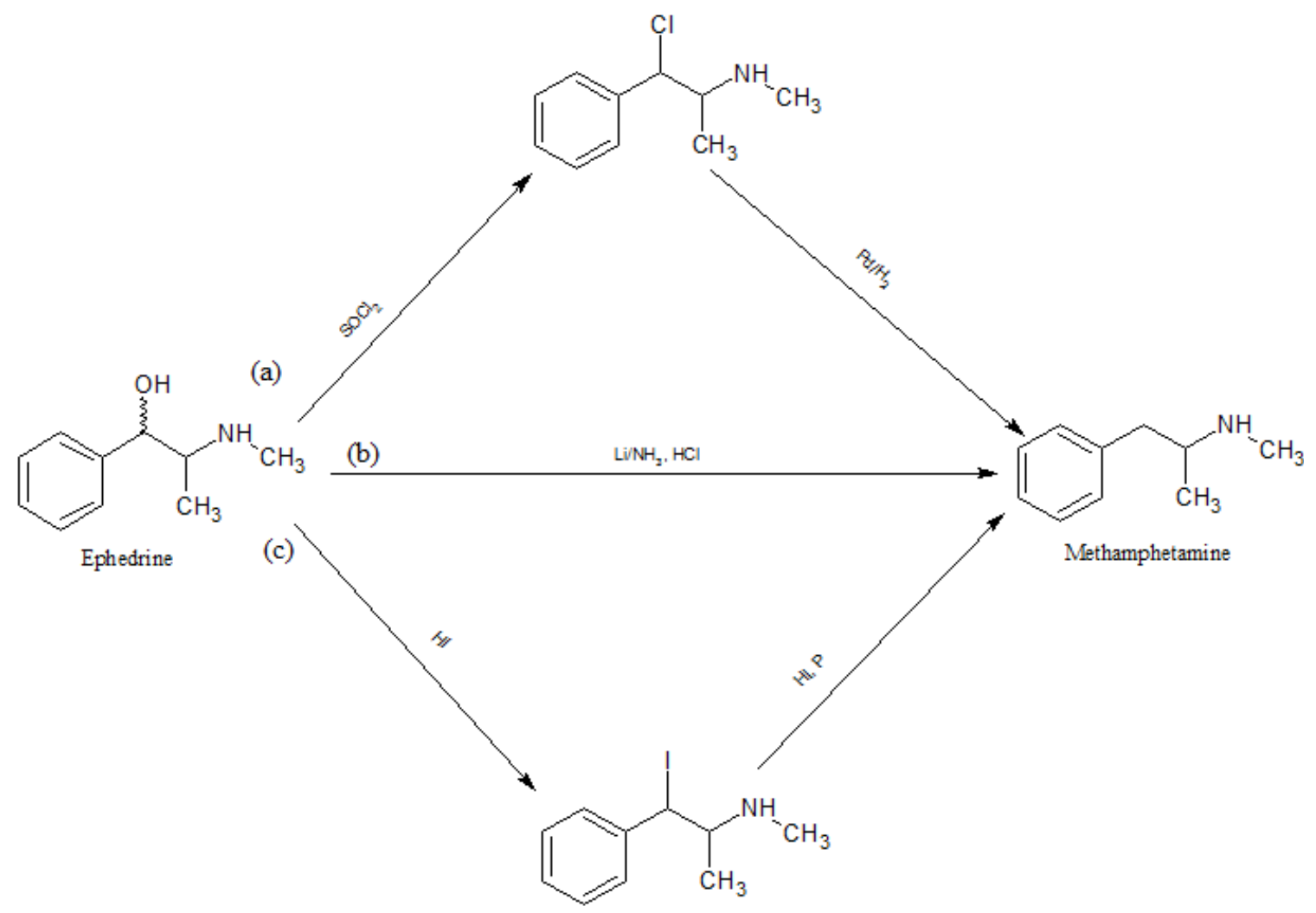

Figure 2: Synthetic routes for converting ephedrine (or pseudoephedrine) to d-methamphetamine. (a) Emde method (b) Modified Birch reduction/"Nazi" method (c) Nagai method [2, 75, 102]

In the Nagai method, hydroiodic acid is used to halogenate the starting compound at the site of the hydroxyl moiety via an $\mathrm{S}_{\mathrm{N}} 2$ reaction [75]. The iodoephedrine product formed is further reduced to methamphetamine in the presence of red phosphorus [75]. There are several modifications of this method also. In the "Moscow" route, hydrogen iodide is replaced by iodine and water [102]. The "Hypo" route involves the substitution of red phosphorous with hypophosphorous or phosphorous acid [75, 102]. While this produces a highly pure product, it is inherently more dangerous as toxic phosphine gas and white phosphorous can be produced as waste [75]. Some of the synthesis byproducts associated with these methods when utilizing ephedrine or pseudoephedrine as the starting material include (2E)- $N$-methyl-3-phenyl- $N$-(1-phenylpropan-2-yl)prop-2- 
enamide, iodoephedrine, $N$-methyl- $N$-(alpha-methylphenyl)amino-1-phenyl-2-propanone, and (Z)- $N$-methyl- $N$-(alpha-methylphenylethyl)-3-phenylpropanamide.

Safrole is a phenylpropene which is found in the sassafras plant as well as other spices such as cinnamon and nutmeg. It is easily converted to methylenedioxyamphetamine (MDA) and similar analogues via an amination reaction. In 2011 at a Mexican airport, 2,500 liters of safrole were seized by authorities, further indicating large-scale manufacturing operations there [92].<smiles>[R7]NC(C)Cc1ccc2c(c1)O[C@H](CN=[R]CC)O2</smiles>

Figure 3: Conversion of safrole to generic methylenedioxyphenethylamine. The actual product generated is dependent on the structure of the $R_{1}$ substituent. $R_{1}=H, 3,4$-methylenedioxyamphetamine (MDA); $R_{1}=C_{3}, 3,4-$ methylenedioxy- $\mathrm{N}$-methamphetamine (MDMA); $\mathrm{R}_{1}=\mathrm{CH}_{2} \mathrm{CH}_{3}, 3,4$-methylenedioxy- $\mathrm{N}$-ethylamphetamine (MDEA). [2, 75, 102]

Phenyl-2-propanone has the distinction of being a precursor for amphetamine production, as well as a product of amphetamine metabolism in the human body. Because of restrictions in accessing other precursors such as ephedrine and pseudoephedrine, there has been an increase in production methods utilizing it as the starting material. It can be prepared via the ketonization of phenylacetic acid and acetic acid at high temperature with aluminum oxide as a catalyst. 


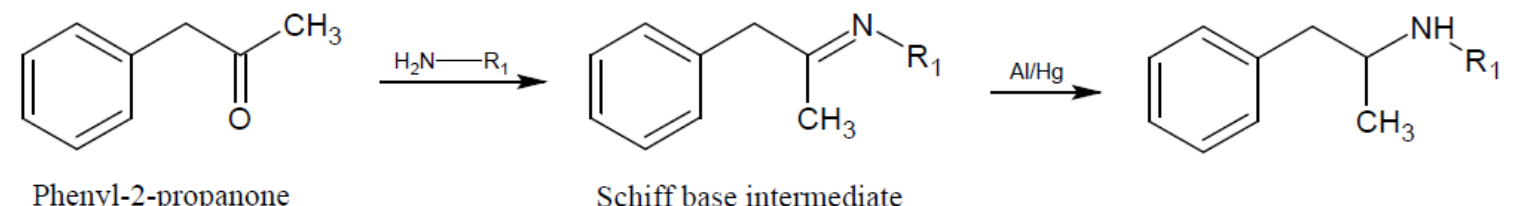

Figure 4: Synthesis of amphetamine-type stimulant through Leuckart reductive amination of phenyl-2-propanone. $[2,75,102]$

Another synthesis method is through the condensation of benzaldehyde with nitroethane followed by a reduction reaction. Benzaldehyde and its derivatives, such as piperanol, can also be used in the manufacture of ATS directly.<smiles>O=Cc1ccccc1</smiles><smiles>C/C(=C\c1ccccc1)[N+](=O)[O-]</smiles>

(a)<smiles>CC(=O)Cc1ccccc1</smiles>

(b)

Figure 5: Synthesis of ATS from benzaldehyde in the presence of nitroethane. [2, 75, 102]

In the presence of a basic catalyst, such as an amine, benzaldehyde can be converted to phenyl-2-nitropropene through a condensation reaction. The product generated can then either be reduced to (a) phenyl-2-propanone or (b) amphetamine as seen in figure 5.

By identifying the synthetic pathways used to generate seized samples law enforcement officials gain valuable intelligence. This is done through the identification of any contaminants/byproducts present, as well as their ratios to each other and the target compound. This assists investigators in tracing distribution patterns from the 
manufacturers to the customers, and determining what kind of scale said manufacturers are operating at.

\subsection{Toxicology}

Because of their similarity in structure to that of catecholamines such as dopamine, and adrenaline, the mechanism of behavior for these sympathomimetic compounds is somewhat well understood. They can be classified as either, direct-acting, indirect-acting, or mixed acting which is a combination of the two [21]. Direct-acting drugs target adrenergic receptors (with varying degrees of specificity) and in essence, act as false transmitters. An example of one such compound is phenylephrine. Indirect-acting compounds increase the concentration of the neurotransmitters within the synaptic cleft, thus increasing the level of stimulation experienced by the receptors. Examples of this type of agonist are amphetamine and MDMA. Mixed action agonists utilize both mechanisms increase the neurotransmitter concentration within the synapse. An example of a mixed action sympathomimetic compound is ephedrine.

This stimulation can be achieved through various modes of action including interactions with the synaptic vesicles or pre-synaptic membrane of different neurons inducing the release of the neurotransmitter from the nerve terminal. Binding with the reuptake transporter for specific catecholamines can cause a reverse in directional flow of the corresponding neurotransmitter, also resulting in increased concentrations within the synaptic cleft. In high doses, ATS have also been observed to act as monoamine oxidase inhibitors (MAOIs) preventing the degradation of previously released neurotransmitters. 
Adrenergic neurotransmitters such as dopamine, adrenaline, and noradrenaline are responsible for fight-or-flight responses. Physiological hallmarks of this kind of reaction include increased heart rate and respiration, constriction of various blood vessels, and elevated blood pressure. As a result of excessive stimulation of the receptors controlling this phenomenon, persons under the influence of ATS's can experience arrhythmias, sudden death, and stereotyped behaviors such as facial tics and muscular twitching. [21] Actions at dopaminergic sites within the brain can also affect behavior and motor control. As these compounds are neurotoxic, prolonged use can result in permanent nerve damage at the various receptor sites. [14]

Amphetamine-type stimulants can be taken via a variety of routes including oral ingestion, smoking, and intravenous injection. They have a half-life ranging from 4 to 30 hours and are metabolized in the liver. Under normal conditions ATS are excreted with a significant portion unchanged, however, urinary $\mathrm{pH}$ plays a major role in this process, and in the half-life observed for these drugs. At acidic $\mathrm{pH}$, ATS are highly ionized and excreted rapidly $[21,44]$. Due to this, there is little opportunity for metabolism to take place resulting in high concentrations of the parent drug being excreted. At more basic $\mathrm{pHs}$, the drug is partly neutralized yielding greater retention. As a result, these compounds remain within the system for longer periods of time which allows for more extensive absorption and metabolism to occur. The metabolic pathway for methamphetamine is given in figure 6. 


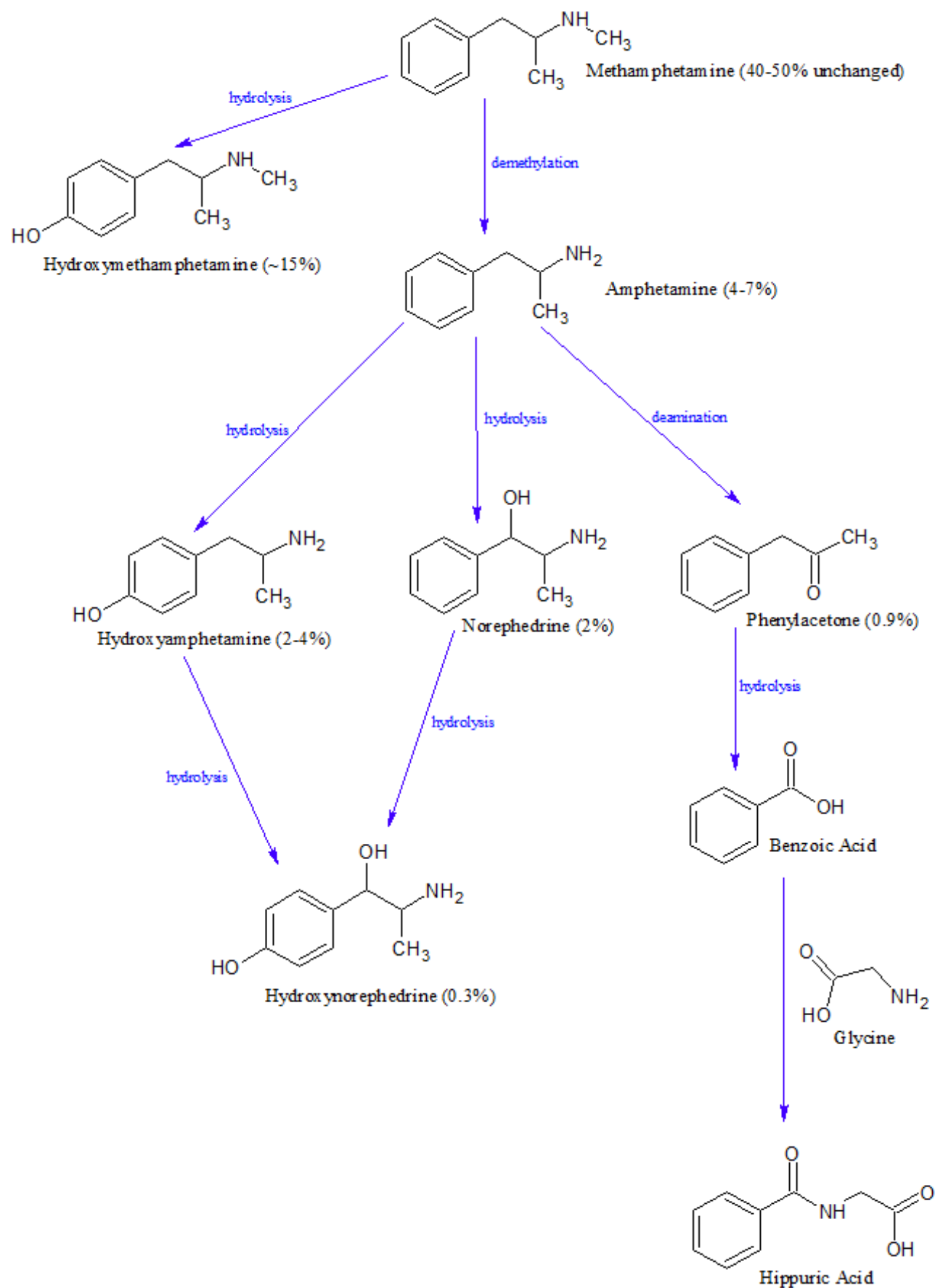

Figure 6: Simplified metabolic pathway for methamphetamine with relative amounts of each product from a single dose. Adapted from [44]. 


\subsection{Methods of Analysis}

There are several presumptive and confirmatory methods for the analysis of amphetamine-type stimulants. Three presumptive methods commonly utilized in forensic settings are color tests, thin-layer chromatography (TLC) and immunoassay. Color tests utilize characteristic reactions between analytes and reagents to induce a change in appearance. These changes are based on the properties of the product formed and tend to be specific for particular moieties. While this is helpful in distinguishing between compounds with similar physical properties but different molecular structures, to differentiate among different compounds from the same class of drugs multiple testing reagents must be used. Some color tests typically used for ATS are Chen, Mandelin, Marquis, Mecke, Robadope, and Simon. A summary of the expected positive results of three of these tests (Marquis, Simon, and Chen) with various ATS is given in table 1 [91].

\begin{tabular}{|c|c|c|c|}
\hline Table 1: Summary of positive responses for selected ATS with three common color tests. [91] & Chen \\
\hline Compound & Marquis & Simon & No reaction \\
\hline Amphetamine & Orange, slowly & No reaction & No reaction \\
\hline turns brown & Orange, slowly & Deep blue & Purple \\
\hline Ephedrine/ & turns brown & & Slowly turns yellow or \\
\hline pseudoephedrine & No reaction & No reaction & orange \\
\hline Cathinone & No reaction & No reaction & No reaction \\
\hline 4-Bromo-2,5- & Yellow to green & & \\
\hline
\end{tabular}




\begin{tabular}{|c|c|c|c|}
\hline (2C-B) & & & \\
\hline Methcathinone & No reaction & $\begin{array}{c}\text { Slightly blue, spot or } \\
\text { ring-like precipitate }\end{array}$ & $\begin{array}{c}\text { Slowly turns yellow or } \\
\text { orange }\end{array}$ \\
\hline $\begin{array}{c}\text { para- } \\
\text { Methoxyamphetamine } \\
\text { (PMA) }\end{array}$ & No reaction to \\
light green & No reaction & Unknown \\
\hline MDA & Dark blue/black & No reaction & No reaction \\
\hline MDMA & Dark blue/black & Deep blue & No reaction \\
\hline MDEA & Dark blue/black & Blue to brown & No reaction \\
\hline Methylone & Brown & Blue & No reaction \\
\hline MDMC) & & & \\
\hline
\end{tabular}

In TLC samples are extracted and treated with various chemicals before being spotted on a plate coated with a sorbent material. Plates are inserted into chambers with an appropriate solvent system which then travels up via capillary action moving the solutes with it. Spots are visualized under UV light and the distance traveled by each analyte is measured. The ratio between the distance traveled by the analyte and the distance traveled by the solvent is known as the retention factor $\left(R_{f}\right)$. The $R_{f}$ value is characteristic of specific analytes under specific conditions. However, TLC can be labor intensive and time consuming with somewhat high limits of detection at $0.5 \mathrm{mg} / \mathrm{L}$ [44].

Immunoassays are a more sensitive alternative to spot tests as they are based on specific binding behaviors between the analytes of interest and the antibodies. The extent to which the analytes bind to the antibodies can be determined in a variety of ways depending on the type of immunoassay being utilized. The most common detection 
mechanisms include enzymes, radioactive isotopes, and fluorescence. In enzyme based immunoassays the antibodies used preferentially bind to the analytes of interest over an analyte-bound enzyme in the system. The analyte then displaces the bound enzyme that is attached to the antibody. Analyte-bound enzymes are deactivated when attached to the antibody so by displacing some of them, the analyte of interest changes the alters the level of enzyme activation. This deactivation of the enzyme typically is expressed by some visible change in appearance such as, color or the emission of light. The extent to which the enzyme present is bound to the antibody, determines the intensity of the signal produced. While immunoassays are very useful and convenient for usage as a screening method, particularly for routine drug testing, they are susceptible to cross-reactivity between analytes of similar structure.

\subsubsection{Chromatographic Methods}

Unlike the presumptive methods previously discussed, chromatographic methods are capable of separation individual analytes and confirmatory identification based on the characteristic partitioning behavior of the analyte between the mobile and stationary phases utilized. Chromatography is a separation method which is based on the partitioning of the analyte of interest between the mobile phase and the stationary phase. The two major chromatographic methods used in the analysis of ATS are gas chromatography (GC), and reversed-phase high performance liquid chromatography (HPLC). Both techniques are capable of being coupled to a variety of detectors. For GC analysis of phenethylamines, the current "gold standard" of detection is mass spectrometry (MS) with electron impact ionization. As a result, qualitative and 
quantitative results can be obtained. Due to some ATS being thermally labile under GC conditions, the possibility of sample decomposition before the analytes can be detected is a legitimate concern. Due to this, amphetamines are almost always derivatized prior to sample injection. This also can serve as a method to increase the analyte's volatility making the analysis more efficient.

Derivatization agents commonly encountered include heptafluorobutyric anhydride (HFBA), pentafluoropropionic anhydride (PFPA), and trifluoroacetic anhydride (TFAA). The derivatives generated from these reactions can be of diagnostic value given the commonality in structure between phenethylamines. The derivatives synthesized generally produce larger mass fragments giving a more definitive spectrum for each compound. In Habrdova's work analyzing several synthetic cathinones and mescaline in blood plasma, limits of quantitation (LOQs) for all analytes was determined to be $5.0 \mu \mathrm{g} / \mathrm{L}$ [30]. However, the extraction and derivatization process leading up to these results had twenty individual steps before the sample could even be injected. For this reason, liquid based techniques such as HPLC and capillary electrophoresis are commonly suggested as alternatives to $\mathrm{GC}$, as there is no need to produce volatile analytes.

Reversed-phase HPLC is another method commonly used for the analysis of amphetamines. It is typically coupled to an ultraviolet (UV) / diode-array detector (DAD) detector. Identification of compounds requires the combination of a separation and spectroscopic technique which results in characteristic retention times and spectral response under specific conditions. In HPLC this can easily be done by incorporating an 
internal standard to stabilize retention time and using a chromatographic library for comparison of UV spectra. However, spectra of ATS can be very similar and minor changes in the $\mathrm{pH}$ or separation conditions can affect retention values making the library ineffective. Quantitation is usually done by calculating peak area rather than height since band broadening can occur as the stationary phase deteriorates [89].

In 2002, Santagati reported an HPLC method specific for primary phenethylamines using electrochemical detection (ECD) [71]. However, ECD is not a commonly utilized detection method as it is dependent on analytes being electrochemically active. For HPLC analysis, as with GC, the most commonly used detection method is mass spectrometry. Concheiro et al demonstrated this with the analysis of seven phenethylamines in urine using a reversed-phase HPLC column coupled to a triple quadrupole mass spectrometer [18]. An electrospray ionization (ESI) source was used to introduce the extracted samples to the mass spectrometer which was run in positive ion mode. Limits of detection ranging from 0.2 to $2 \mathrm{ng} / \mathrm{mL}$ were determined for all analytes.

\subsubsection{Capillary Electrophoresis}

Capillary electrophoresis (CE) is a separation method whereby analytes of interest are separated on the basis of their relative mobility when placed under the influence of an electric field. The distal ends of the capillary are placed in an electrolytic solution, known as a buffer, along with electrodes through which a voltage can be applied. This produces an electric field (E) whose magnitude depends on the applied potential and the length of the capillary. 


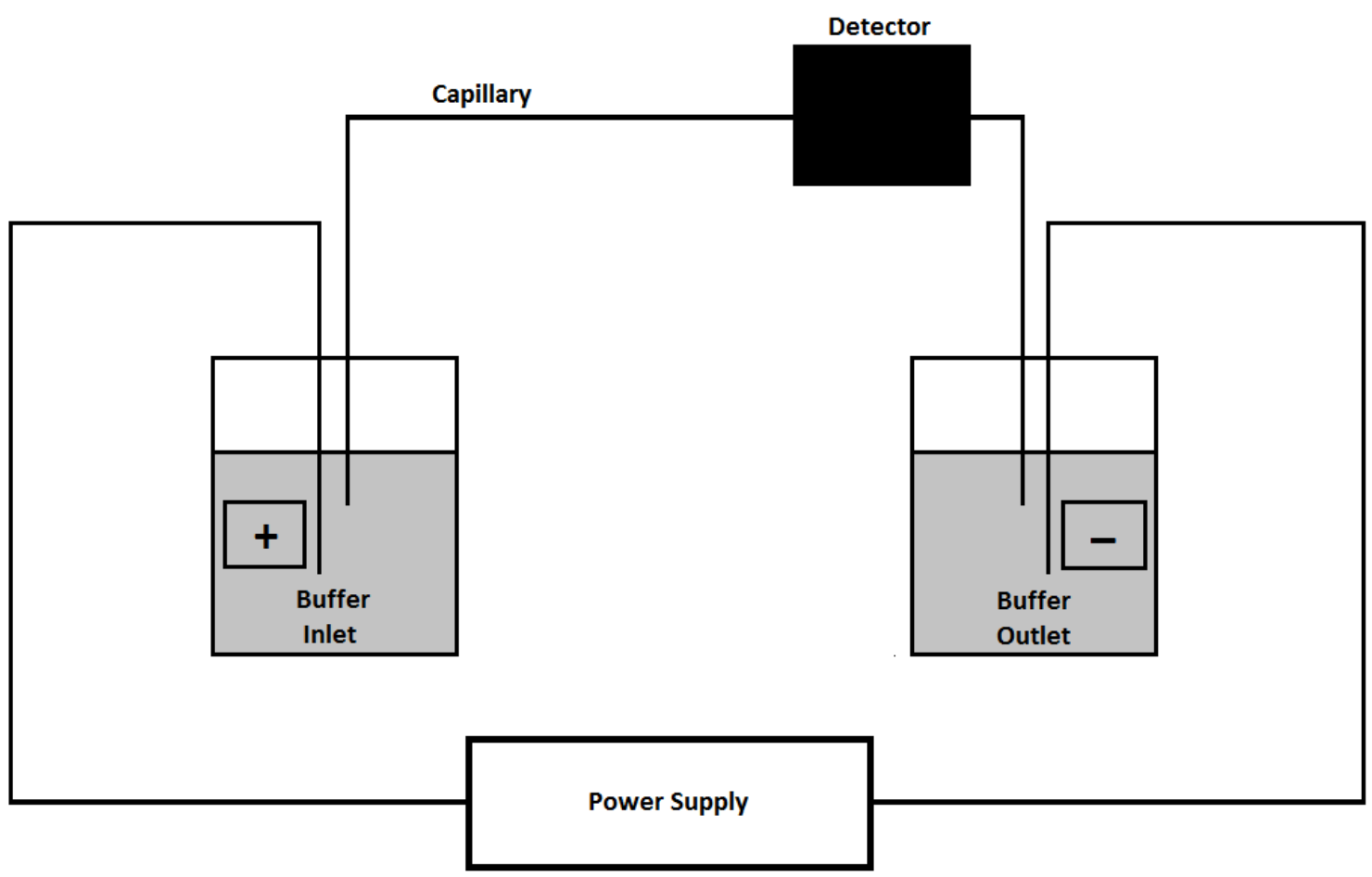

Figure 7: Simplified schematic of a capillary electrophoresis system.

Electrophoretic mobility $\left(\mu_{\mathrm{ep}}\right)$ is based on the analyte's charge $(\mathrm{q})$, radius $(\mathrm{r})$, and the viscosity of the buffer $(\eta)$ being utilized.

$$
\mu_{e p}=q / 6 \pi \eta r
$$

Because of these parameters and their relation to one another, ions are separated on the basis of their charge-to-size ratio. The speed at which the analytes migrate is known as the electrophoretic velocity $\left(\mathrm{v}_{\mathrm{ep}}\right)$. It is the product of the analyte's electrophoretic mobility and the magnitude of the electric field.

$$
v_{e p}=\mu_{e p} E
$$


Aside from the electrophoretic velocity, there is also the bulk movement of the buffer solution which plays a role in a CE separation. This electrodriven motion of the buffer is known as the electroosmotic flow (EOF) and it is affected by the chemistry of the capillary walls and that of the buffer itself. At a $\mathrm{pH}$ greater than three, the silanol (Si$\mathrm{OH}$ ) groups on the surface of the fused silica capillary are negatively charged as silanoate ( $\mathrm{Si}^{-} \mathrm{O}^{-}$) groups [41]. As a result of this, the positively charged ions in the buffer solution are drawn to the walls forming a layer of cations. This initial cation layer is not capable of fully neutralizing all of these negatively charged groups so a second layer of cations is formed. This is known as the electrical double layer.

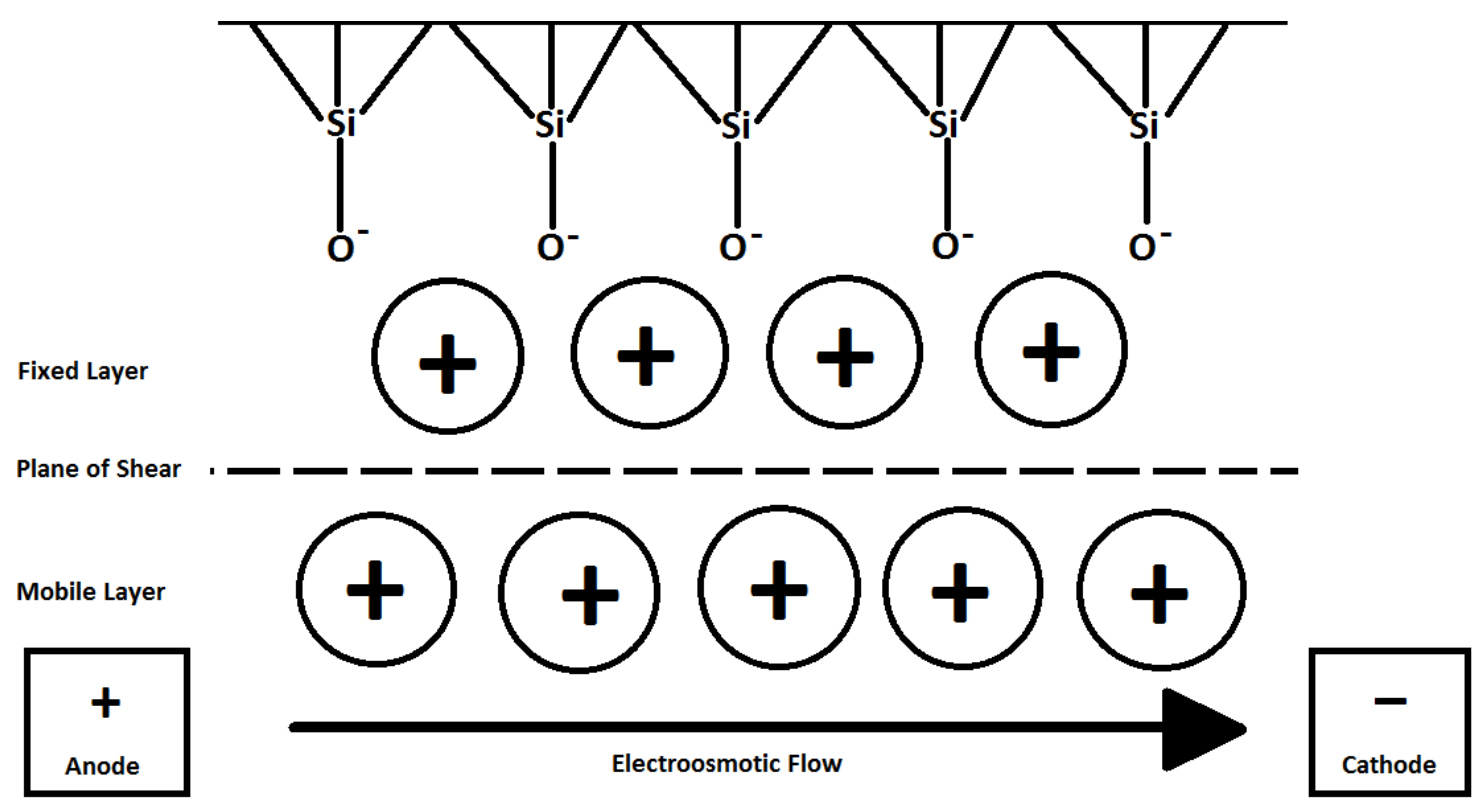

Figure 8: Diagram of the electric bilayer formed on the walls of silica capillaries in electrophoresis.

While the innermost layer is fixed to the walls of the capillary, the second layer is not given its distance from the actual silanoate groups [41]. As a result of this, when the 
electric field is applied, the charged cations of the mobile layer are pulled towards the cathode. Given that these cations are solvated, they in essence drag the bulk solution towards the cathode as well thus generating the EOF. The electroosmotic velocity $\left(\mathrm{v}_{\mathrm{eo}}\right)$ depends on the dielectric constant and viscosity of the buffer, and the zeta potential at the surface of the capillary.

$$
v_{e o}=\varepsilon \zeta E / 4 \pi \eta
$$

It can also be expressed in terms of mobility.

$$
\mu_{e o}=\varepsilon \zeta / 4 \pi \eta
$$

Therefore, the overall mobility of an analyte of interest is the sum of its electrophoretic mobility and the electroosmotic mobility of the buffer $[41,73]$.

$$
\mu_{\text {overall }}=\mu_{e p}+\mu_{e o}
$$

Under normal polarity conditions, small, highly charged cations will elute first followed by cations of lesser charge, neutral molecules, and finally anions of increasing charge last. Because of their lack of charge, neutral molecules will not separate and thus will elute as a single peak midway through the separation. This characteristic elution order is observed in capillary zone electrophoresis (CZE) which is the most common mode of CE analysis [73]. Other modes of CE include micellar electrokinetic chromatography (MEKC), capillary isoelectric focusing (CIEF), capillary gel electrophoresis (CGE), and capillary isotachophoresis (CITP). In MEKC, a pseudostationary phase, typically in the form of a surfactant, is added to the run buffer. These surfactants interact with the analytes based on their polarity and can allow for 
neutral molecules to be separated. This is done by the formation of micelles around the analytes of interest, altering their electrophoretic mobility. 


\subsection{Electrophoretic Analysis of Phenethylamines}

Britt E. Turnquest, Bruce R. McCord*, Florida International University

Correspondence: Dr. Bruce R. McCord, Department of Chemistry \& Biochemistry, Florida International University, 11200 SW $8^{\text {th }}$ Street, Miami, FL 33199

Email: mccordb@fiu.edu

Fax: $305-348-3772$

Keywords: amphetamines, capillary electrophoresis, phenethylamines

Word Count: 3,298 


\begin{abstract}
The rise in production and seizures of amphetamines and related phenethylamine analogues has highlighted the need for rapid, sensitive, and selective methods of analysis for these compounds. One analytical technique which is very versatile for the investigation of these compounds is capillary electrophoresis. In this review, the application of capillary electrophoresis towards phenethylamine analysis is discussed. The review will cover various modes of separation including $\mathrm{CE}, \mathrm{MEKC}$, and $\mathrm{CEC}$ in standard and chip based formats. Methods of detection such as UV, LIF and mass spectrometry will also be discussed.
\end{abstract}

\title{
Introduction
}

In 1991 Weinberger and Lurie published one of the first applications of capillary electrophoresis as an analytical method for illicit drugs [1]. In that work, micellar electrokinetic capillary chromatography (MEKC) was compared to high-performance liquid chromatography (HPLC) for the analysis of several drugs and associated impurities, which spanned several drug classifications. Thirty-five analytes were observed in total including benzodiazepines, cannabinoids, amphetamines, and opiates. Capillaries of varying length were used and detection was performed by utilizing a photodiode array detector to measure UV absorbance. Since this seminal work, a number of differing variations of capillary zone electrophoresis (CZE) and micellar electrokinetic chromatography (MEKC) have been utilized for the analysis of phenethylamines and related compounds. There are a variety of possible detection methods which can be utilized based on the nature of the separation. 


\section{Capillary Zone Electrophoresis}

In capillary zone electrophoresis (CZE) the movement of analytes within the system to achieve separation is electro-driven, rather than pressure-driven as is seen in chromatographic methods. Capillaries of small diameter are filled with electrolytic solutions and when a voltage is applied to its distal ends, the electric field generated results in the electroosmotic flow of the buffer towards the cathode. By taking advantage of this characteristic behavior, analytes of interest, particularly those which are charged can be separated based on their inherent mobility.

Given the sample volumes utilized in electrophoretic experiments and the high sensitivity which can be achieved, this method of analysis has great potential for the field of forensic science. As a result of this, the applications of electrophoresis grow more every year particularly in the areas of drug and explosives analysis.

\section{Micellar Electrokinetic Capillary Chromatography}

As previously mentioned, phenethylamines have a common structural skeleton which can make traditional CZE difficult as a consequence of similar mobilities between different compounds. To overcome this analytical hurdle and promote greater distinction between analyte zones, modifiers can be added to the separation buffer. These modifiers achieve their purposes either by direct interactions with the solutes or, by affecting the electroosmotic flow within the capillary. Examples of modifiers include surfactants such as sodium dodecyl sulfate (SDS), complexating agents such as cyclodextrins, and organic solvents like isopropanol. Though SDS is still commonly used, a greater focus has now 
been turned towards cyclodextrins. These sugar rings can be substituted with different functional moieties which in turn, affect the inclusion complexes they make with analytes in solution.

The use of MEKC with UV absorption detection for the analysis of several phenethylamines including seized samples was done by Trenerry [5] and results were compared to that obtained by gas chromatography. The micellar additive used in this work was cetyltrimethylammonium bromide (CTAB) rather than SDS. The run buffer was comprised of $10 \mathrm{mM}$ sodium tetraborate, $\mathrm{pH} 11.5$ and $25 \mathrm{mM}$ CTAB solution with $1 \%$ ethanolamine and $11 \%$ dimethylsulfoxide (DMSO). The results obtained demonstrated not only that the two methods were comparable in terms of quantitative ability.

In Meng et al [6], cation-selective exhaustive injection (CSEI) was used as an oncolumn concentration method for the analysis of selected phenethylamines (amphetamine, methamphetamine, and MDMA) using MEKC. Cation-selective exhaustive injection is based on the theory of sample stacking whereby differences in the ionic strength between buffer zones is used to restrict the analytes of interest to a particular zone as they are electrokinetically injected so that the sample is highly concentrated prior to separation being implemented. This in turn increases the sensitivity of the method. Cation-selective exhaustive injection-sweeping changes the capillary wall chemistry to the extent that positively charged analytes are preferentially electrokinetically injected. In order to modify the wall chemistry the capillary is first conditioned with a non-micellar BGE (100mM phosphate, $\mathrm{pH} 2.9$ with $20 \%$ methanol) 
and then injecting a plug of buffer at greatly increased conductivity $(200 \mathrm{mM}$ phosphate buffer, $\mathrm{pH}$ 2.9) followed by a plug of water. Analytes were prepared in low conductivity solutions such as water and electrokinetically injected. Due to the huge differences in conductivity between the injected buffer and water, the analytes stacked in the interface between the two zones.

The analytes were then separated by a micellar run buffer $(100 \mathrm{mM}$ phosphate, $\mathrm{pH}$ 2.9 with $25 \mathrm{mM}$ SDS and $20 \%$ methanol) using reverse polarity. An applied voltage of $18 \mathrm{kV}$ was able to fully resolve all three analytes and the internal standard (benzylamine). This resulted in a limit of detection of $0.05 \mathrm{ng} / \mathrm{mL}$ which is a thousand-fold improvement over that determined using MEKC without CSEI $(0.5 \mu \mathrm{g} / \mathrm{mL})$

These guest-host complexes are not only analyte specific in their level of interaction (e.g., amphetamine versus methamphetamine), they are also stereochemistry specific (e.g., ephedrine versus pseudoephedrine). This specificity makes them very useful in enantiomeric separations where isomer conformation is the major determination for legality. Both Liu [2] and Mohr [3] have discussed the use of different cyclodextrins for the separation of phenethylamine enantiomers. CE coupled to electrospray mass spectrometry (CE-ESI-MS) is also gaining a foothold as an excellent method of analysis. It maintains the high efficiency and resolution which $\mathrm{CE}$ is well noted for while incorporating the high selectivity and sensitivity of mass spectrometric techniques.

Liu used a $75 \mathrm{mM}$ Tris buffer, $\mathrm{pH} 2.5$ with $40 \mathrm{mM}$ dimethyl- $\beta$-cyclodextrin (DM$\beta$-CD) to analyze ephedrine and several related compounds including enantiomers. A $75 \mu \mathrm{m}$ inner diameter capillary with an effective length of $50 \mathrm{~cm}$ was used for the 
separation. Prior to analysis the walls of the capillary were cleaned and activated by washing sequentially with methanol, $1 \mathrm{M}$ hydrochloric acid, and $1 \mathrm{M}$ sodium hydroxide with water washes between each. All analytes were fully resolved within 22 minutes and the detection limits ranged from 65 to $161 \mathrm{ng} / \mathrm{mL}$.

In Mohr's work several types of cyclodextrins were tested to determine the optimal conditions for the enantiomer-selective separation of 19 cathinone derivatives. These included native $\beta$-cyclodextrin, carboxymethyl- $\beta$-cyclodextrin, 2-hydroxypropyl- $\beta$ cyclodextrin, sulfated- $\beta$-cyclodextrin, and native $\gamma$-cyclodextrin. The optimal buffer composition was determined to be $50 \mathrm{mM}$ ammonium acetate, $\mathrm{pH} 4.5$ with $20 \mathrm{mg} / \mathrm{mL}$ sulfated- $\beta$-cyclodextrin and 10\% acetonitrile. Of the 19 total analytes, all except methedrone were resolved although its' presence was confirmed using chiral HPLC.

\section{Capillary Electrochromatography}

In capillary electrochromatography (CEC) analysis, capillaries are filled with a stationary phase which allows for partition-based separation as in traditional chromatography with the efficiency characteristic of electrophoresis. In its initial incarnation capillaries were manually packed with the stationary sorbent which was held in place by frits at the terminal ends. However, this was difficult to do, susceptible to shifting, and not as efficient as the chromatographic methods it was meant to emulate.

Monolithic stationary phases provide a useful alternative to packed CEC columns which are susceptible significant backpressure. These monoliths, unlike traditional packing, are chemically linked to the wall of the capillary itself so there is little chance of 
the packing shifting. Also, the chemical nature and pore sizes within the monolith can be easily designated based on the cross-linking agents, monomers and porogens used. The temperature at the time of polymerization can also play a role. Other monoliths available include modified silica and sol gels depending on the analytes of interest.

Given that the presence of the monolith reduces the available volume within the capillary, CEC injections are low in volume. As a result of this, only small amounts of analyte can be introduced into the system resulting in lower sensitivity. This issue can be overcome somewhat, however, by preconcentrating the analyte at the column head (before the monolith starts). In the work by Lurie [7] CEC with laser-induced fluorescence detection was used to analyze natively fluorescent impurities in heroin. A sulfonic acid $\mathrm{C}_{12}$ polymer monolith was prepared within $\mathrm{UV}$ transparent capillaries with an inner diameter of $100 \mu \mathrm{m}$. The packed length was $39 \mathrm{~cm}$ in total (effective length, 29 $\mathrm{cm}$ ), and a doubled argon laser with a $257 \mathrm{~nm}$ wavelength was utilized. This investigation resulted in a limit of detection of $66 \mathrm{pg} / \mathrm{mL}$ for the most abundant analyte, acetylthebaol.

Aturki utilized a cyano-derivatized silica monolith for the analysis of nine drugs of abuse, including amphetamines, with mass spectrometry as the detection method [8]. Prior to CEC-MS analysis, samples were first extracted using a strong cation exchange solid-phase extraction cartridge which provided a recovery of 80 to $95 \%$. Limits of detection were determined to range between 0.78 and $3.12 \mathrm{ng} / \mathrm{mL}$ for all the analytes of interest. A recent modification of the CEC technique is pressure-assisted CEC (pCEC) which combines the efficiency of CE with the selectivity of HPLC [9]. 
A novel analysis method utilizing magnetic solid-phase extraction coupled with capillary zone electrophoresis (MSPE-CZE) was used by Chen et al [4] to determine the presence of eight illicit drugs in urine. The magnetic microspheres used in this work were comprised of magnetite, silica, and poly(methacrylic acid-co-ethylene glycol dimethacrylate). The separation buffer utilized was comprised of $30 \mathrm{mM}$ phosphate, $\mathrm{pH}$ 2.0 with $15 \%$ acetonitrile. Extraction, baseline separation, and detection of these analytes by UV-Vis absorption was achieved within 20 minutes. Limits of detection ranged from 0.015 to $0.105 \mu \mathrm{g} / \mathrm{mL}$ with field-amplified sample stacking (FASS) to enhance the method sensitivity.

\section{Microfluidics}

As electrophoretic methods are continuously investigated and developed, the conversion of traditional techniques to miniaturized systems is increasing as well. One example of this is the analysis of DNA fragments and proteins using which was initially done using gels before being taken onto capillary electrophoresis. Now, there are several lab-on-chip (LOC) platforms for this kind of work. One such is the Agilent Bioanalyzer which is available commercially. Lab-on-chip devices have the benefits of being fast, portable, and relatively inexpensive. In the work by Lloyd et al [10], the Agilent Bioanalyzer was used to separate several phenethylamines which had been fluorescently labeled prior to chip loading with fluorescein isothiocyanate (FITC). The separation buffer was comprised of 50mM sodium tetraborate, $\mathrm{pH} 9.66$ with 50mM SDS and completed in less than a minute with 3 minutes for fluorescent labeling beforehand. An average limit of detection was determined to be $0.6 \mu \mathrm{g} / \mathrm{mL}$, which is comparable to that 
of a full-sized CE method. Microfluidic chips can be made from a variety of materials based on the wall chemistry desired including borosilicate glass and polydimethylsiloxane (PDMS).

An example of the use of glass chips is the work done by Wallenborg [11] where a mixture of chiral phenethylamines were separated and detected via laser-induced fluorescence after being labeled with 20mM 4-fluoro-7-nitrobenzofurazane (NBD-F). The separation chips utilized in this work were developed from commercially available glass wafers. The chip patterns used were generated by transferring the desired design onto the wafers which had been coated with chromium and photoresist. Hydrofluoric acid was utilized to chemically etch the channels and leftover photoresist and chromium were removed. Labeled analytes were diluted 10-20 fold in buffer before being separated using with a running buffer comprised of 50mM borate, $\mathrm{pH} 8.5,50 \mathrm{mM}$ SDS, and 20\% 1propanol. Voltage applied was $4 \mathrm{kV}$ and the entire separation was complete in less than ten minutes.

\section{Non-aqueous Capillary Electrophoresis}

In conventional electrophoresis the electrolytic buffer is comprised of an appropriate salt dissolved in aqueous solution. This environment can make the analysis of hydrophobic species difficult. In non-aqueous capillary electrophoresis (NACE), all water within the system is replaced with the organic solvent of choice. The use of organic solvents has many advantages over aqueous solution based electrophoresis in terms of analytical parameters. In conventional CE, capillaries with very small internal diameters are utilized in order to minimize Joule heating which can increase the amount of 
longitudinal diffusion resulting in band broadening. In NACE less heat is produced due to the organic buffer's lower thermal conductivity in comparison to that of an aqueous buffer [11]. This not only allows for the usage of larger diameter capillaries, but also for higher salt concentrations and larger electric fields. Larger capillaries translate into larger sample sizes and longer optical path lengths which in turn, increase sensitivity.

Despite the lack of water in NACE, electroosmotic flow (EOF) can still be generated due to the solvents accepting protons from the silanol groups on the capillary wall. However, the extent to which an organic solvent can do so is dependent on the chemical nature of the solvent itself. The magnitude of the EOF generated is based on various solvent properties including dielectric constant $(\varepsilon)$, zeta potential $(\zeta)$, and viscosity (n).

$$
v_{e o}=\frac{\varepsilon \zeta}{4 \pi \eta} E
$$

Given that these properties can greatly differ between different solvents, this gives NACE the potential to be extremely selective. NACE can effectively be coupled to many different detection techniques.

When coupled to ESI-MS, the spray produced is stable in nature and evaporates very quickly. This stable, volatile electrospray allows for lower gas flow rates to be used and thus, greater amounts of ions to be introduced to the mass spectrometer. Steiner [12] found while assessing the influence of different organic solvents in the separation of basic analytes similar to phenethylamines NACE-MS was capable of resolving between 
analytes which would normally coelute under aqueous conditions. Other useful detection methods include direct and indirect UV absorbance spectroscopy, direct and indirect fluorescence, and electrochemical detection.

\section{Concluding Remarks}

Advantages of capillary electrophoresis include small sample sizes, minimal waste produced, sensitivity, and wide applicability to a variety of analytes of interest. All of these and more make it an excellent technique for the analysis of phenethylamines, particularly those in seized samples. 


\section{References}

1. Weinberger, R.; Lurie, I. S. Micellar Electrokinetic Capillary Chromatography of Illicit Drug Substances. Anal. Chem. 1991, 63, 823.

2. Liu, L.; Zheng, Z.; Lin, J. Application of dimethyl-beta-cyclodextrin as a chiral selector in capillary electrophoresis for enantiomer separation of ephedrine and related compounds in some drugs. Biomedical Chromatography 2005, 19, 447.

3. Mohr, S.; Pilaj, S.; Schmid, M. G. Chiral separation of cathinone derivatives used as recreational drugs by cyclodextrin-modified capillary electrophoresis.

Electrophoresis 2012, 33, 1624.

4. Chen, M. L.; Suo, L. L.; Gao, Q.; Feng, Y. Q. Determination of eight illegal drugs in human urine by combination of magnetic solid-phase extraction with capillary zone electrophoresis. Electrophoresis 2011, 32, 2099-2106.

5. Trenerry, V. C.; Robertson, J.; Wells, R. J. Analysis of illicit amphetamine seizures by capillary electrophoresis. Journal of Chromatography A 1995, 708, 169.

6. Meng, P.; Fang, N.; Wang, M.; Liu, H.; Chen, D. D. Y. Analysis of amphetamine, methamphetamine and methylenedioxy-methamphetamine by micellar capillary electrophoresis using cation-selective exhaustive injection. Electrophoresis 2006, 27, 3210-3217.

7. Lurie, I.S.; Anex, D.S.; Fintschenko, Y.; Choi, W. Profiling of impurities in heroin by capillary electrochromatography and laser-induced fluorescence detection. $J$. Chromatog. A 2001, 924, 421 .

8. Aturki, Z.; D’Orazio, G.; Rocco, A.; Bortolotti, F.; et al. CEC-ESI ion trap MS of multiple drugs of abuse. Electrophoresis 2010, 31, 1256.

9. Pascali, J. P.; Bortolotti, F.; Tagliaro, F. Recent advances in the application of CE to forensic sciences, an update over years 2009-2011. Electrophoresis 2012, 33, 117-126.

10. Lloyd, A.; Blanes, L.; Beavis, A.; Roux, C.; Doble, P. A rapid method for the infield analysis of amphetamines employing the Agilent Bioanalyzer. Analytical Methods, 2011, 3, 1535.

11. Wallenborg, S. R.; Lurie, I. S.; Arnold, D. W.; Balley, C. G. On-chip chiral and achiral separation of amphetamine and related compounds labeled with 4-fluoro7-nitrobenzofurazane. Electrophoresis 2000, 21, 3257.

12. Riekkola, M.; Jussila, M.; Porras, S. P.; Valko, I. E. Non-aqueous capillary electrophoresis. J. Chromatogr. A 2000, 892, 155-170. 
13. Steiner, F.; Hassel, M. Influence of solvent properties on separation and detection performance in non-aqueous capillary electrophoresis-mass spectrometry of basic analytes. J. Chromatogr. A 2005, 1068, 131-142.

14. Anastos, N.; Barnett, N. W.; Lewis, S. W. Capillary electrophoresis for forensic drug analysis: A review. Talanta 2005, 67, 269-279.

15. Aubrey, A.D.; Chalmers, J.H.; Bada, J.L.; Grunthaner, F.J.; et al. The Urey Instrument: An Advanced In Situ Organic and Oxidant Detector for Mars Exploration. Astrobiology 2008, 8, 1-13.

16. Bishop, S. C.; Lerch, Margaret; McCord, B. R. Micellar electrokinetic chromatographic screening method for common sexual assault drugs administered in beverages. Forensic Science International 2004, 141, 7.

17. Bishop, S. C.; McCord, B. R.; Gratz, S. R.; Loeliger, J. R.; Witkowski, M. R. Simultaneous Separation of Different Types of Amphetamine and Piperazine Designer Drugs by Capillary Electrophoresis with a Chiral Selector. Journal of Forensic Sciences, J Forensic Sci 2005, 50, 1.

18. Brettell, T.A.; Butler, J.M.; Almirall, J.R. Forensic Science. Analytical Chemistry 2007, 79, 4365 .

19. Brettell, T.A.; Butler, J.M.; Almirall, J.R. Forensic Science. Analytical Chemistry 2009, 81, 4695.

20. Drake, S. J.; Morrison, C.; Smith, F. Simultaneous chiral separation of methylamphetamine and common precursors using gas chromatography/mass spectrometry. Chirality 2011, 23, 593-601.

21. Fanali, S.; Aturki, Z.; Desiderio, C. New strategies for chiral analysis of drugs by capillary electrophoresis. Forensic Sci. Int. 1998, 92, 137-155.

22. Fanali, S.; Cristalli, M.; Vespalec, R.; Bocek, P. Chiral separations in capillary electrophoresis. Adv. Electrophor. 1994, 7, 1-86.

23. Fanali, S.; Desiderio, C.; Aturki, Z. Enantiomeric resolution study by capillary electrophoresis. Selection of the appropriate chiral selector. J. Chromatogr. A 1997, 772, 185-194.

24. Ferrance, J.; Landers, J. P. Exploiting sensitive laser-induced fluorescence detection on electrophoretic microchips for executing rapid clinical diagnostics. Luminescence 2001, 16, 79-88.

25. Gübitz, G.; Schmid, M. G. Chiral separation by capillary electromigration techniques. Journal of Chromatography A 2008, 1204, 140-156. 
26. Habrdova, V.; Peters, F.T.; Theobald, D.S.; Maurer, H.H. Screening for and validated quantification of phenethylamine-type designer drugs and mescaline in human blood plasma by gas chromatography/mass spectrometry. Journal of Mass Spectrometry, 2005, 40, 785 .

27. Kato, M.; Gyoten, Y.; Sakai-Kato, K.; Toyo'oka, T. Rapid analysis of amino acids in Japanese green tea by microchip electrophoresis using plastic microchip and fluorescence detection. J Chromatogr A 2003, 1013, 183-189.

28. Kuroda, N.; Nomura, R.; Al-Dirbashi, O.; Akiyama, S.; Nakashima, K. Determination of methamphetamine and related compounds by capillary electrophoresis with UV and laser-induced fluorescence detection. J Chromatogr A 1998, 798, 325-334.

29. Lomsadze, K.; Dominguez Vega, E.; Salgado, A.; Crego, A. L.; Scriba, G. K. E.; Marina, M. L.; Chankvetadze, B. Separation of enantiomers of norephedrine by capillary electrophoresis using cyclodextrins as chiral selectors: Comparative CE and NMR studies. Electrophoresis 2012, 33, 1637.

30. Lurie, Ira S. Capillary electrophoresis of illicit drug seizures. Forensic Science International 1998, 92, 125.

31. Lurie, I.S.; Anex, D.S.; Fintschenko, Y.; Choi, W. Profiling of impurities in heroin by capillary electrochromatography and laser-induced fluorescence detection. J. Chromatog. A 2001, 924, 421.

32. Lurie, I. S.; Bozenko Jr., J. S.; Li, L.; Miller, E. E.; Greenfield, S. J. Separation of Methamphetamine and Related Compounds using Capillary Electrophoresis with Dynamically Coated Capillaries. Microgram Journal , 8, 24.

33. Mandrioli, R.; Mercolini, L.; Raggi, M. A. Chiral analysis of amphetamines, methadone and metabolites in biological samples by electrodriven methods. Electrophoresis 2011, 32, 2629-2639.

34. McCord, B. R.; Turner, C.; Blas, M.; Bishop, S. C.; Lerch, M.; Dehere, S.; Pannepucci, R. Development of Microfluidic Devices for the Rapid Isolation and Detection of Drugs of Abuse. National Institute of Justice , 2004-WG-BX-K077.

35. Meng, L.; Wang, B.; Luo, F.; Shen, G.; Wang, Z.; Guo, M. Application of dispersive liquid-liquid microextraction and CE with UV detection for the chiral separation and determination of the multiple illicit drugs on forensic samples. Forensic Sci. Int. 2011, 209, 42-47.

36. Pascali, J. P.; Bortolotti, F.; Tagliaro, F. Recent advances in the application of CE to forensic sciences, an update over years 2009-2011. Electrophoresis 2012, 33, 117-126. 
37. Ramseier, A.; von Heeren, F.; Thormann, W. Analysis of fluorescein isothiocyanate derivatized amphetamine and analogs in human urine by capillary electrophoresis in chip-based and fused-silica capillary instrumentation. Electrophoresis 1998, 19, 2967-2975.

38. Sanchez-Hernandez, L.; Castro-Puyana, M.; Marina, M. L.; Crego, A. L. Recent approaches in sensitive enantioseparations by CE. Electrophoresis 2012, 33, 228242.

39. Santagati, N. A.; Ferrara, G.; Marrazzo, A.; Ronsisvalle, G. Simultaneous determination of amphetamine and one of its metabolites by HPLC with electrochemical detection. J. Pharm. Biomed. Anal. 2002, 30, 247-255.

40. Sarmini, K.; Kenndler, E. Influence of organic solvents on the separation selectivity in capillary electrophoresis. J. Chromatogr. A 1997, 792, 3-11.

41. Tagliaro, F.; Bortolotti, F. Recent advances in the applications of CE to forensic sciences (2005-2007). Electrophoresis 2008, 29, 260-268.

42. Tagliaro, F.; Bortolotti, F. Recent advances in the applications of CE to forensic sciences (2001-2004). Electrophoresis 2006, 27, 231-243.

43. Tagliaro, F.; Bortolotti, F.; Pascali, J. P. Current role of capillary electrophoretic/electrokinetic techniques in forensic toxicology. Anal. Bioanal. Chem. 2007, 388, 1359-1364.

44. Tagliaro, F.; Pascali, J.; Fanigliulo, A.; Bortolotti, F. Recent advances in the application of CE to forensic sciences: A update over years 2007-2009. Electrophoresis 2010, 31, 251-259.

45. Tagliaro, F.; Turrina, S.; Pisi, P.; Smith, F. P.; Marigo, M. Determination of illicit and/or abused drugs and compounds of forensic interest in biosamples by capillary electrophoretic/electrokinetic methods. J. Chromatogr. B: Biomed. Sci. Appl. 1998, 713, 27-49.

46. Taylor, R.B.; Low, A.S.; Reid, R.G. Determination of opiates in urine by capillary electrophoresis. Journal of Chromatography B 1996, 675, 213.

47. UNODC World Drug Report 2013. United Nations publication 2013.

48. UNODC Recommended Methods for the Identification and Analysis of Amphetamine, Methamphetamine and their Ring-substituted Analogues in Seized Materials. United Nations publication 2006.

49. Vega, E. D.; Lomsadze, K.; Chankvetadze, L.; Salgado, A.; Scriba, G. K. E.; Calvo, E.; Lopez, J. A.; Crego, A. L.; Marina, M. L.; Chankvetadze, B. Separation of enantiomers of ephedrine by capillary electrophoresis using cyclodextrins as 
chiral selectors: Comparative CE, NMR and high resolution MS studies.

Electrophoresis 2011, 32, 2640.

50. Verpoote, E. Microfluidic chips for clinical and forensic analysis. Electrophoresis 2002, 23, 677-712.

51. Weinberger, R.; Lurie, I. S. Micellar Electrokinetic Capillary Chromatography of Illicit Drug Substances. Anal. Chem. 1991, 63, 823.

52. Wicks, D. A.; Li, P. C. H. Separation of fluorescent derivatives of hydroxylcontaining small molecules on a microfluidic chip. Anal Chim Acta 2004, 507, 107-114.

53. Yassine, O.; Morin, P.; Dispagne, O.; Renaud, L.; Denoroy, L.; Kleimann, P.; Faure, K.; Rocca, J. L.; Ouaini, N.; Ferrigno, R. Electrophoresis PDMS/glass chips with continuous on-chip derivatization and analysis of amino acids using naphthalene-2,3-dicarboxaldehyde as fluorogenic agent. Anal Chim Acta 2008, $609,215-222$. 


\section{CHAPTER 2: FLUORESCENCE DETECTION}

\subsection{Detection Methods in Electrophoresis}

In capillary electrophoresis there are many detection techniques available, each with its own advantages and shortcomings. Some of the most commonly encountered are ultraviolet-visible (UV-Vis) absorbance spectroscopy, mass spectrometry (MS), and laser-induced fluorescence (LIF). Ultraviolet/visible spectrophotometry, while being a virtually universal detector, is limited in sensitivity. This is a result of Beer's Law which states that an analyte's absorbance is dependent on its molar absorptivity $(\varepsilon)$, concentration $(c)$, and the distance light must travel to cross through it or path length $(b)$. As a result of this, the size of the capillary's inner diameter a vital factor.

$$
A=\varepsilon b c
$$

While immunoassays and color tests are relatively fast and can be utilized for several compounds, they are often subject to issues with cross-reactivity and are not often selective for individual compounds, just classes analytes (e.g., phenethylamines and opiates rather than methamphetamine, MDMA, heroin, morphine, etc.). Mass spectrometry is another universal detector with quantitative capabilities. However, its usage is limited by the mode of CE being utilized. Certain surfactants and modifiers which are used in micellar electrokinetic chromatography would result in heavy and persistent contamination within the instrument if ever they were introduced making analysis and device maintenance difficult. 


\begin{tabular}{|c|c|c|c|}
\hline Detection Mode & $\begin{array}{c}\text { LOD } \\
\text { (moles injected) }\end{array}$ & $\begin{array}{c}\text { LOD } \\
(\mathrm{mol} / \mathrm{L})\end{array}$ & Comments \\
\hline UV/Visible & $10^{-13}-10^{-16}$ & $10^{-3}-10^{-8}$ & $\begin{array}{l}\text { At }<200 \mathrm{~nm} \text { almost a universal detector; } \\
\text { sensitivity limited by capillary ID }\end{array}$ \\
\hline Fluorescence & $10^{-15}-10^{-17}$ & $10^{-5}-10^{-9}$ & $\begin{array}{l}\text { Limited to fluorescent compounds and } \\
\text { derivatives; xenon-lamp-based }\end{array}$ \\
\hline $\begin{array}{l}\text { Laser-induced } \\
\text { fluorescence }\end{array}$ & $10^{-18}-10^{-22}$ & $10^{-10}-10^{-16}$ & $\begin{array}{l}\text { Very sensitive, but restricted to situations } \\
\text { where the wavelength of lasers matched the } \\
\text { excitation wavelength of the analyte }\end{array}$ \\
\hline Amperometric & $10^{-18}-10^{-20}$ & $10^{-5}-10^{-11}$ & Limited to electroactive species \\
\hline Conductivity & $10^{-15}-10^{-16}$ & $10^{-4}-10^{-8}$ & Universal towards ions, but lacks sensitivity \\
\hline Mass spectrometry & $10^{-15}-10^{-17}$ & $10^{-8}-10^{-10}$ & Universal detection, but CE modes limited \\
\hline Indirect UV & $10^{-10}-10^{-12}$ & $10^{-2}-10^{-5}$ & Universal for ions, but lacks sensitivity \\
\hline Indirect fluorescence & $10^{-15}-10^{-17}$ & $10^{-5}-10^{-6}$ & Universal for ions, but lacks sensitivity \\
\hline
\end{tabular}

Fluorescence detection makes use of the characteristic nature of the photons produced when excited electrons in a compound deactivate from higher electronic energy levels via radiation. The intensity of the radiation produced as a result of the deactivation of the excited electrons can be affected by the route in which the analyte's electrons take in order to return to the ground state. These include vibrational relaxation, internal conversion, external conversion, and intersystem crossing. A few of these is shown in the simplified Jablonski diagram given in figure 9.

The mechanism for the internal conversion process is not very well understood. However, the general consensus is that it is the result of two energy levels being near 
enough to one another for an overlap in the vibrational energy of the excited molecule to occur. External conversion, on the other hand, is the result of energy being lost as the result of interactions/collisions between the excited molecules and other molecules present in the solution. Intersystem crossing is also the result of nearby energy levels experiencing overlap. However, in this case it results in a reversal of the excited electron's spin.

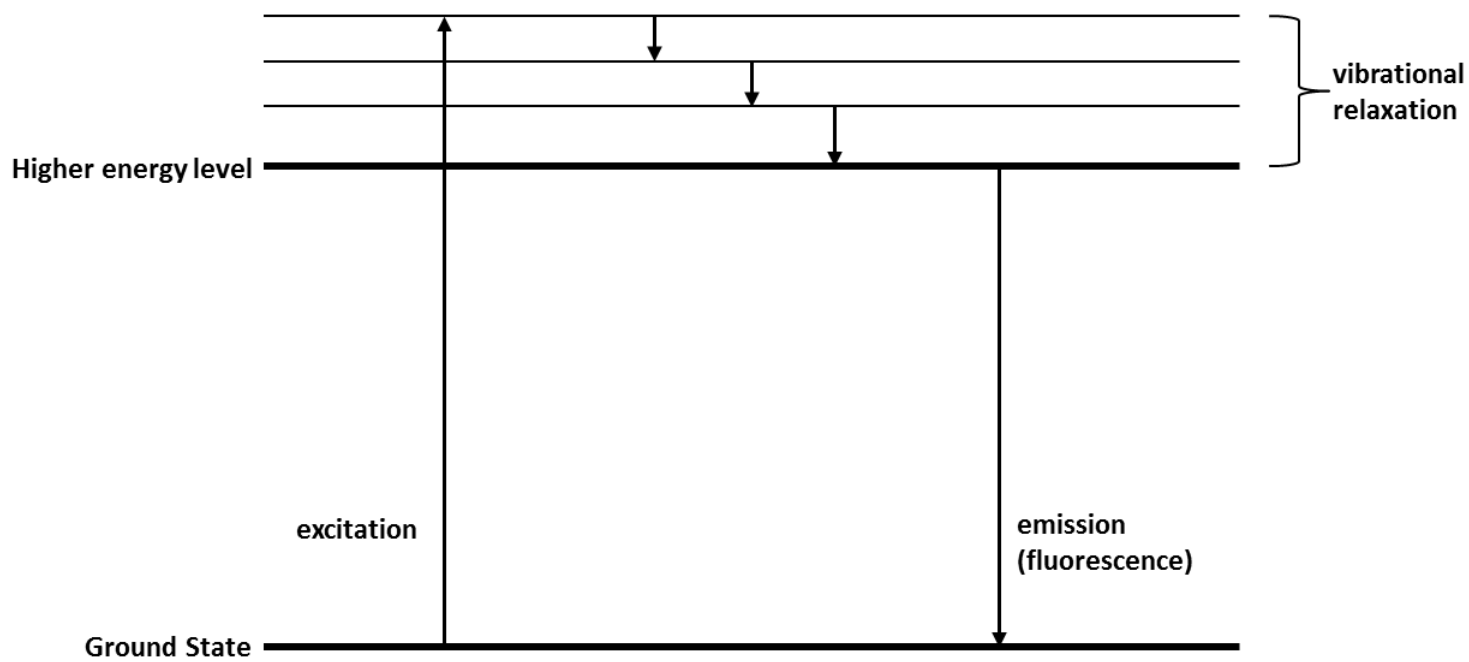

Figure 9: Simplified Jablonski diagram illustrating energy deactivation routes.

In laser-induced fluorescence, a fluorophore is excited by irradiation from laser of set wavelength. The excited molecules in the sample can then relax back to the ground state through the emission of a photon, whose intensity varies based on the quantum yield and absorbance cross section of the fluorophore. 


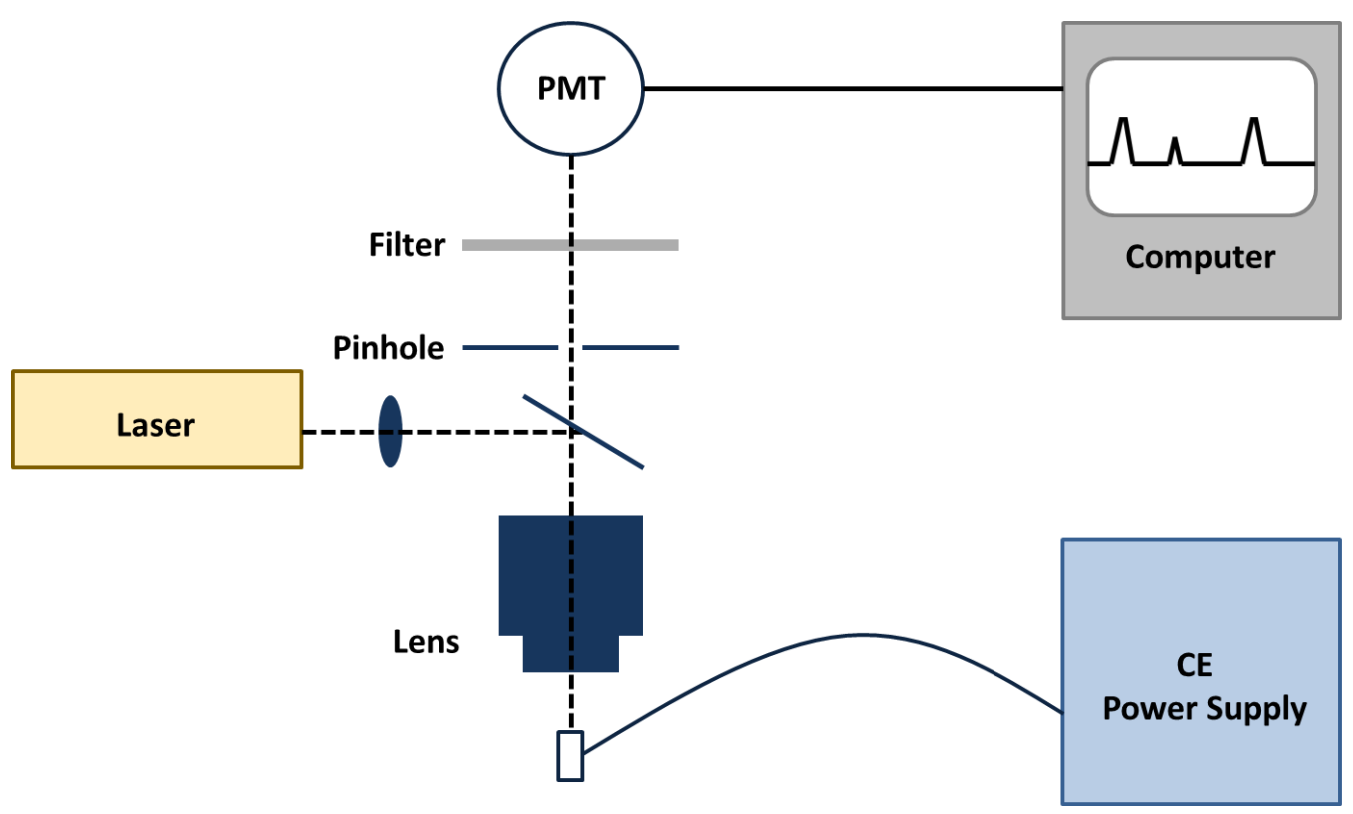

Figure 10: Schematic of LIF detection system coupled to CE.

The intensity of the light produced through this process at each wavelength is then transmitted to the photomultiplier within the detector at a $90^{\circ}$ angle to the incident beam. The photons produced generate a signal as they strike the detector which is plotted with the corresponding wavelength to give a fluorescence spectrum such as that seen in figure 11 for fluorescein isothiocyanate (FITC). The closer in wavelength the laser beam is to the apex of the absorbance/excitation spectrum, the greater the intensity of the produced emission spectrum.

$$
I=I \circ \varepsilon \beta C \varphi k
$$

Laser induced fluorescence is particularly advantageous in capillary electrophoresis due to the fact that fluorescence output $I$ is proportional to the input light flux $I_{o}$. By focusing the laser to a small detection zone created by etching a window in 
the capillary, the inherent disadvantage of the relatively short detection path length in capillary electrophoresis is overcome

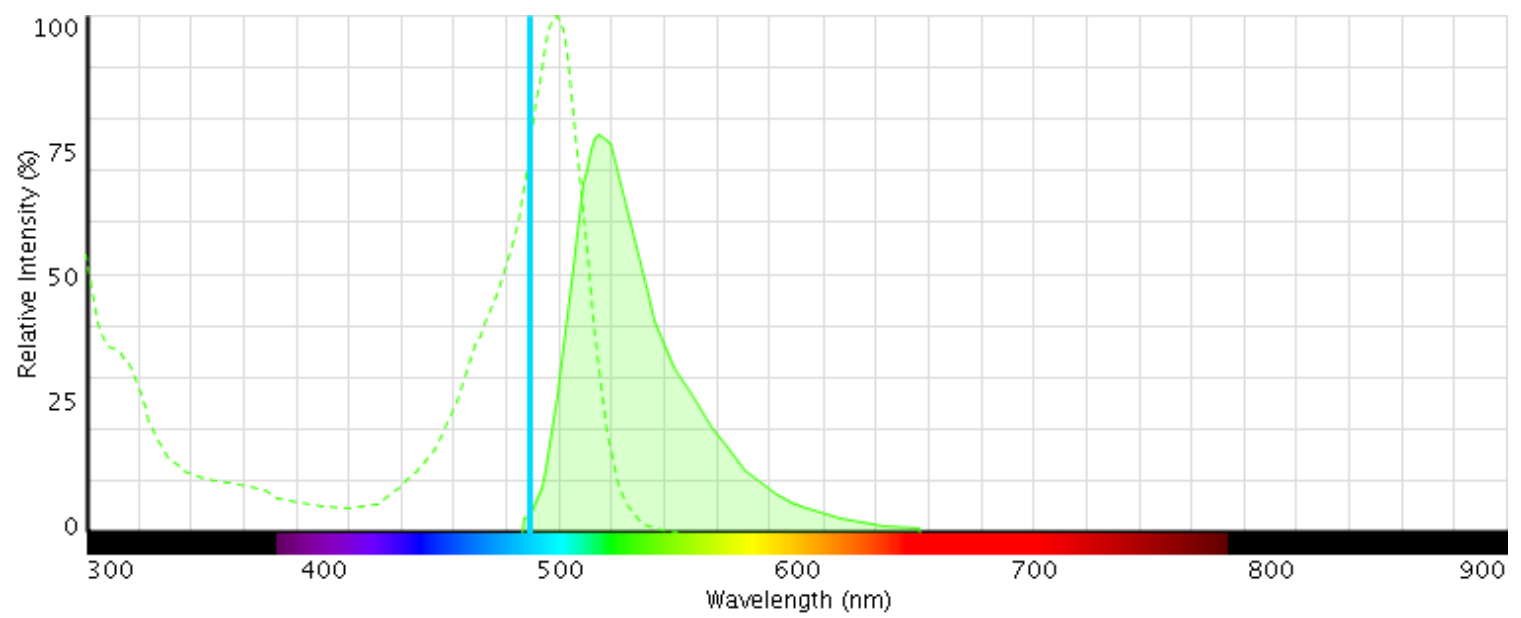

Figure 11: Excitation and emission fluorescence spectrum for fluorescein isothiocyanate using a 488nm laser.

The LIF method has the benefits of being both sensitive and selective. However, very few compounds naturally fluoresce thus derivatization is necessary to permit this type of detection. To do this it is necessary to covalently attach a fluorescent agent or a functional moiety which produces a fluorescent effect to the molecule of interest. This derivatizaton reaction can be undertaken either before the sample is injected into the system (pre-capillary), after the separation has taken place (post-capillary), or within the capillary (inline) prior to or during separation [99].

Pre-capillary derivatization can be time consuming and often requires harsh working conditions [37]. The use of such a labor-intensive method is not desirable in a forensic setting where the caseload can be significant. It also introduces greater probability of user-based errors. 


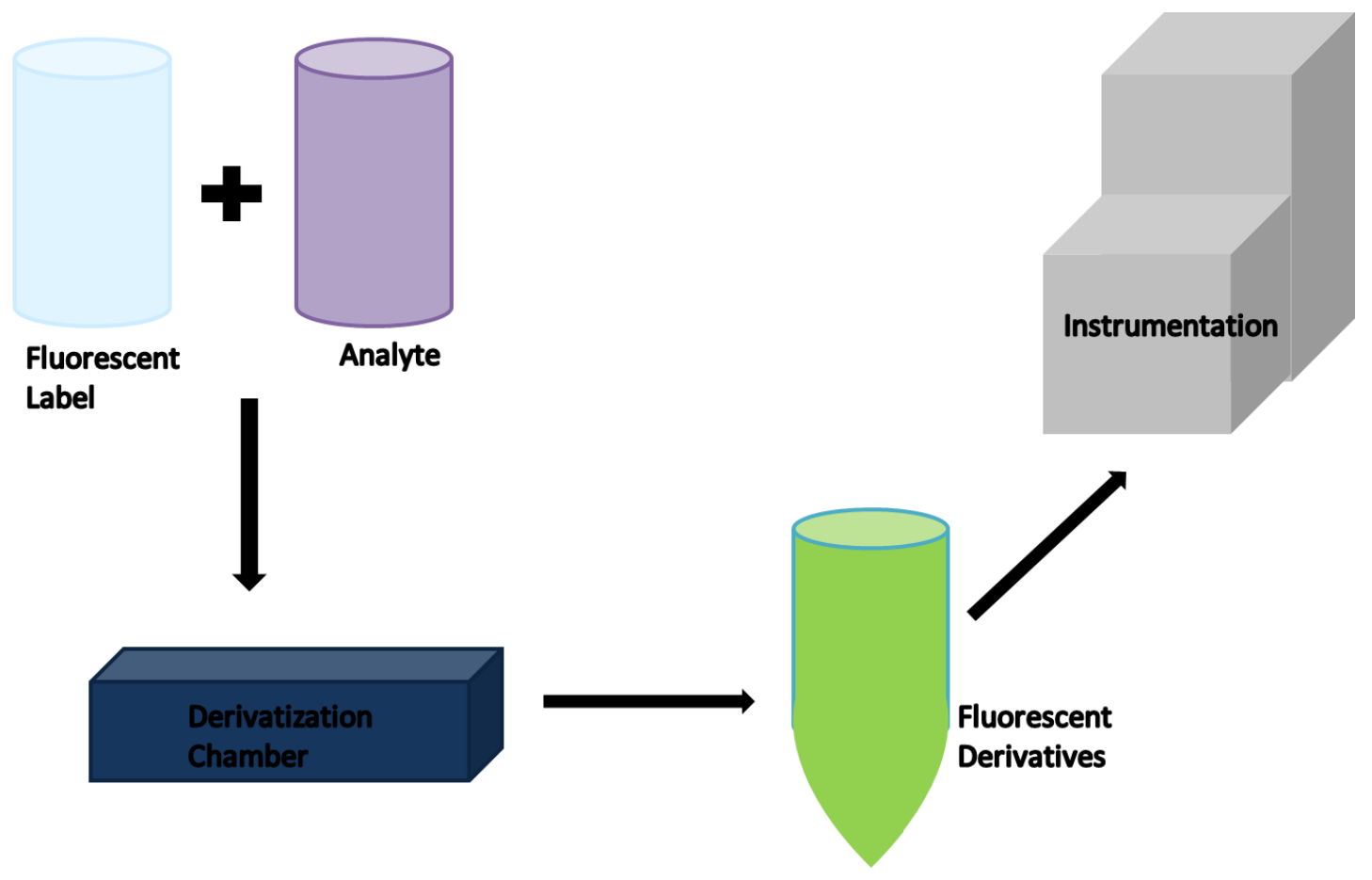

Figure 12: Workflow diagram for pre-capillary derivatization.

The alternative to derivatization prior to sample injection is post-capillary derivatization whereby the analytes are fluorescently labeled after the separation has taken place. One way in which is method can be implemented is by introducing a coaxial sheathed capillary reactor [41]. The reactor encompasses the separation capillary which has had its terminal end fitted into a significantly larger diameter capillary. As the separated analytes pass through the fluorescent reagent is released into the top of the chamber and the fills the large capillary. As analyte zones reach the end of the separation capillary, they are labeled and detected. This method, while effective, is difficult to integrate into commercially available systems and often presents issues in obtaining reproducible results [99]. 


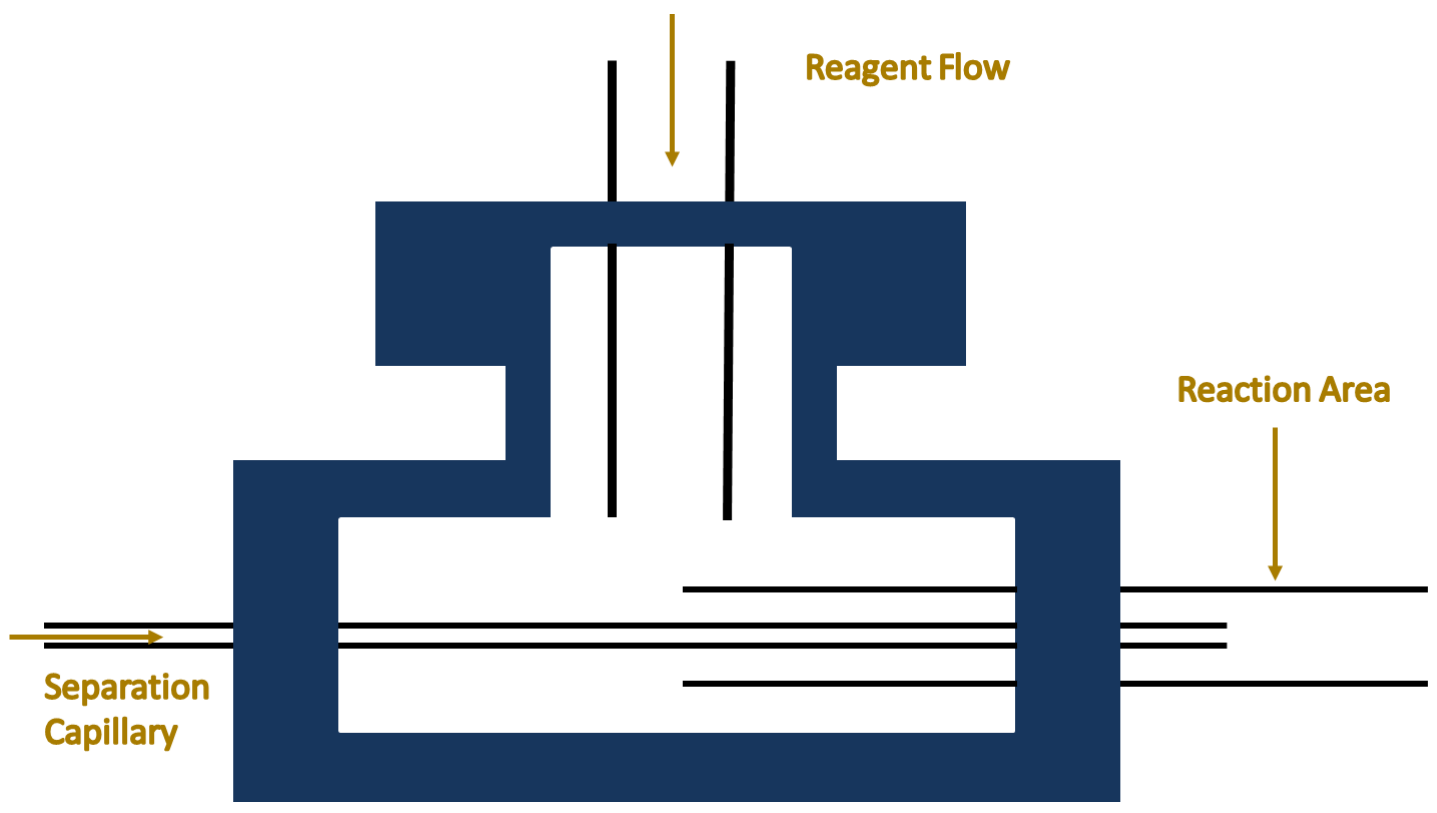

Figure 13: Schematic of coaxial sheathed capillary reactor for post-capillary derivatization. [41]

An alternative to pre and post column derivatization methods involves in-line derivatization. While inline derivatization methods can be restricted by limited sample size and reaction time, the ease of automation reduces the potential for user errors and reproducibility issues. There are three main inline derivatization methods which will be discussed; at inlet, zone passing, and throughout capillary.

\subsection{Derivatization of Analytes}

\subsubsection{At Inlet}

When using the at inlet derivatization method, the process is exclusively driven by diffusion. The sample and fluorescent tag of choice are alternately injected several times followed by a large amount of electrophoretic buffer. The instrument then sits for a prescribed wait period during with the different layers diffuse into one another [77]. At 
the end of this wait time the potential is applied and the actual separation takes place. A diagram of the process is given in figure 14.
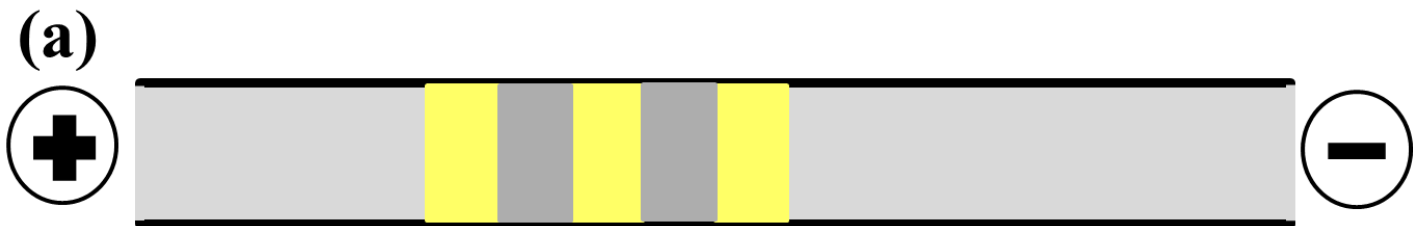

(b)
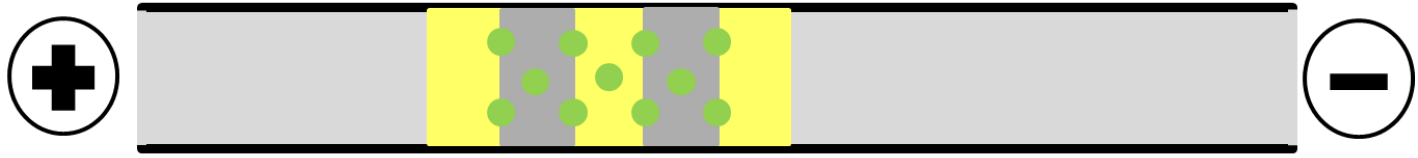

(c)
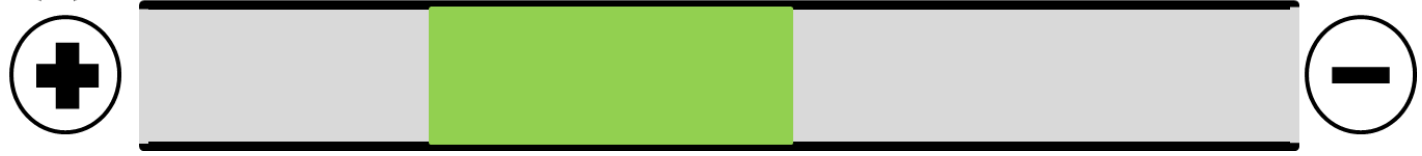

Figure 14: Schematic of at inlet method of inline derivatization. (a) Several plugs of the fluorescent tag and analyte are injected in alternating order. (b) During a set waiting period, diffusion between the zones starts to take place. (c) Plugs have completely mixed and derivatization reaction has gone to completion leaving the fluorescent derivatives of the analytes of interest to be separated.

While this method is simple to implement, it is based on two assumptions. Firstly, that the derivatization reaction between the sample and the fluorescent tag is one hundred percent (or nearly) efficient leaving little excess reagent. This is rarely the case and unless the labeling reagent being used is non-fluorescent in its underivatized state, the separation will experience a large background making interpretation difficult [99]. The second assumption is that substantial diffusion between the two liquids is possible given the miniscule diameter, and therefore small cross-sectional area, of the capillary itself [60]. 


\subsubsection{Zone Passing}

In zone passing, a more moderate injection approach is used in comparison to at inlet. Rather than injecting several alternating plugs, only one injection of the sample and fluorescent label is introduced into the system [106]. These are done sequentially and the order is based on the relative mobility of each aliquot. The liquid with the higher mobility (and thus, the one which will move faster when the electric field is active) is injected second.

Instead of relying on diffusion to mix the layers, a small potential is applied for a short time span. This results in a solutes migrating a bit due to the generated EOF and their own electrophoretic mobility. Given that the aliquot with the faster mobility was injected second, it then moves through the other zone towards the detector. This is known as electrokinetic mixing, which is much more effective than longitudinal diffusion alone [106]. An outline for this derivatization scheme is given in figure 15. 


\section{(a)}
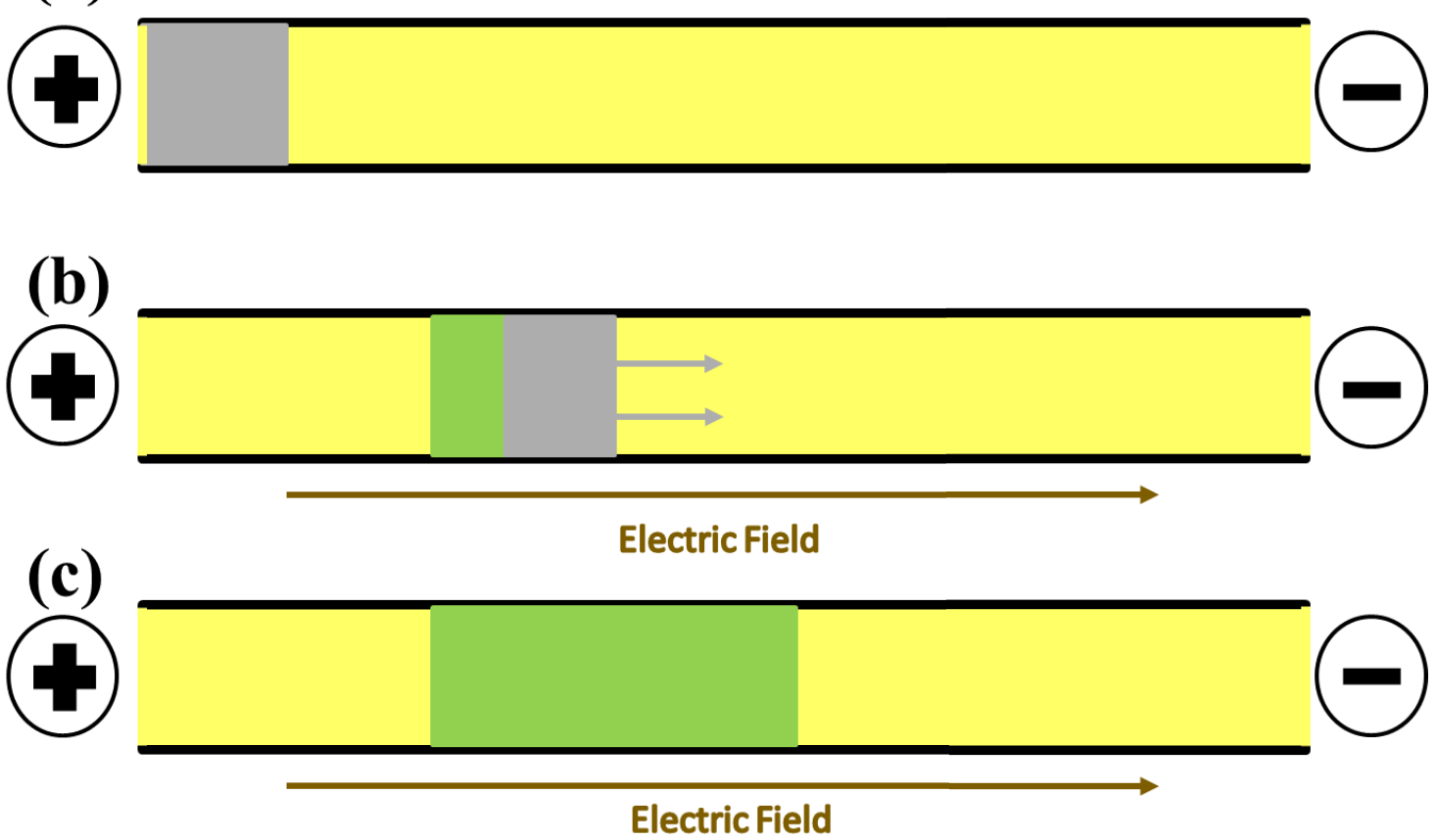

Figure 15: Schematic of zone passing method of inline derivatization. (a) Plugs of analyte and fluorescent tag are injected sequentially into a buffer filled capillary (with faster moving plug injected second). (b) Potential is applied generating an electric field. Faster moving zone begins to move through preceding zone allowing the two to mix. (c) As derivatization reaction takes place, fluorescent derivatives produced are separated.

Zone-passing derivatization is a much more efficient labeling technique than at inlet, using less of the sample and reagent. The electropherogram generated also tends to be easier to interpret as the background produced is much diminished in comparison, and the position of underivatized products is easier to predict based on the injection sequence [78]. The faster moving compound is injected second but due to its faster mobility, will tend to elute first.

\subsubsection{Throughout Capillary}

In throughout capillary derivatization, the separation buffer is usually spiked with a fluorescent derivatization agent. As the injected analyte moves through the capillary 
under the influence of the electric field, derivatization occurs, producing highly fluorescent products. However, throughout capillary derivatization is reliant on the underivatized dye having minimal or no fluorescence at the wavelengths being monitored as otherwise a large and constant background would interfere with analysis. This makes its applicability very limited. A schematic of this process is shown in figure 16.

An early example of this procedure is seen in the experiments done by Taga et al [79]. In this work, amino acids were analyzed via this technique using $o$-phthaldialdehyde (OPA) as the derivatizing agent. The $100 \mathrm{mM}$ borate buffer, $\mathrm{pH} 10.0$ was combined in equal quantities with the fluorescent label OPA at varying concentrations. These spiked buffers were then used to separate the non-fluorescent amino acid analytes which were being labeled as the separation occurred [79]. 


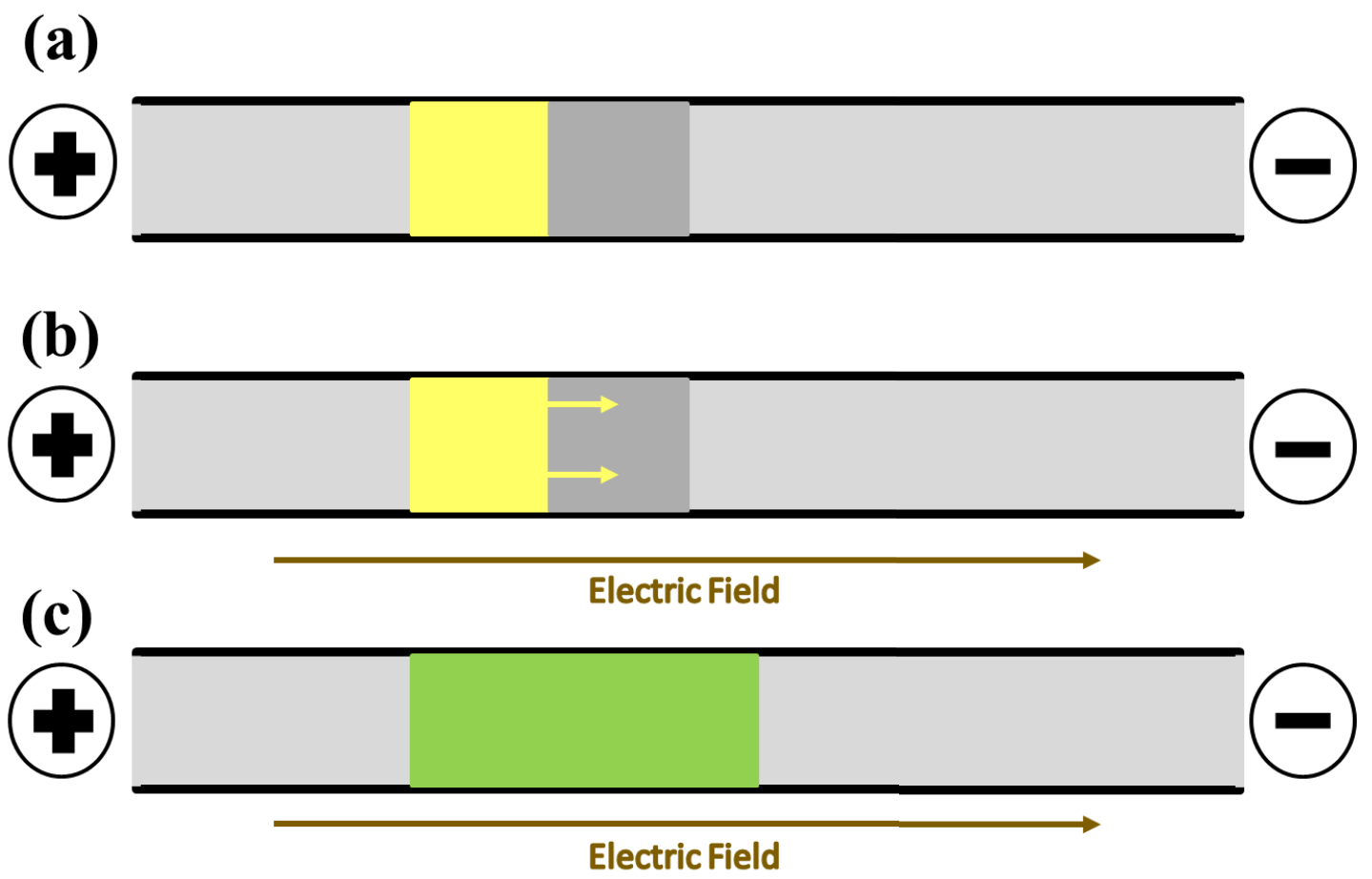

Figure 16: Schematic of throughout capillary method of inline derivatization. (a) Analyte is injected into capillary filled with run buffer spiked with fluorescent dye. (b) Electric field is generated causing sample to migrate towards the detector, mixing with the fluorescent label in the bulk solution. (c) Fully derivatized sample moves towards the detector while being separated into individual components.

\subsection{Fluorescence Derivatization of Phenethylamines}

There are several criteria which should be considered when selecting a fluorescent tag. It should be selective for the analyte of interest, in order to minimize interferences. The derivatization reaction should be able to go to completion within a reasonable amount of time under relatively mild conditions. Also, the fluorescent derivative generated should provide a high quantum yield for the analyte in order to permit sensitive detection of the analyte. For phenethylamines, the best site for derivatization to take place is the characteristic terminal amine moiety present in this group of compounds. 
The level of reactivity of the molecule is dependent on the level of substitution of the amine, (primary or secondary) with primary amines being the most reactive.

In the research undertaken, several amine reactive dyes were assessed for their suitability with the analytes of interest and the instrumentation available. A comprehensive list of available reagents, their peak excitation and emission wavelengths, and target moiety is given in table 3 [33].

Table 3: Overview of selected fluorescent labels and their fluorescence properties. Adapted from [33]

\begin{tabular}{|c|c|c|c|c|c|}
\hline Fluorescent Label & Abbreviation & $\begin{array}{c}\text { Molecular } \\
\text { Weight }\end{array}$ & $\begin{array}{c}\text { Absorption } \\
\text { Wavelength, } \\
\lambda_{\text {abs }}(\mathrm{nm})\end{array}$ & $\begin{array}{c}\text { Emission } \\
\text { Wavelength, } \\
\lambda_{\mathrm{em}}(\mathrm{nm})\end{array}$ & $\begin{array}{l}\text { Target } \\
\text { Moiety }\end{array}$ \\
\hline $\begin{array}{l}\text { 4-Fluoro-7- } \\
\text { nitrobenzofurazan }\end{array}$ & NBD-F & 183.1 & $\begin{array}{r}337 \\
(464)\end{array}$ & $\begin{array}{l}\text { None } \\
(512)\end{array}$ & $\begin{array}{c}-\mathrm{NH}_{2} \\
-\mathrm{NHR} \\
-\mathrm{SH}\end{array}$ \\
\hline $\begin{array}{l}\text { 4-Chloro-7- } \\
\text { nitrobenzofurazan }\end{array}$ & $\mathrm{NBD}-\mathrm{Cl}$ & 199.6 & $\begin{array}{r}337 \\
(464)\end{array}$ & $\begin{array}{l}\text { None } \\
(512)\end{array}$ & $\begin{array}{c}-\mathrm{NH}_{2} \\
-\mathrm{NHR} \\
-\mathrm{SH}\end{array}$ \\
\hline $\begin{array}{l}\text { 5-(4,6-Dichlorotriazinyl) } \\
\text { aminofluorescein }\end{array}$ & 5-DTAF & 495.3 & 492 & 517 & $\begin{array}{c}-\mathrm{NH}_{2} \\
-\mathrm{NHR} \\
-\mathrm{SH} \\
-\mathrm{OH}\end{array}$ \\
\hline $\begin{array}{l}\text { Naphthalene-2,3- } \\
\text { dicarboxaldehyde }\end{array}$ & NDA & 184.2 & 419 & 493 & $-\mathrm{NH}_{2}$ \\
\hline Fluorescamine & & 278.3 & $\begin{array}{r}315 \\
(385)\end{array}$ & $\begin{array}{l}\text { None } \\
(486)\end{array}$ & $-\mathrm{NH}_{2}$ \\
\hline
\end{tabular}




\begin{tabular}{|c|c|c|c|c|c|}
\hline Fluorescein isothiocyanate & FITC & 389.4 & 494 & 519 & $\begin{array}{r}-\mathrm{NH}_{2} \\
-\mathrm{NHR} \\
-\mathrm{SH}\end{array}$ \\
\hline $\begin{array}{l}\text { Rhodamine-B- } \\
\text { isothiocyanate }\end{array}$ & RITC & 536.1 & 552 & 588 & $\begin{array}{l}-\mathrm{NH}_{2} \\
-\mathrm{NHR}\end{array}$ \\
\hline $\begin{array}{c}\text { Rhodamine-B-sulfonyl } \\
\text { chloride }\end{array}$ & Lissamine & 577.1 & 568 & 584 & $\begin{array}{l}-\mathrm{NH}_{2} \\
-\mathrm{NHR}\end{array}$ \\
\hline $\begin{array}{c}\text { 5(6)Carboxy-X-rhodamine- } \\
\mathrm{N} \text {-succinimidyl ester }\end{array}$ & $\begin{array}{l}\text { 5(6)-ROX, } \\
\text { SE }\end{array}$ & 631.7 & 575 & 602 & $\begin{array}{l}-\mathrm{NH}_{2} \\
-\mathrm{NHR}\end{array}$ \\
\hline $\begin{array}{c}\text { Tetramethylrhodamine-5- } \\
\text { isothiocyanate }\end{array}$ & 5-TRITC & 443.5 & 543 & 571 & $\begin{array}{l}-\mathrm{NH}_{2} \\
-\mathrm{NHR}\end{array}$ \\
\hline $\begin{array}{l}\text { 5-Carboxytetramethyl- } \\
\text { rhodamine }\end{array}$ & 5-TAMRA & 430.5 & 541 & 568 & $\begin{array}{l}-\mathrm{NH}_{2} \\
-\mathrm{NHR}\end{array}$ \\
\hline C2-Dichlorotriazine & Texas Red & 796.7 & 588 & 601 & $\begin{array}{r}-\mathrm{NH}_{2} \\
-\mathrm{NHR} \\
-\mathrm{OH}\end{array}$ \\
\hline $\begin{array}{l}\text { 5(6)-Carboxyfluorescein, } \\
\text { succinimidyl ester }\end{array}$ & $\begin{array}{l}\text { 5(6)-FAM, } \\
\text { SE }\end{array}$ & 473.4 & 494 & 519 & $\begin{array}{l}-\mathrm{NH}_{2} \\
-\mathrm{NHR}\end{array}$ \\
\hline Eosin $Y$ & & 691.9 & 527 & 556 & $-\mathrm{NH}_{2}$ \\
\hline
\end{tabular}

Prior to the completion of the initial experimental design each fluorescent derivatizing agent was assessed to determine its suitability for the proposed work. Factors utilized in assessing the viability of these compounds included the absorption/excitation spectrum of the tags, the target moiety, and the minimum reaction conditions required in order to obtain a high yield of the fluorescent derivative. The level of background signal 
generated was also a cause of concern, as underivatized reagents and their by-products can greatly complicate interpretation. Unfortunately, while some analytes such as NDA and fluorescamine are non-fluorescent in their underivatized form, they are generally only reactive with primary amines. As a result of this, they are unsuitable for the determination of analytes which may contain secondary amine moieties. At the completion of the assessment, NBD-F and 5-DTAF were selected for further study. The selection of these compounds was based on their ability to produce maximum excitation at wavelengths near to that of the laser being used (488nm argon), both permit the analysis of primary and secondary amines, and both produce highly fluorescent products following derivatization at room temperature [33]. Also, in the case of NBD-F, the underivatized reagent does not fluoresce therefore minimizing the resulting background signal [33].

4-Fluoro-7-nitrobenzofurazan (NBD-F) is comprised of a fluorinated benzene ring with a furazan group attached. It is reactive with both primary and secondary amines, as well as thiols. NBD-derivatives of amines produce maximum absorbance and emission at wavelengths from $465-485 \mathrm{~nm}$ and $535-540 \mathrm{~nm}$, respectively. The fluorescent spectra observed is dependent on whether they are primary phenethylamines $\left(\lambda_{\mathrm{ex}}=465 \mathrm{~nm}\right.$, $\left.\lambda_{\mathrm{em}}=535\right)$ or secondary phenethylamines $\left(\lambda_{\mathrm{ex}}=485 \mathrm{~nm}, \lambda_{\mathrm{em}}=540 \mathrm{~nm}\right)$. The derivatization of an amine-containing analyte takes place via an $\mathrm{S}_{\mathrm{N}} 2$ reaction as illustrated in figure 17. 


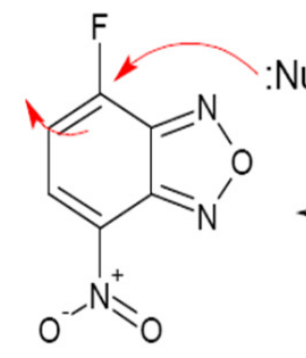

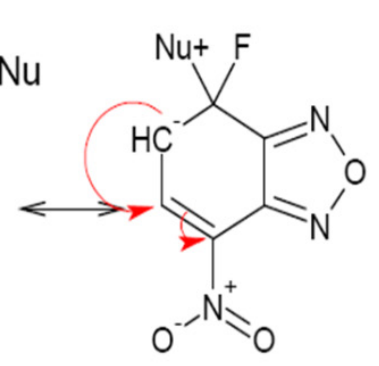<smiles>CC(C)CC1C=CC(F)([N+](=O)[O-])c2nonc21</smiles>

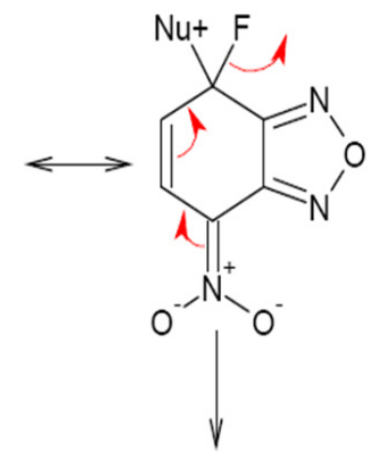<smiles>N#Cc1ccc([N+](=O)[O-])c2nonc12</smiles><smiles>O=[N+]([O-])c1ccc([N+](=O)[O-])c2nonc12</smiles>

Figure 17: Derivatization mechanism for NBD-F via an $S_{N} 2$ reaction scheme. The nucleophilic amine group of the analyte attacks at the fluorine bound carbon site prompting the migration of electrons from the double bond eventually resulting in the fluorine and a hydrogen atom being ejected from the molecule [33].

The resulting NBD-derivative has a good fluorescent yield as opposed to the underivatized NBD-F which is non-fluorescent. However, in aqueous solutions, NBD-F will form a hydrolysis product which is weakly fluorescent.

Unlike NBD-F, 5-DTAF is fluorescent in its native form with excitation and emission peak wavelengths at $492 \mathrm{~nm}$ and $516 \mathrm{~nm}$ respectively. At $\mathrm{pHs}$ greater than 9 , this dye reacts most rapidly with amines (primary and secondary), followed by thiols, and then hydroxyl groups [33]. NBD-F has historically been used in the labeling of proteins but applicability in the analysis of amine containing drugs has been apparent for some time $[37,90]$. 5-DTAF, as with NBD-F, follows the $\mathrm{S}_{\mathrm{N}} 2$ reaction mechanism as seen in figure 18 . 


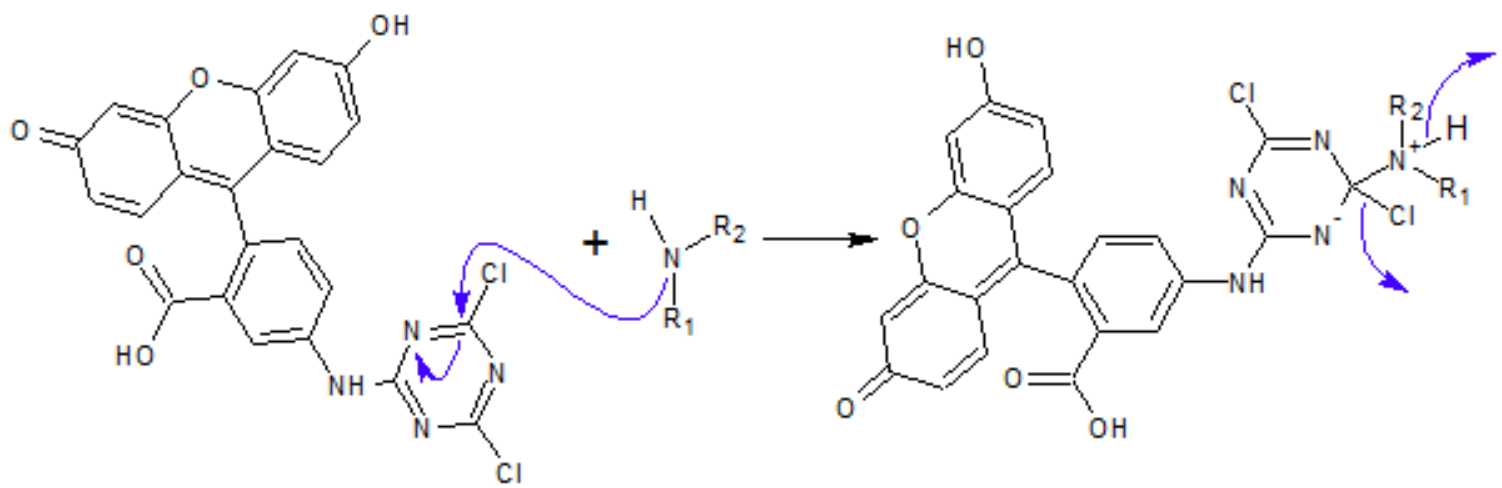<smiles>[Y][Y]([R2])c1nc(Cl)nc(Nc2ccc(-c3c4ccc(=O)cc-4oc4cc(O)ccc34)c(C(=O)O)c2)n1</smiles>

Figure 18: Derivatization mechanism for reaction of 5-DTAF with generic amine via an $S_{N} 2$ reaction. The nucleophilic amine group of the analyte attacks at one of the chlorine bound carbon sites prompting the migration of electrons from the double bond eventually resulting in a chlorine and a hydrogen atom being ejected from the molecule. [33]

The derivatization reaction between 5-DTAF and amino groups is rather simple in nature. However, the electropherograms produced are prone to producing background interferences comprised of other, fluorescent byproducts and excess reagent. As a result of this, there can be difficulties in interpreting electropherograms as analyte peaks may coelute or be overwhelmed by these interferences. 
<smiles>C[C](N)Cc1ccccc1</smiles>

Amphetamine<smiles>C[C@H](N)[C@H](O)c1ccccc1</smiles>

Norephedrine<smiles>CN[C@@H](C)Cc1ccccc1</smiles>

Methamphetamine<smiles>CNC(C)Cc1ccc2c(c1)OCO2</smiles>

Figure 19: Chemical structures of several analytes of interest. 


\section{CHAPTER 3: METHODOLOGY}

\subsection{Offline Derivatization}

\subsubsection{Chemicals}

Amphetamine sulfate salt, +-methamphetamine, DL-norephedrine hydrochloride, ephedrine, phenethylamine, 3,4-methylenedioxy- $N$-amphetamine (MDA), 3,4methylenedioxy- $N$-methamphetamine (MDMA), and 3,4-methylenedioxy- $N$ ethylamphetamine (MDEA) were obtained from Sigma Aldrich (St. Louis, MO) via the International Forensic Research Institute (IFRI) at Florida International University. Native $\beta$-cyclodextrin ( $\beta$-CD) was obtained from TIC America (Portland, OR), sulfated$\beta$-cyclodextrin (S- $\beta$-CD) and Brij-35 from Sigma Aldrich, and dimethyl- $\beta$-cyclodextrin (DM- $\beta-C D)$ was acquired via Beckman Coulter (Brea, CA).

Acetonitrile, boric acid, ethanol, hydrochloric acid, sodium borate tetrahydrate, and sodium hydroxide $(\mathrm{NaOH})$ are commercially available from Fisher Scientific. Fluorescein isothiocyanate (FITC) and 1,2-dichloroethane were obtained from Sigma Aldrich, sodium bicarbonate from Spectrum Chemical Mfg. Corp. (New Brunswick, NJ), fluorescein (single isomer) from Fluka, sodium dodecyl sulfate (SDS) from Acros Organics (Geel, Belgium) and 5-DTAF, 6-DTAF, and NBD-F were all acquired from AnaSpec (Fremont, CA).

\subsubsection{Apparatus and Conditions}

A P/ACE MDQ CE (Beckman Coulter) was fitted with an argon laser for laserinduced fluorescence (LIF) detection. Fluorescence detection was carried out using 
$520 \mathrm{~nm}$ notch filter. Control of the instrumentation, data acquisition, and sample processing was performed using 32 Karat software, version 7.0. Fused silica capillaries with polyimide outer coating were used. The capillary was conditioned every day prior to analysis by rinsing sequentially with distilled water $(5 \mathrm{~min}), 0.1 \mathrm{M} \mathrm{NaOH}(10 \mathrm{~min})$, and running buffer (15 min) at high pressure (20 psi). After each sample run, the capillary was flushed sequentially with distilled water (2 min), $0.1 \mathrm{M} \mathrm{NaOH}(3 \mathrm{~min})$, and background electrolyte $(2 \mathrm{~min})$. The $\mathrm{CE}$ system was operated in normal polarity mode with the cathode placed at the detector end. Samples were injected hydrodynamically for 5 seconds at a pressure of 0.5 psi.

\subsubsection{NBD-F Analysis}

The capillary system was run at $45^{\circ} \mathrm{C}$ using an applied voltage of $15 \mathrm{kV}$. The capillary was $40 \mathrm{~cm}$ in length $(30 \mathrm{~cm} \mathrm{EL})$ with an inner diameter of $75 \mu \mathrm{m}$. Based on these parameters, the electric field generated was $375 \mathrm{~V} / \mathrm{cm}$. Separations were carried out using a running buffer comprised of $50 \mathrm{mM}$ sodium borate, $\mathrm{pH} 8.5$, and $10 \mathrm{mM}$ SDS.

\subsubsection{DTAF Analysis}

The system was run at $35^{\circ} \mathrm{C}$ with a potential of $20 \mathrm{kV}$. The capillary was $60 \mathrm{~cm}$ in length $(50 \mathrm{~cm}$ EL) with an inner diameter of $50 \mu \mathrm{m}$. Under optimized conditions separations were carried out using a running buffer comprised of $50 \mathrm{mM}$ sodium borate, $\mathrm{pH} 9.5,15 \mathrm{mM} \beta-\mathrm{CD}, 10 \mathrm{mg} / \mathrm{mL} \mathrm{DM}-\beta-\mathrm{CD}$, and $15 \%$ acetonitrile (by volume). 


\subsubsection{Sample Preparation}

Stock solutions containing $1.0 \mathrm{mg} / \mathrm{mL}$ of each drug were prepared in methanol, and stored in a refrigerator at $4{ }^{\circ} \mathrm{C}$. Prior to analysis samples were diluted to the desired concentrations with a dilution solution comprised of deionized water and methanol (9:1, $\mathrm{v} / \mathrm{v})$.

\subsubsection{Derivatization Procedure}

Thin-walled PCR tubes were used as reaction vessels. A Perkin Elmer DNA Thermal Cycler 480 was utilized as it allowed for the steady heating of the analytes. Temperature settings and heating times were adjusted at the control panel.

\subsubsection{NBD-F Analysis}

Sample, derivatization buffer (50mM borate, $\mathrm{pH} 6.5)$, and NBD-F (20mM in ethanol) were combined in a 1:1:1 ratio within a PCR tube. The tube was then capped, placed in the thermal cycler, and heated at $60^{\circ} \mathrm{C}$ for 10 minutes. After heating, vials were allowed to cool in a light-free environment to avoid photo-bleaching and $5 \mu \mathrm{L}$ of $1 \mathrm{M} \mathrm{HCl}$ was added to terminate the derivatization reaction.

\subsubsection{DTAF Analysis}

An aliquot of the diluted sample $(90 \mu \mathrm{L})$ was added to a thin-walled PCR tube along with $20 \mu \mathrm{L}$ of the derivatization buffer $\left(0.5 \mathrm{M} \mathrm{NaHCO}_{3} / \mathrm{Na}_{2} \mathrm{CO}_{3}, \mathrm{pH} 9.5\right), 10 \mu \mathrm{L}$ of $0.5 \mathrm{mM}$ 5-DTAF in ethanol/1,2-dichloroethane $(9: 1, \mathrm{v} / \mathrm{v})$, and $80 \mu \mathrm{L}$ of deionized water. The tube 
was then capped, placed in the thermal cycler, and heated at $35^{\circ} \mathrm{C}$ for 10 minutes. After heating, vials were allowed to cool in a light-free environment to avoid photo-bleaching.

\subsection{Inline Derivatization}

\subsubsection{Apparatus and Conditions}

Fused silica capillaries with polyimide outer coating were used. They were $60 \mathrm{~cm}$ in total length with an effective length (EL, distance to detector) of $50 \mathrm{~cm}$ and an inner diameter of $50 \mu \mathrm{m}$. The capillary was conditioned every day prior to analysis by rinsing sequentially with distilled water ( $5 \mathrm{~min}), 0.1 \mathrm{M} \mathrm{NaOH}$ (10 min), and running buffer (15 min) at high pressure (20 psi). After each sample run, capillary was flushed sequentially with distilled water (2 min), $0.1 \mathrm{M} \mathrm{NaOH}$ ( $3 \mathrm{~min}$ ), and background electrolyte (2 min).

The CE system was operated in normal polarity mode meaning the cathode was at

the detector end. Samples were injected hydrodynamically with a pressure of $0.5 \mathrm{psi}$. The system was run at $35^{\circ} \mathrm{C}$ with a potential of $20 \mathrm{kV}$. Under optimized conditions separations were carried out using a running buffer comprised of $50 \mathrm{mM}$ sodium borate, $\mathrm{pH} 9.5$, $15 \mathrm{mM} \beta-\mathrm{CD}, 10 \mathrm{mg} / \mathrm{mL}$ DM- $\beta-\mathrm{CD}$, and $15 \%$ acetonitrile (by volume). An overview of the method is given in table 3 . 


\begin{tabular}{|c|c|c|c|}
\hline Table 4: Inline derivatization method parameters. & Time & Description \\
\hline Action & Pressure/Voltage & $1.0 \mathrm{~min}$ & Capillary filled with running \\
binse & $20 \mathrm{psi}$ & & Capillary filled with \\
& & & background electrolyte \\
\hline Rinse & $20 \mathrm{psi}$ & $1.0 \mathrm{~min}$ & Sample \\
\hline Inject & $0.5 \mathrm{psi}$-DTAF \\
\hline Inject & $0.5 \mathrm{psi}$ & $5 \mathrm{sec}$ & Background electrolyte \\
\hline Inject & $0.5 \mathrm{psi}$ & $35 \mathrm{sec}$ & Electrokinetic mixing \\
\hline Voltage & $5 \mathrm{kV}$ & $0.75 \mathrm{~min}$ & Diffusion \\
\hline Wait & & $10 \mathrm{~min}$ & $15 \mathrm{~min}$ \\
\hline Separate & $20 \mathrm{kV}$ & & \\
\hline
\end{tabular}

\subsubsection{Sample Preparation}

Stock solutions containing $1.0 \mathrm{mg} / \mathrm{mL}$ of each drug were prepared in methanol, and stored in a refrigerator at $4^{\circ} \mathrm{C}$. Prior to analysis samples were diluted to the desired concentrations with a dilution solvent comprised of distilled water and reagent grade methanol $(9: 1, \mathrm{v} / \mathrm{v})$. Aliquots of diluted sample $(180 \mu \mathrm{L})$ and derivatization buffer $(20$ $\mu \mathrm{L})$ were transferred to spring vial inserts and capped. Aliquots of distilled water (140 $\mu \mathrm{L}), 5$-DTAF $(40 \mu \mathrm{L})$, and derivatization buffer $(20 \mu \mathrm{L})$ were transferred to a separate spring vial insert and capped. 


\section{CHAPTER 4: RESULTS}

\subsection{Analysis of Pre-capillary Labeled NBD-Derivatives}

Initial investigations were performed utilizing the reagent 4-fluoro-7-nitro-2,1,3benzoxadiazole (NBD-F). Derivatizations were performed via heating a 1:1:1 ratio of the sample $(1.0 \mu \mathrm{g} / \mathrm{mL}$ of norephedrine, ephedrine, MDA, and MDMA), reagent (20mM NBD-F), and derivatization buffer $(50 \mathrm{mM}$ borate, $\mathrm{pH} 6.5)$ at $60^{\circ} \mathrm{C}$ for 10 minutes. This process results in NBD-derivatives including hydrolysis product.

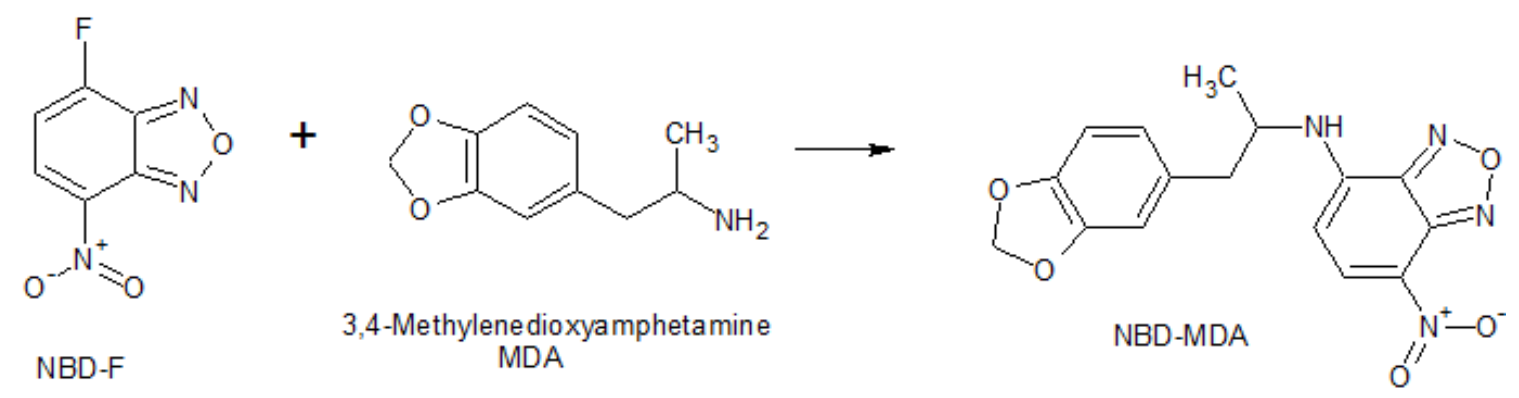

Figure 20: Reaction between NBD-F and primary amine containing MDA to give NBD-derivative. 

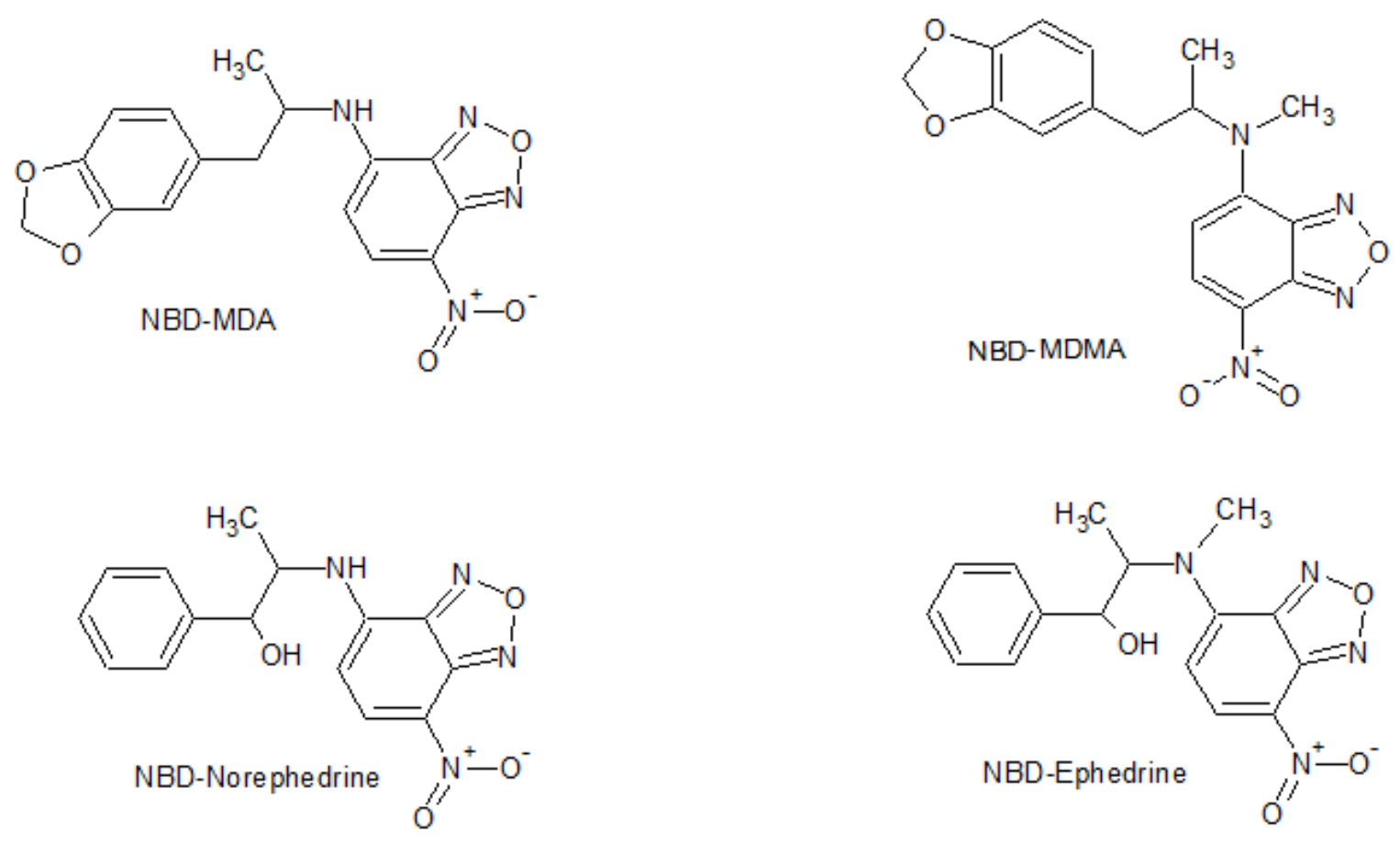<smiles>O=[N+]([O-])c1ccc(O)c2nonc12</smiles>

NBD-Hydrolysis Product

Figure 21: Derivatization products of NBD-F.

In order to assess whether the derivatization process was effective and to determine the relative concentration of products and reactants, derivatized samples were directly infused into the Agilent electrospray ionization time-of-flight mass spectrometer (ESITOF-MS). The fluorescence intensity of the hydrolysis reaction product was also investigated by scanning the entire emission spectrum with the FluoroMax-3 fluorimeter (Jobin Yvon Horiba). Given that NBD-F is non-fluorescent unless coupled to an analyte, a peak for the unbound label was not expected to be observed. This analyte (NBD-OH) 
was generated using the previously outlined offline derivatization method for NBD-F with deionized water being used as the analyte of interest. The results are illustrated in figures 22 and 23. The expected mass-to-charge ratio of $182 \mathrm{amu}$ (analyte + hydrogen) was observed in the mass spectrum.

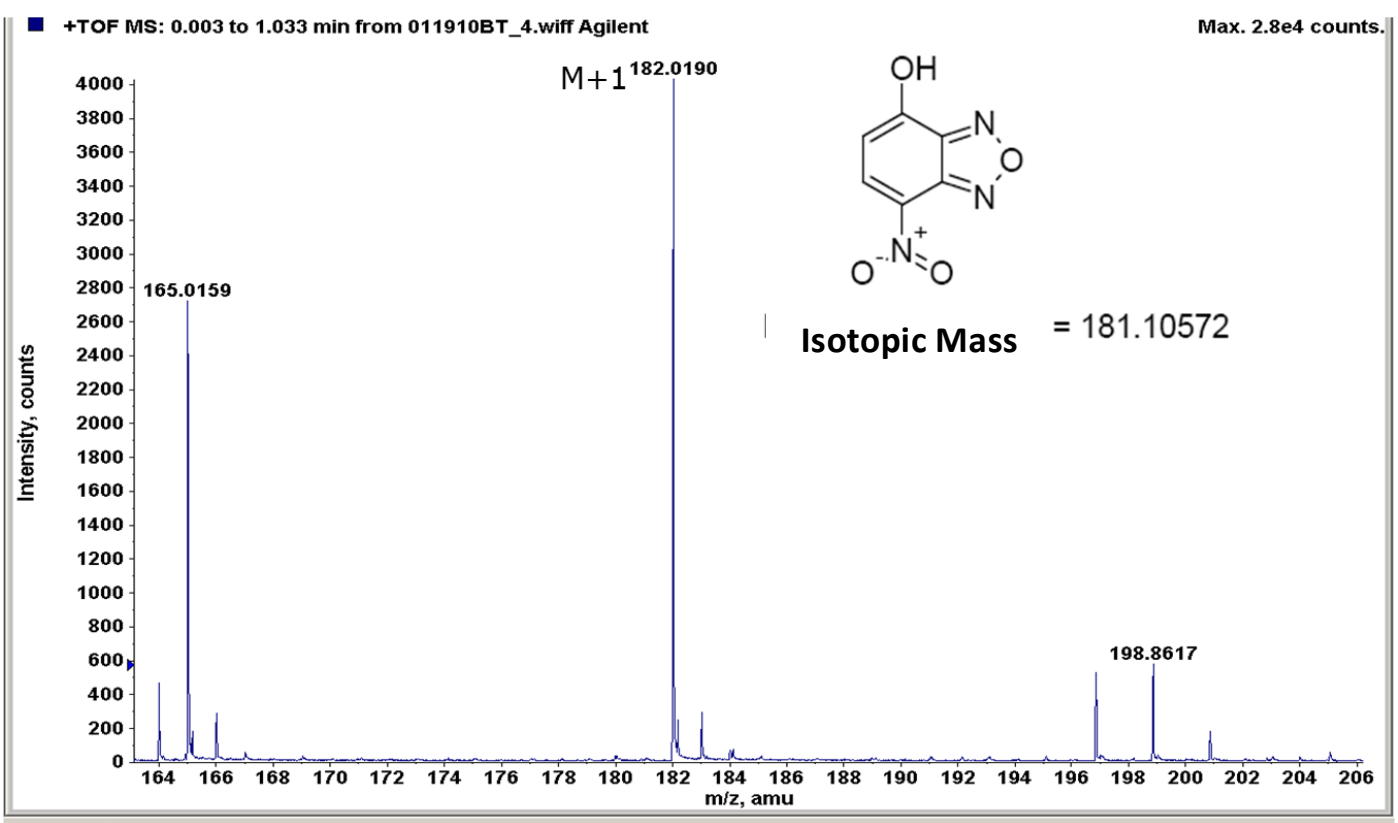

Figure 22: ESI mass spectrum of directly infused NBD-OH. Analyte $\mathrm{m} / \mathrm{z}$ is observed at 182.0190 amu which is representative of the target analyte with an extra hydrogen atom. 


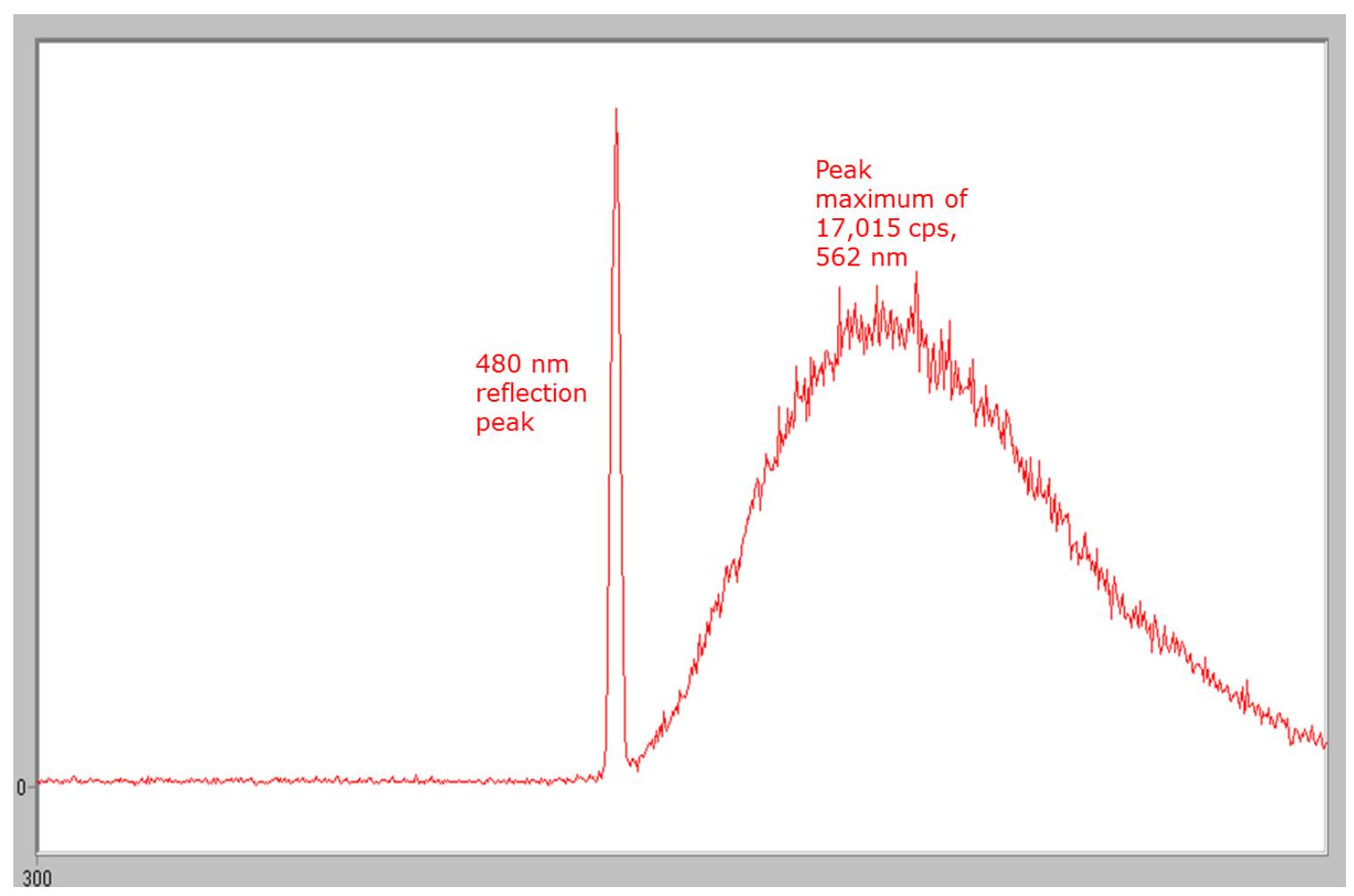

Figure 23: Emission spectrum of NBD-OH following excitation at $480 \mathrm{~nm}$ wavelength. Peak fluorescence was observed at $562 \mathrm{~nm}$ with a maximum intensity of 17,015 cps (counts per second).

The experiment was then applied to $1.0 \mu \mathrm{g} / \mathrm{mL} 3,4$-methylenedioxyamphetmine (MDA) and the results compared. It was found that the fluorescent derivative was being successfully generated by the reaction. However, the quantity produced was very low. The maximum of the emission peak was observed to be $557 \mathrm{~nm}$ which is near to that of the hydrolysis product which was $562 \mathrm{~nm}$. This was to be expected as the fluorescence of both compounds is imparted by the presence of the same NBD-moiety making large spectral differences unlikely. Unfortunately, both analytes also had fluorescence intensities of similar magnitudes. For MDA, 16,444 cps versus $17,015 \mathrm{cps}$ for the hydrolysis product was observed. This is seen in figures 24 through 27 . 


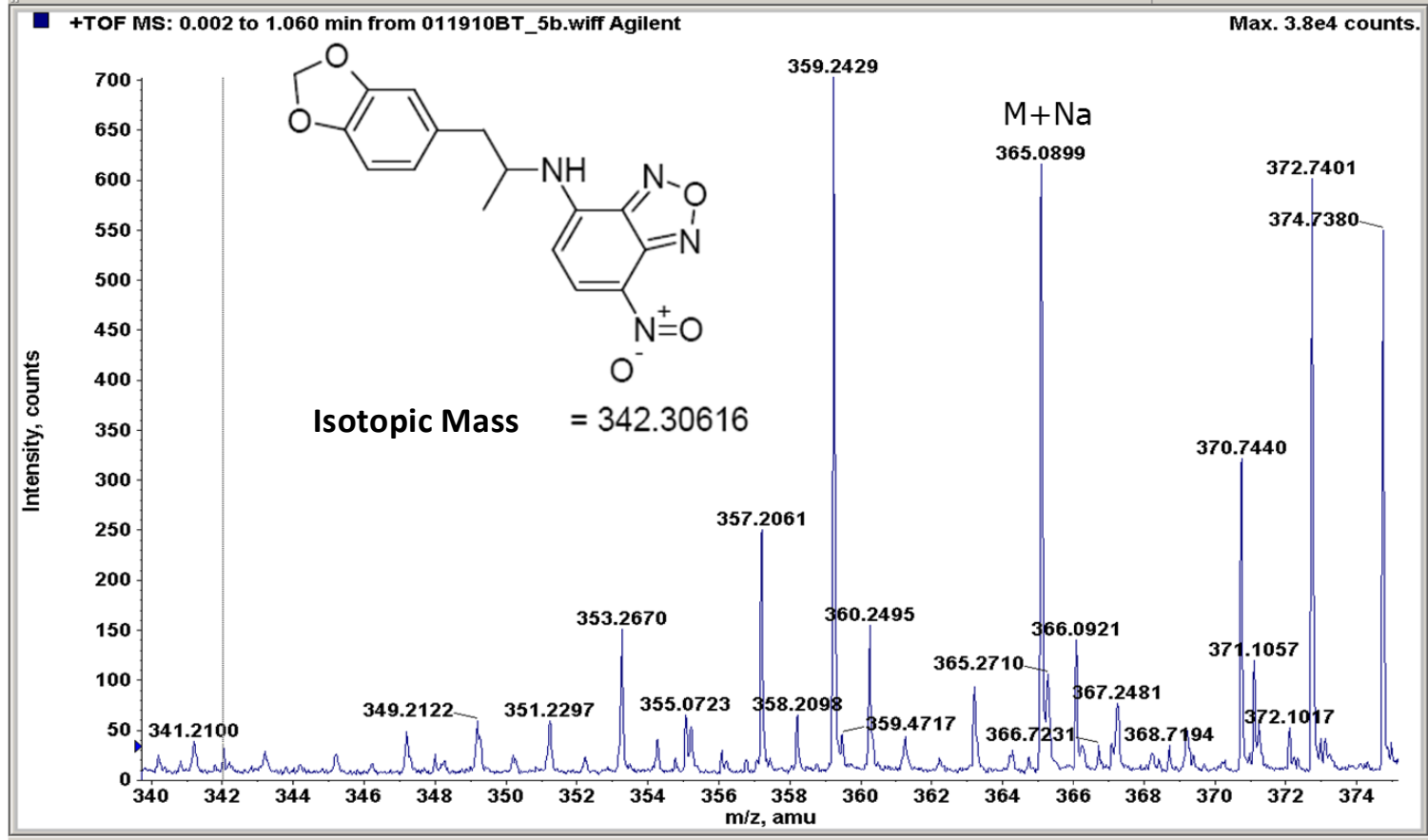

Figure 24: ESI mass spectrum for NBD-MDA. Fragment for sodium adduct of analyte is observed at 365 amu.

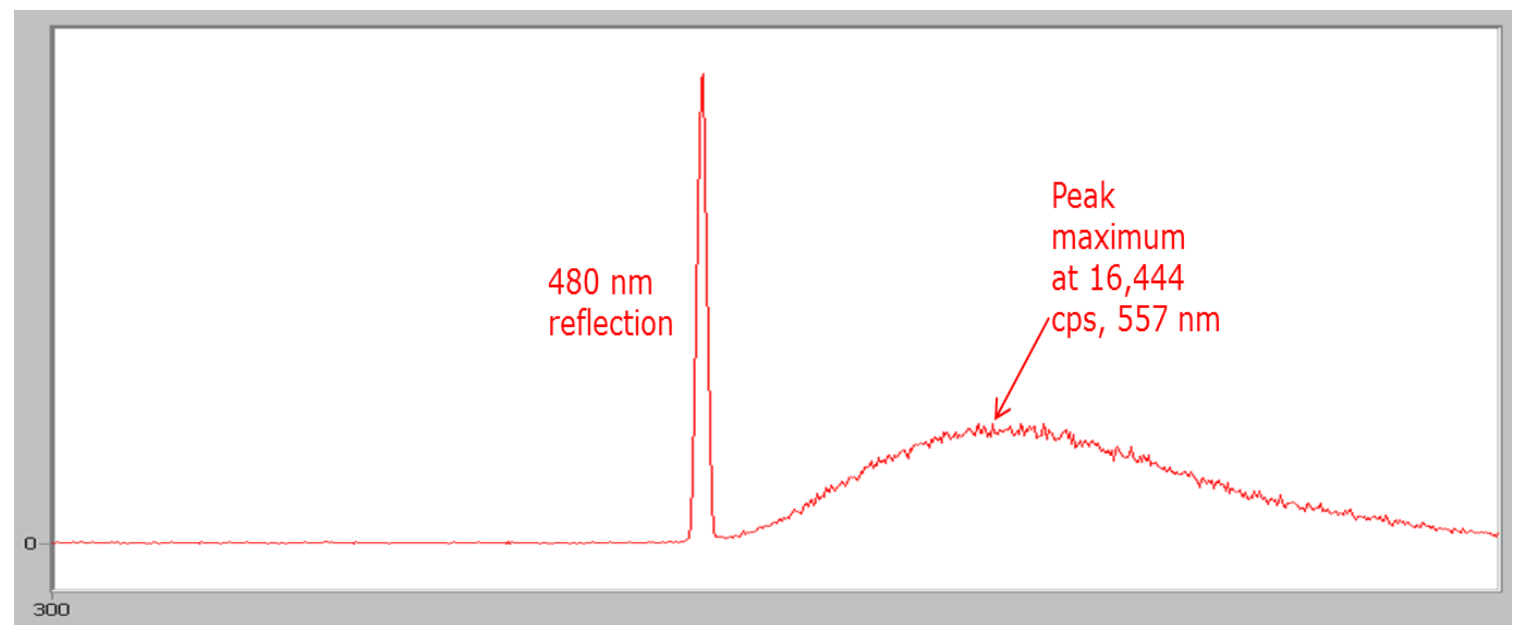

Figure 25: Emission spectrum of NBD-MDA following excitation at 480nm wavelength. Fluorescence maximum observed at $557 \mathrm{~nm}$ at a value of 16,444 cps.

When observing the mass spectrum for the MDA derivative, fragments for the sodium adduct of the analyte was observed (at $365 \mathrm{amu}$ ), as well as that of an ammonium adduct 
(359 amu) as a result of the ammonium formate sheath liquid. Unfortunately, the fragment for the derivative was not observed at the expected $343 \mathrm{amu}$. This fact coupled with the overall low intensity for the spectrum suggests that the derivatization is not occurring efficiently enough to produce a high yield of derivatives. This trend was further observed with all four of the analytes investigated for this study with the exception of norephedrine.

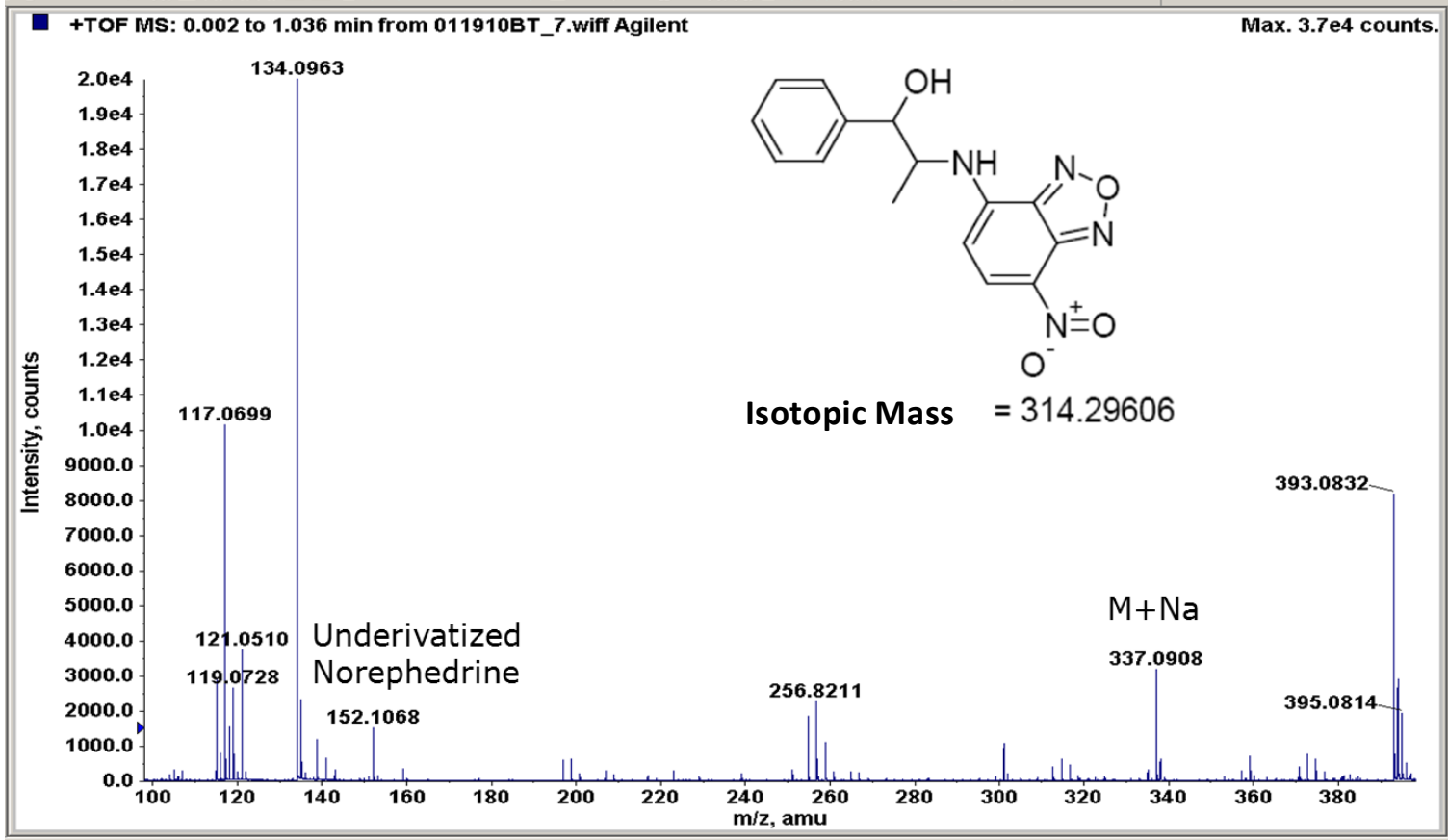

Figure 26: ESI mass spectrum for NBD-norephedrine. Fragments for the sodium adduct of the derivative $(\mathrm{m} / \mathrm{z} 337$ amu), underivatized analyte $(\mathrm{m} / \mathrm{z} 152 \mathrm{amu})$, and dehydroxylated underivatized analyte $(\mathrm{m} / \mathrm{z} 134 \mathrm{amu})$ were observed. Dehydroxylated underivatized analyte peak is largest fragment produced further supporting the hypothesis that the derivatization method is not efficiently labeling the analytes. 


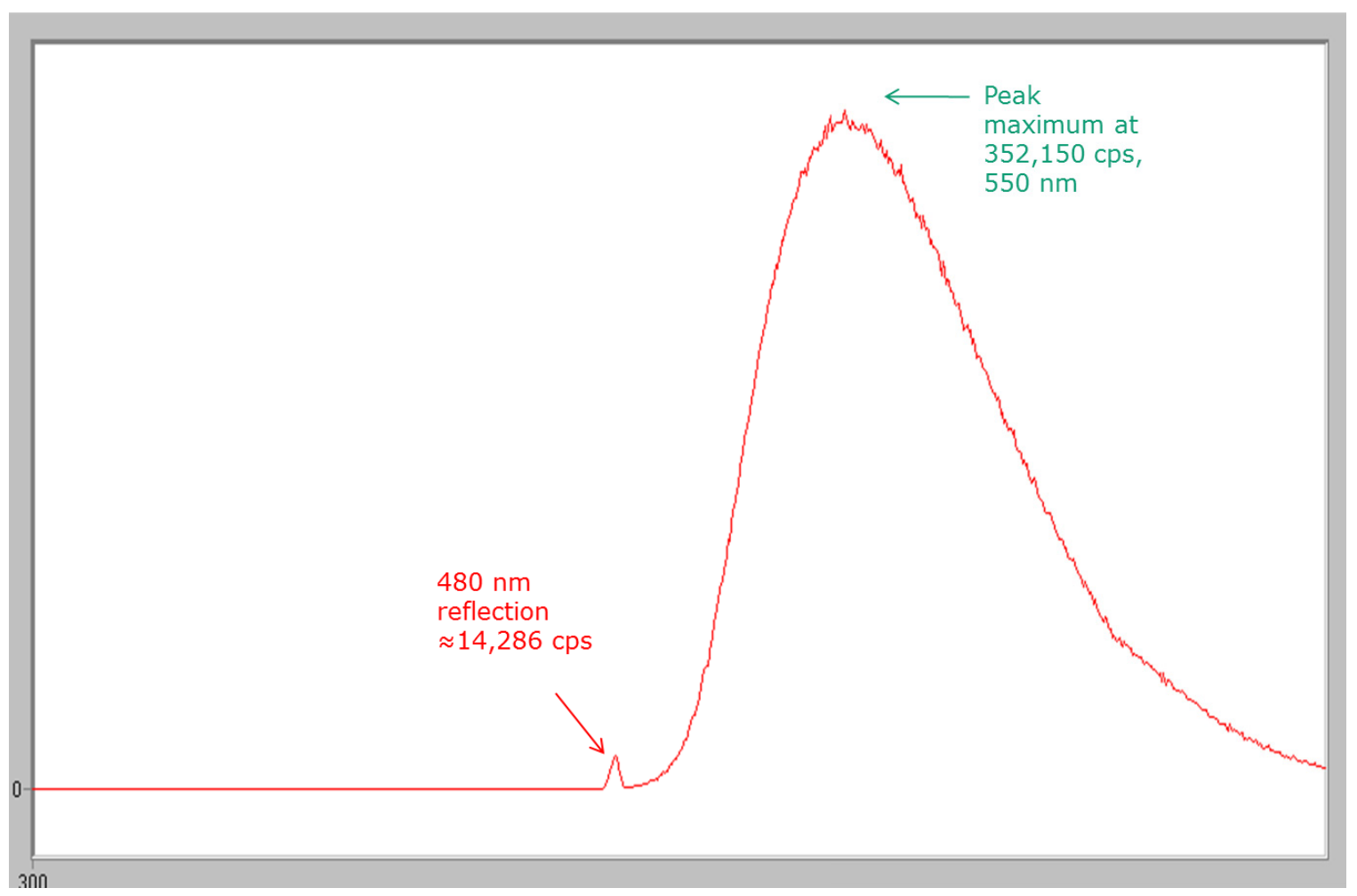

Figure 27: Emission spectrum of NBD-norephedrine following excitation at 480nm wavelength. Emission spectrum peak maximum at $550 \mathrm{~nm}$ and $352,150 \mathrm{cps}$.

In the case of norephedrine, the mass spectrum produced further supports the theory that the derivatization method is inefficient resulting in low yields of fluorescent product as the fragments for the underivatized analyte are much larger. However, in comparison to the other compounds, the intensity of the NBD-norephedrine mass fragment is ten times larger (4,000 counts) and the peak maximum of the fluorescence spectrum is 20 times larger $(352,150 \mathrm{cps})$ despite the initial concentrations of all analytes being $1.0 \mu \mathrm{g} / \mathrm{mL}$. This suggests that norephedrine has a greater reactivity with the fluorescent label than the other analytes of interest. 


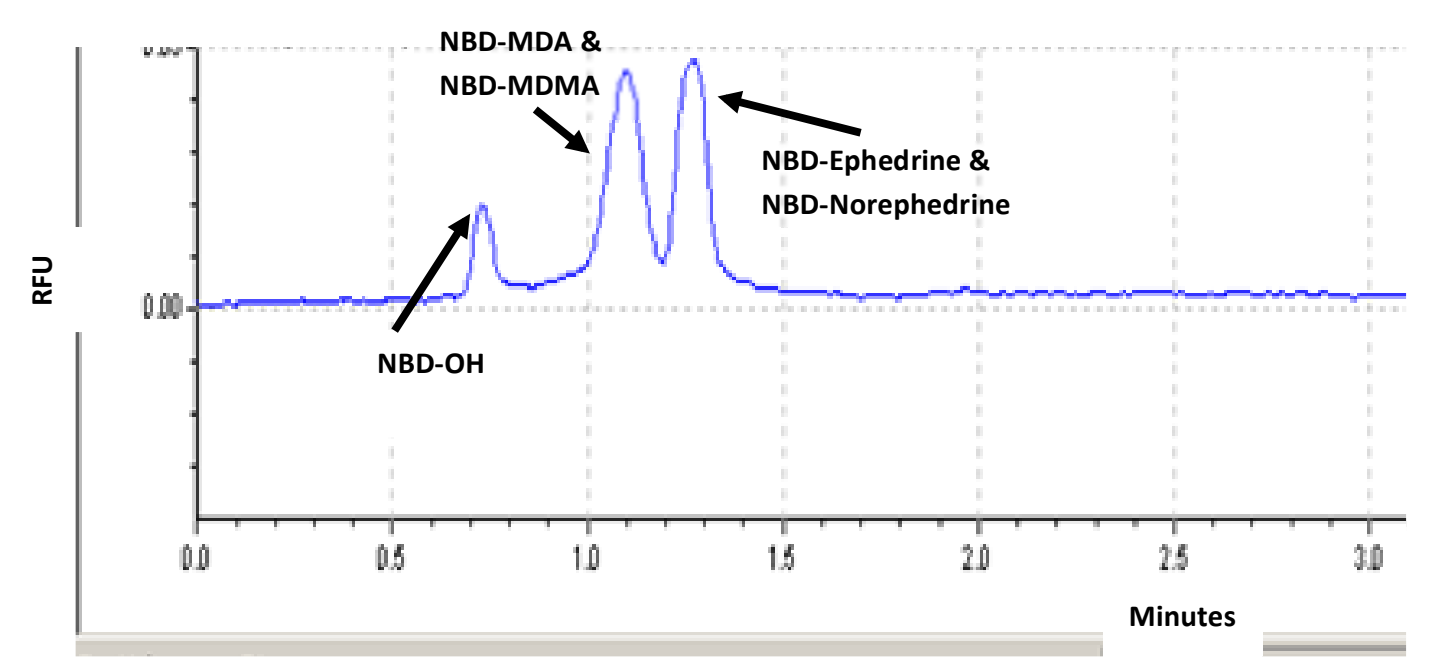

Figure 28: Separation of $1.0 \mu \mathrm{g} / \mathrm{mL}$ mixture of norephedrine, ephedrine, MDA, and MDMA. Conditions: Fused silica capillary, $75 \mu \mathrm{m}$ I.D., $40 \mathrm{~cm}$ length, $30 \mathrm{~cm}$ effective length; capillary temperature, $25^{\circ} \mathrm{C}$; fluorescent tag, $20 \mathrm{mM}$ NBD-

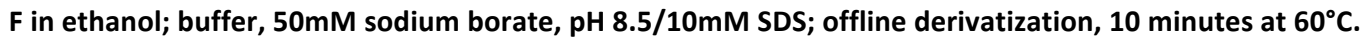

Based on the results of this investigation it was determined that while NBD-F is capable of being used fluorescent labeling of these analytes, the yield of derivatives produced is very low and the separation conditions utilized were unable to resolve the analyte peaks from one another.

\subsection{Analysis of Pre-capillary Labeled DTAF-Derivatives}

As previously stated in section 4.1, usage of NBD-F as a labeling agent for these analytes was deemed unsuccessful overall as the derivative yield was very low and separation of individual analytes could not be achieved. As a result of this, an alternative dye in the form of 5-(4,6-Dichlorotriazinyl)aminofluorescein (5-DTAF) was selected for further study. As with NBD-F, 5-DTAF is highly compatible with the $488 \mathrm{~nm}$ laser utilized by the electrophoresis system $\left(\lambda_{\mathrm{abs}}=492 \mathrm{~nm}, \lambda_{\mathrm{em}}=515 \mathrm{~nm}\right)$ and is reactive with primary and secondary amines. However, unlike NBD-F, efficient derivatization of the 
analytes using this compound can be achieved at near room temperature with high yields of derivatives produced.

In order to optimize the separation of the fluorescently labeled derivatives, the composition of the running buffer was investigated. In the initial adaptation, a method developed by Molina for the inline derivatization and separation of amino acids, amino phosphonic acid-herbicides, and biogenic amines [57] was utilized as the framework with a running buffer of $50 \mathrm{mM}$ borate, $\mathrm{pH} 9.5 / 40 \mathrm{mM}$ Brij-35. This method was chosen due to the investigators' usage of 5-DTAF as a labeling reagent for these amine-containing compounds. It was hypothesized that a similar design scheme would allow for the inline derivatization of the phenethylamines of interest. Also, at $\mathrm{pH} 9.5$ the fluorescent label exists in its dianion form and the analytes are partially ionized. Brij-35 is a nonionic surfactant which forms micelles in solution which act as a pseudo-stationary phase. However, the micellar solution was not capable of resolving the individual drugs in the mixture which consisted of $100 \mu \mathrm{g} / \mathrm{mL}$ of amphetamine, methamphetamine, norephedrine, ephedrine and MDMA.

To improve upon these results, the MEKC buffer was replaced with a separation system consisting of mixtures of various $\beta$-cyclodextrins. These included sulfated- $\beta$ cyclodextrin (S- $\beta-C D)$, and dimethyl- $\beta$-cyclodextrin (DM- $\beta-C D)$. Beta-cyclodextrins are seven-membered sugar rings which have a distinctive toroid shape. The inner core of the $\beta$-CD is hydrophobic in nature with a hydrophilic outer frame. Cyclodextrins assist the separation by forming inclusion complexes with analytes. The effect of the inclusion complex is to modify the mobility of the analyte and thus increase the selectivity between 
different analyte zones as a result of the differential rate of formation of the guest/host complexes. The complexes modify the charge to size ratio of the analytes. Selectivity is achieved due to variation in the rate of complex formation. A generic example of this is shown in figure 29 . Native $\beta-C D$ and DM- $\beta-C D$ are neutral while $S-\beta-C D$ is negatively charged.
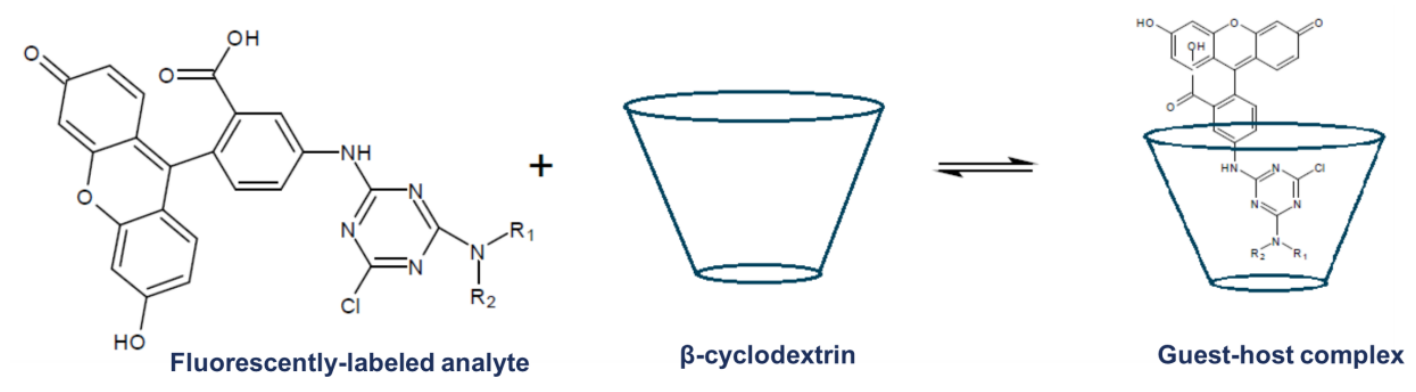

Figure 29: Reversible formation of guest-host complex between fluorescently-labeled derivatives and $\beta$ cyclodextrin.

In order to maximize the separation efficiency of the developed method, the modifier utilized in the separation buffer and its concentration were investigated by using run buffers of various compositions and observing their effect on the analyte signals produced. It was found that all of the cyclodextrins gave improved resolution in comparison to the Brij-35 surfactant with native $\beta$-cyclodextrin being the best. However, native $\beta$-cyclodextrin on its own was not capable of full resolution so its usage in combination with the other two $\beta$-cyclodextrins (sulfated and dimethyl) was investigated at varying concentrations. The results of this study are summarized in figure 30. It was found that sulfated- $\beta$-cyclodextrin gave a slight improvement in resolution in comparison to native $\beta$-cyclodextrin on its own but as the concentration of S- $\beta$-CD was increased, the analyte signal decreased in intensity and there was a decrease in overall resolution. Also, 
capillary blockages from the cyclodextrin precipitating was frequently encountered. On the other hand, DM- $\beta-C D$ increased signal strength and resolution as the concentration was increased.

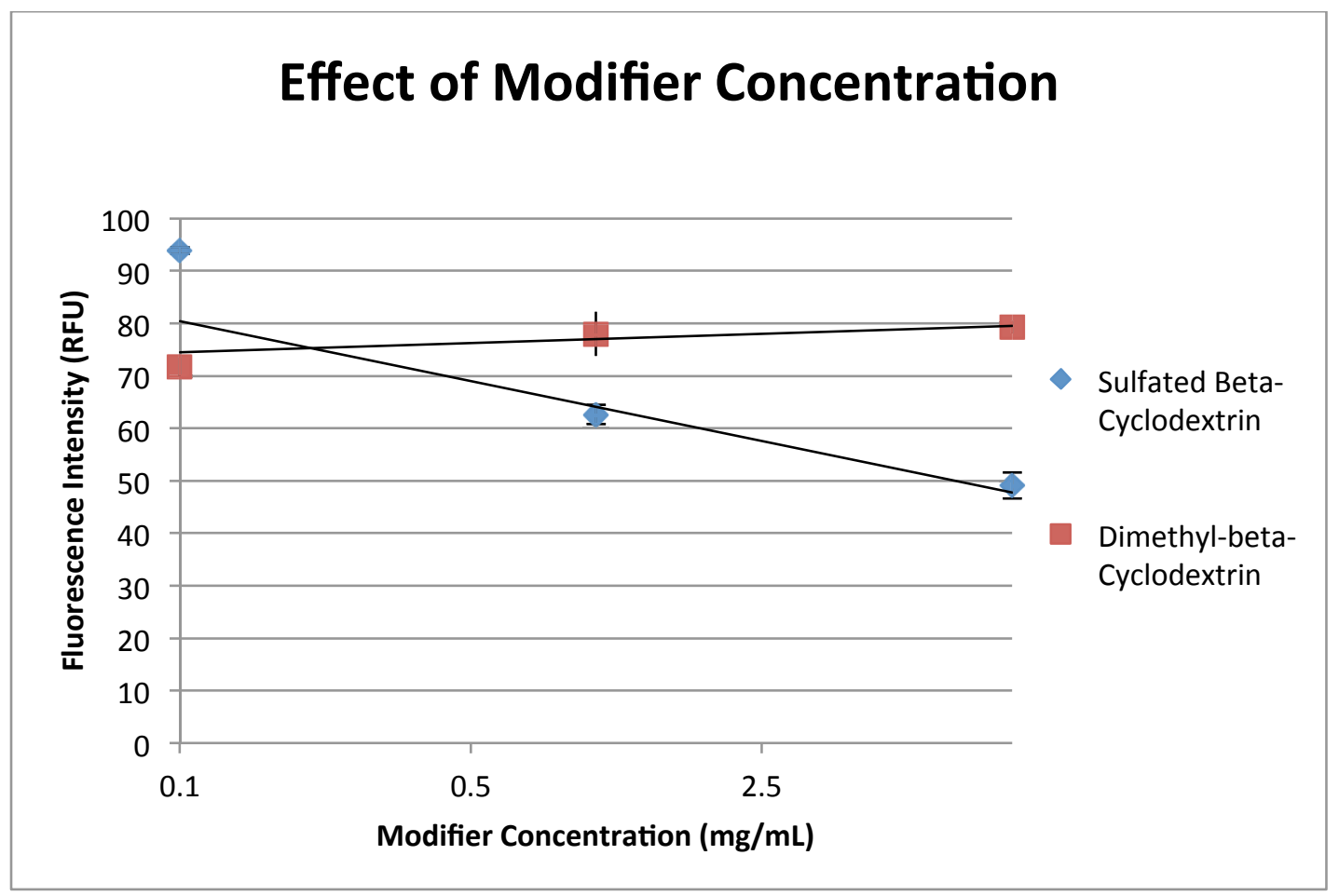

Figure 30: Effect of concentration of secondary $\beta$-cyclodextrins in combination with $15 \mathrm{mM}$ native $\beta$-cyclodextrin on analysis of 5-DTAF labeled ephedrine at $100 \mathrm{ug} / \mathrm{mL}$.

A comparison of the differences in separation efficiency between the three modifiers, Brij-35, S- $\beta-C D$, and DM- $\beta-C D$, is shown in figure 31 . The mechanism of selectivity varies as the Brij-35 forms micelles which predominantly affect selectivity based on differences in polarity while the cyclodextrins selectivity is also based on size/steric interactions. 


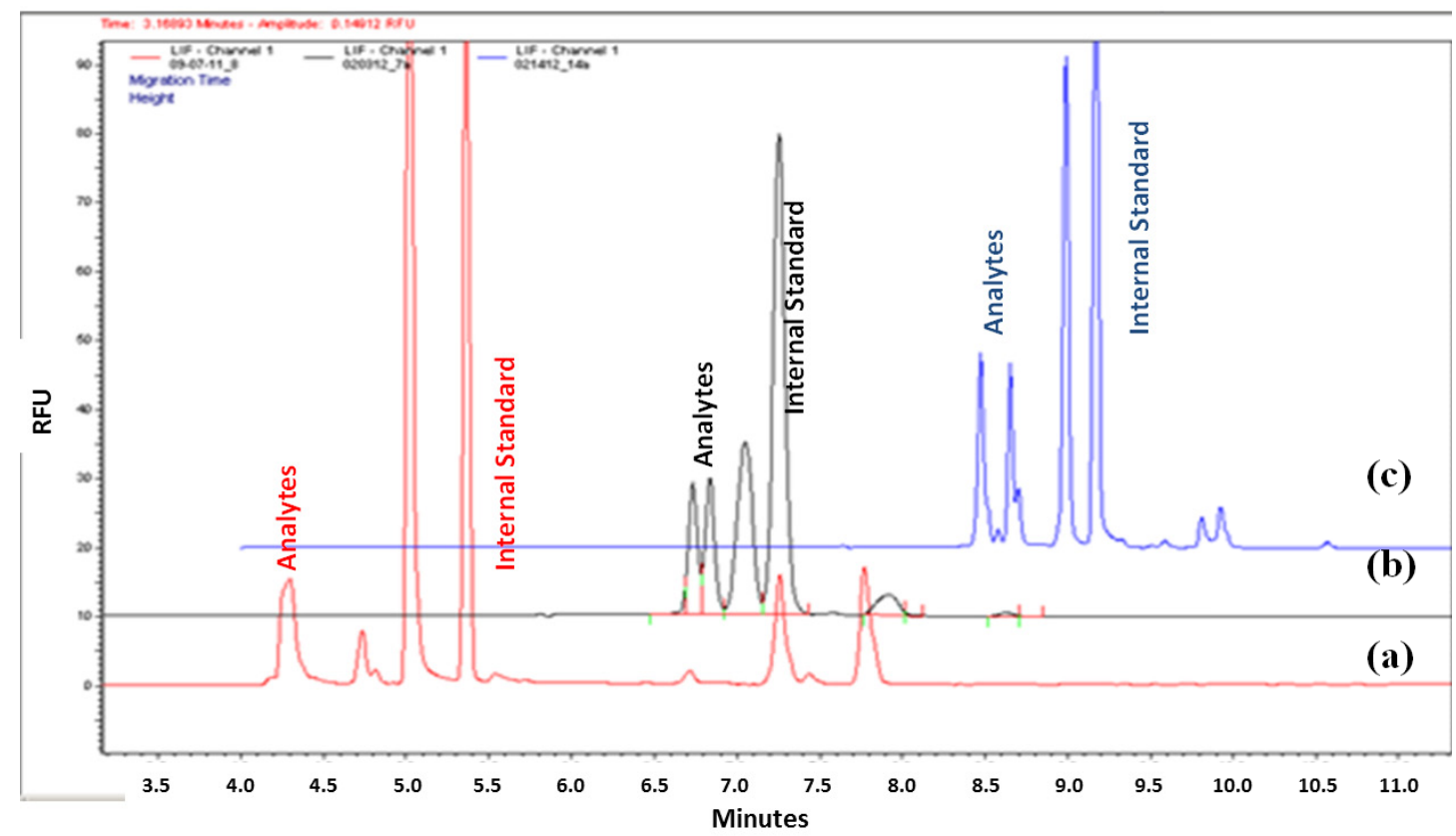

Figure 31: Comparison of three selectivity modifiers in $50 \mathrm{mM}$ borate, $\mathrm{pH} 9.5 / 15 \mathrm{mM} \beta-\mathrm{CD}$ buffer on separation of $100 \mu \mathrm{g} / \mathrm{mL}$ drug mixture labeled with $0.5 \mathrm{mM}$ 5-DTAF. (a) $40 \mathrm{mM}$ Brij-35 (b) $10 \mathrm{mg} / \mathrm{mL} \mathrm{S- \beta -CD} \mathrm{(c)} 10 \mathrm{mg} / \mathrm{mL}$ DM- $\beta$-CD. Brij is a nonionic surfactant that forms micelles, while the cyclodextrins form guest/host complexes.

The electropherogram shown for the separation of the 5-DTAF labeled $100 \mu \mathrm{g} / \mathrm{mL}$ drug mixture utilizing 50mM borate, $\mathrm{pH}$ 9.5/15mM $\beta$-cyclodextrin/40mM Brij-35 (figure 31a) shows no separation of the analytes at all. Other than the internal standard peak, all others were the result of excess DTAF and DTAF-byproducts. By substituting the Brij-35 with sulfated- $\beta$-cyclodextrin $(\mathrm{S}-\beta-\mathrm{CD})$ there was some separation observed in figure $31 \mathrm{~b}$. The first peak represents the amphetamine, methamphetamine, and MDMA components of the mixture. The second peak is for norephedrine and ephedrine. By substituting dimethyl- $\beta$-cyclodextrin (DM- $\beta-C D)$ individual peaks can further be seen in figure $31 \mathrm{c}$.

On the basis of the results obtained, it was determined that the combination of native $\beta-C D$ and $D M-\beta-C D$ provided the improved resolution between the analytes in comparison to the other options. However, even with the combination of cyclodextrins, 
the peaks were not fully resolved. In order to create greater distinctions between the moving zones within the capillary, varying concentrations of the polar, aprotic solvent acetonitrile was added to the run buffer. The results of that study are summarized in figure 32 below.

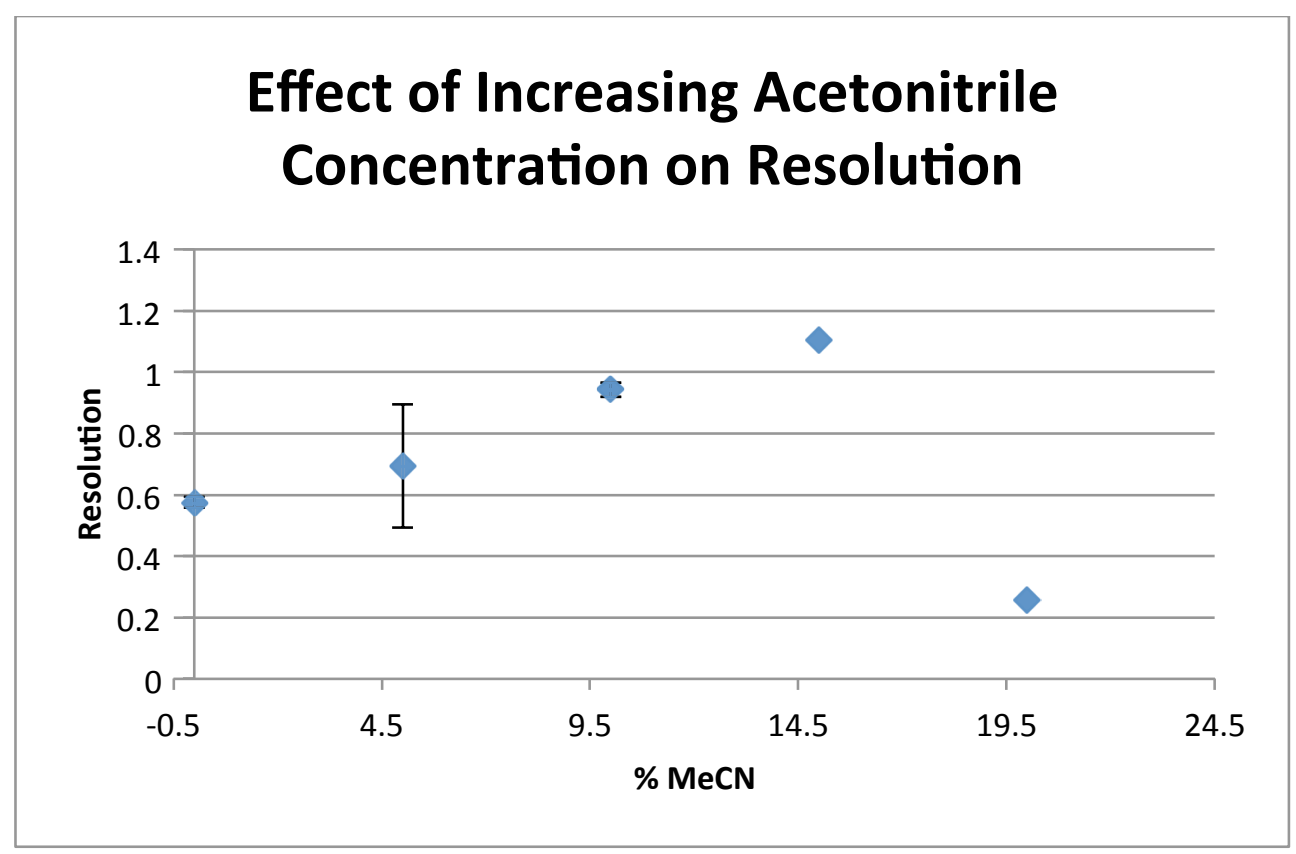

Figure 32: Effect of increasing acetonitrile concentration in running buffer $(50 \mathrm{mM}$ borate, $\mathrm{pH} 9.5 / 15 \mathrm{mM} \beta$ $\mathrm{CD} / 10 \mathrm{mg} / \mathrm{mL}$ DM- $\beta$-CD on resolution between peaks of DTAF-labeled $100 \mu \mathrm{g} / \mathrm{mL}$ drug mixture.

Acetonitrile reduces the EOF allowing for the labeled derivatives to separate to a greater extent, as well as modifying the buffer polarity. This affects the guest/host equilibrium between the analytes and the cyclodextrins which has an overall effect of improving resolution. The final result of this investigation is seen in figure 33 . 


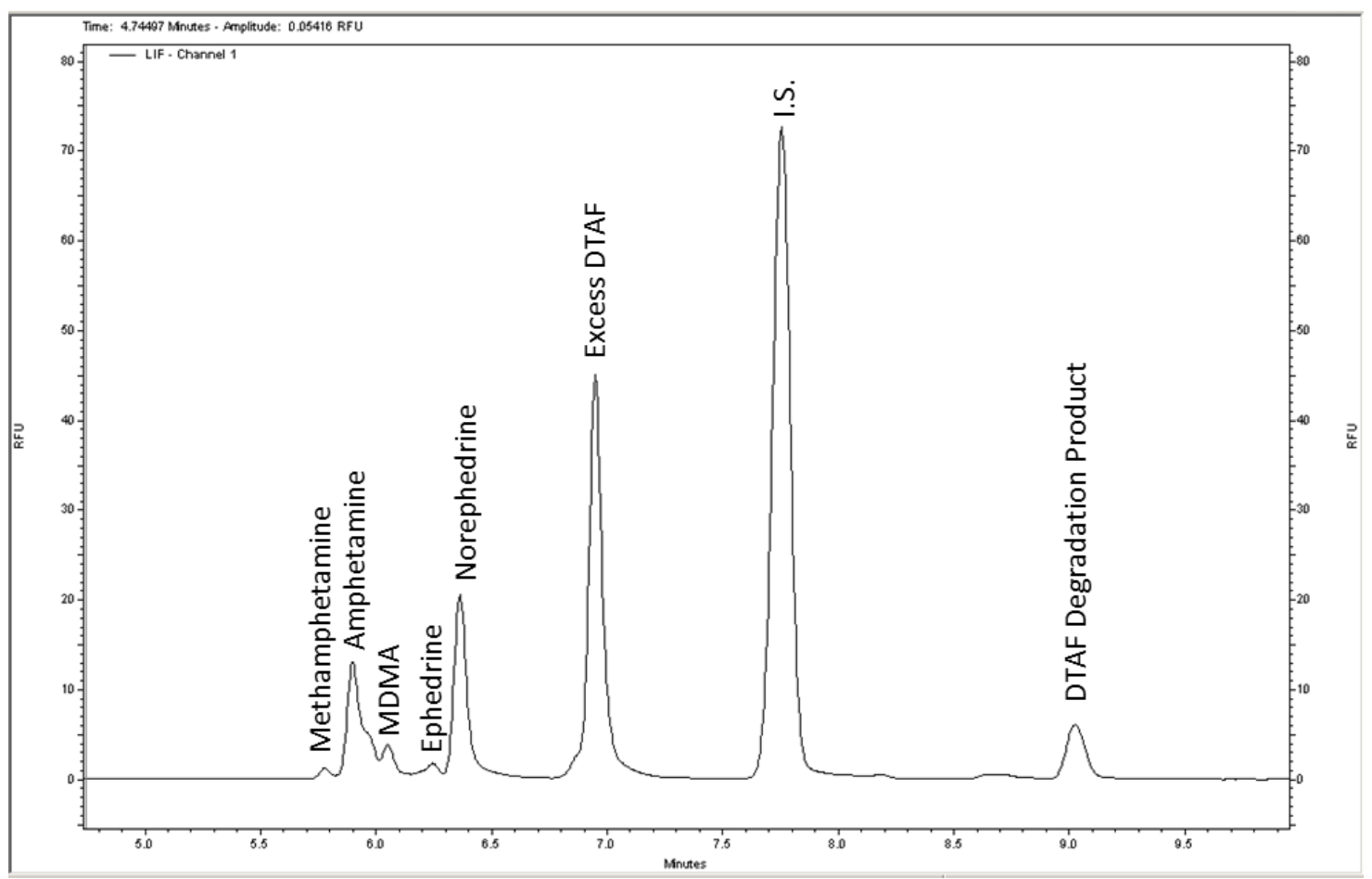

Figure 33: Typical electropherogram of $100 \mathrm{ug} / \mathrm{mL}$ mixture of five phenethylamines derivatized pre-capillary. Conditions: Fused silica capillary, $50 \mu \mathrm{m}$ I.D., $60 \mathrm{~cm}$ length, $50 \mathrm{~cm}$ effective length; capillary temperature, $35^{\circ} \mathrm{C}$; fluorescent tag, 0.5mM 5-DTAF in ethanol/1,2-dichloroethane (9:1); buffer, 50mM sodium borate, pH 9.5/15mM $\beta$ $C D / 10 \mathrm{mg} / \mathrm{mL}$ DM- $\beta-C D / 15 \%$ acetonitrile. All other conditions same as table 3 with the exception that steps 3 and 4 were consolidated into a single injection at $0.5 p s i$ for $5.0 \mathrm{sec}$.

In order to determine the optimal parameters for the derivatization reaction, a five-analyte mixture comprised of amphetamine, methamphetamine, norephedrine, ephedrine and MDMA at $100 \mu \mathrm{g} / \mathrm{mL}$ was derivatized offline using increasing concentrations of 5-DTAF. These derivatives were then separated using the running buffer, $50 \mathrm{mM}$ sodium borate, $\mathrm{pH} 9.5 / 15 \mathrm{mM} \beta-\mathrm{CD} / 10 \mathrm{mg} / \mathrm{mL} \mathrm{DM}-\beta-\mathrm{CD} / 15 \%$ acetonitrile in the presence of an internal standard $(2.5 \mu \mathrm{M}$ fluorescein in BGE). The results are displayed in figure 34. 


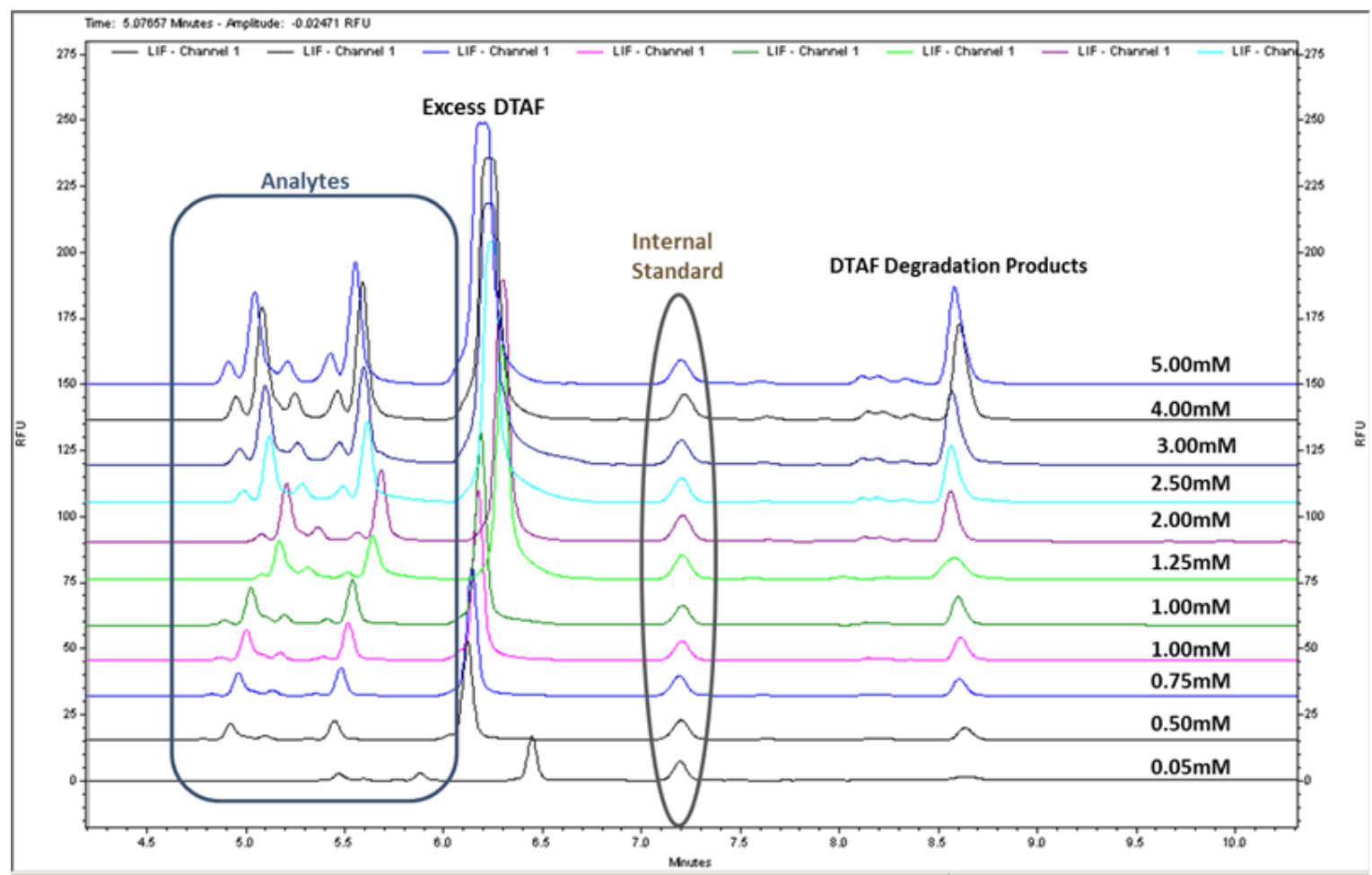

Figure 34: Typical electropherograms for $100 \mathrm{ug} / \mathrm{mL}$ mixture of five phenethylamines labeled with varying concentrations of 5-DTAF pre-capillary. Conditions: Fused silica capillary, $50 \mu \mathrm{m} \mathrm{I.D.,} 60 \mathrm{~cm}$ length, $50 \mathrm{~cm}$ effective length; capillary temperature, $35^{\circ} \mathrm{C}$; buffer, $50 \mathrm{mM}$ sodium borate, $\mathrm{pH} 9.5 / 15 \mathrm{mM} \beta-\mathrm{CD} / 10 \mathrm{mg} / \mathrm{mL} \mathrm{DM}-\beta-\mathrm{CD} / 15 \%$ acetonitrile. All other conditions same as table 3; steps 3 and 4 consolidated into a single injection at $0.5 p s i$ for 5.0 sec.

By stacking the electropherograms based on the position of the internal standard the steady increase in fluorescence is easily visualized. Also, the consistent elution order of the analytes is maintained and while there is slight drift between electropherograms, the usage of the internal standard as a bench mark makes it easier to compensate for this. At 5.0mM it was found that 5-DTAF had attained its maximum solubility for the solvent system being used so further analyses beyond that point were not attempted. An individual electropherogram for the $5.0 \mathrm{mM}$ analysis is given in figure 35 . Based on the excellent separation observed of the individual analytes, this buffer composition $(50 \mathrm{mM}$ borate, $\mathrm{pH} 9.5 / 15 \mathrm{mM} \beta-\mathrm{CD} / 10 \mathrm{mg} / \mathrm{mL} \mathrm{DM}-\beta-\mathrm{CD} / 15 \% \mathrm{MeCN})$ was selected for the inline derivatization experiments. 


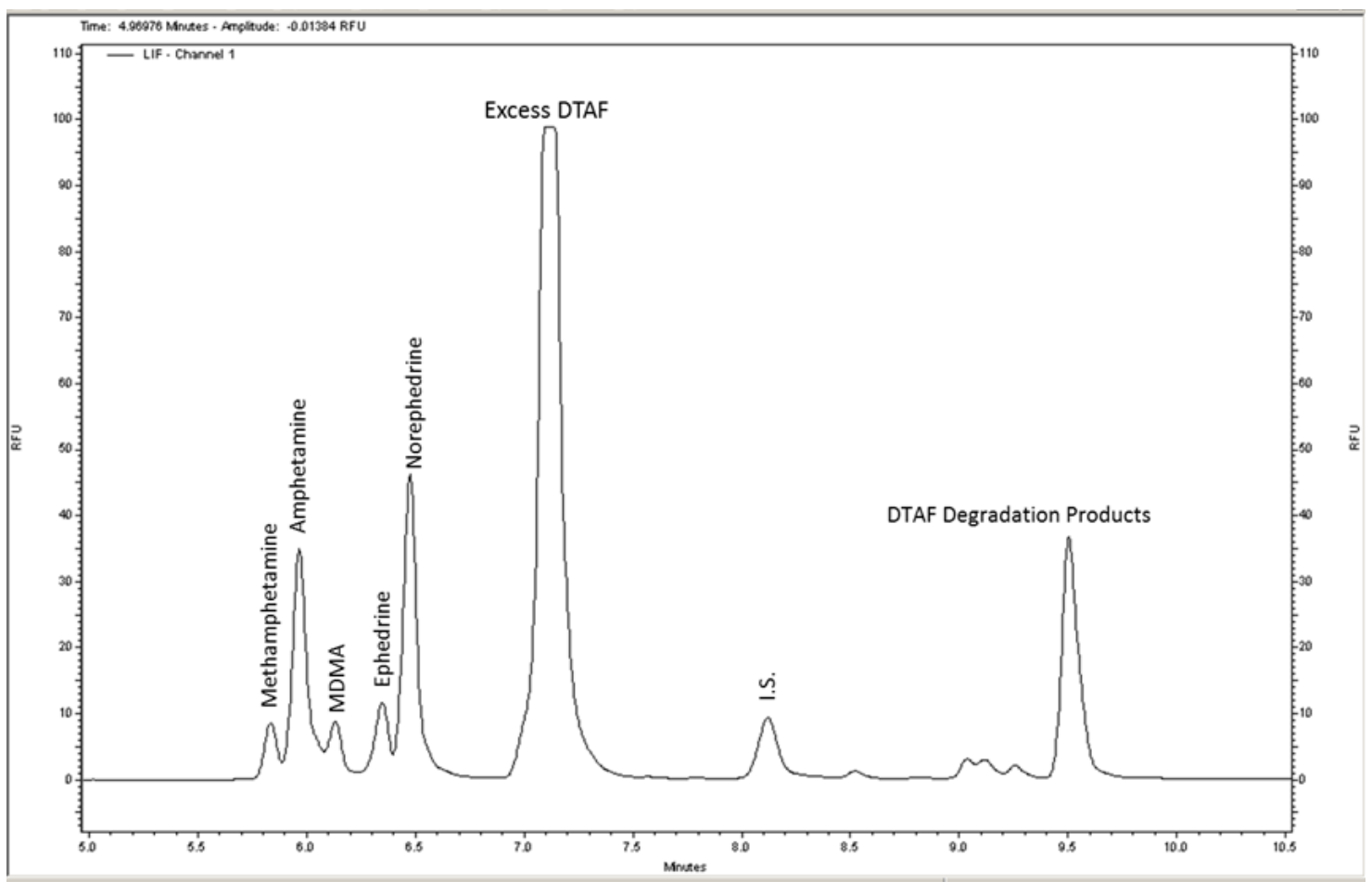

Figure 35: Typical electropherogram of $100 \mathrm{ug} / \mathrm{mL}$ mixture of five phenethylamines labeled with 5.0mM 5-DTAF. Conditions: Fused silica capillary, $50 \mu \mathrm{m}$ I.D., $60 \mathrm{~cm}$ length, $50 \mathrm{~cm}$ effective length; capillary temperature, $35^{\circ} \mathrm{C}$; buffer, $50 \mathrm{mM}$ sodium borate, $\mathrm{pH} 9.5 / 15 \mathrm{mM} \beta-\mathrm{CD} / 10 \mathrm{mg} / \mathrm{mL} \mathrm{DM}-\beta-\mathrm{CD} / 15 \%$ acetonitrile. All other conditions same as table 3; steps 3 and 4 consolidated into a single injection at $0.5 p s i$ for 5.0 sec.

These optimized parameters resulted in limits of detection for the individual drugs ranging from approximately $1.4 \mathrm{ng} / \mathrm{mL}$ to $0.48 \mu \mathrm{g} / \mathrm{mL}$. In the design of this method it was always intended for the offline procedure to be translated into the inline procedure with as little modification to the method as possible. By optimizing the buffer composition and separation parameters in this stage of the work, further optimization studies of those factors were not necessary in later experiments which will be discussed in the following section. 


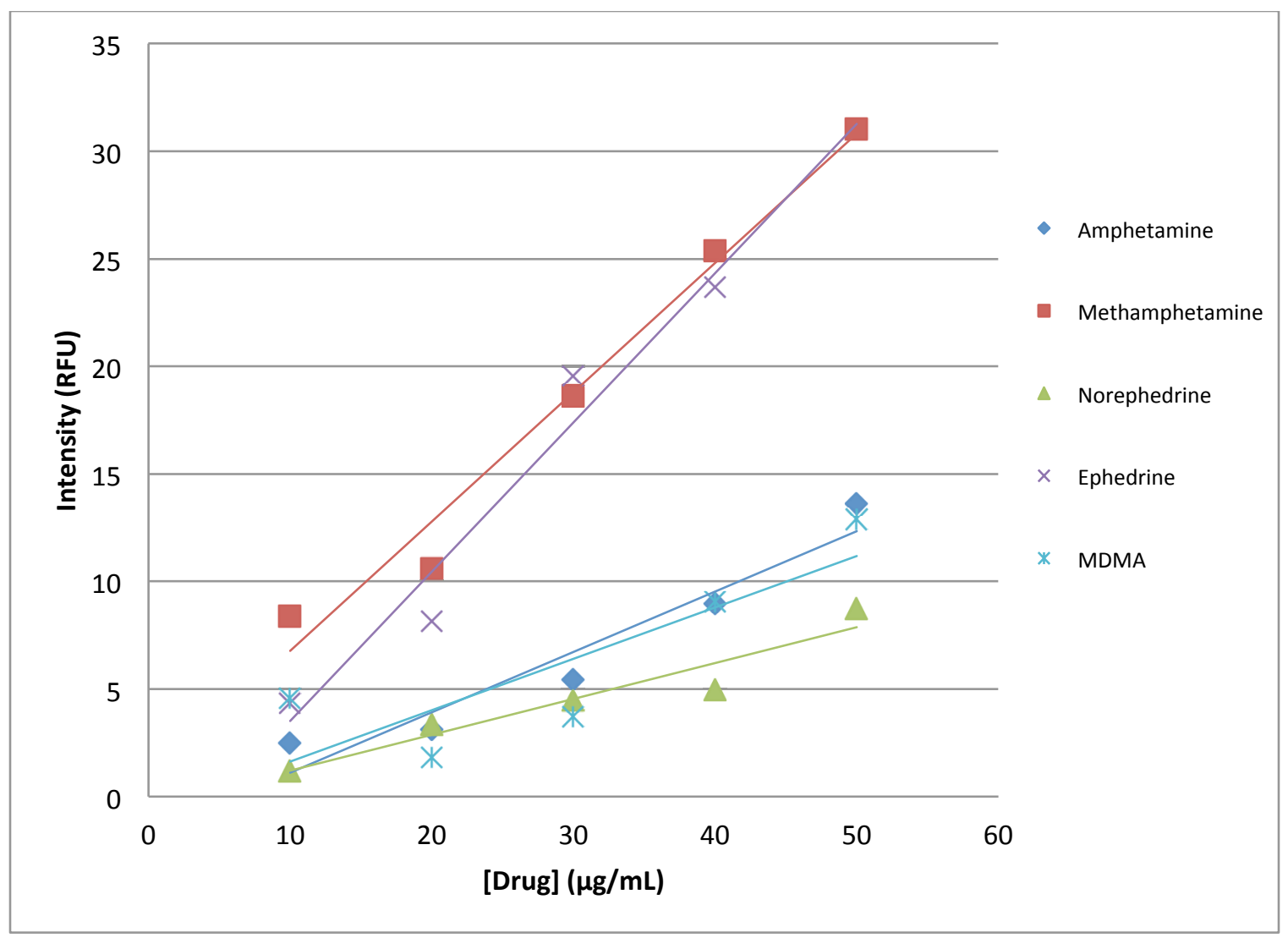

Figure 36: Calibration curves for online-derivatized analytes using 5-DTAF.

Table 5: Figures of merit for offline derivatization with 5-DTAF.

\begin{tabular}{|c|c|c|c|c|}
\hline \multirow{2}{*}{ Analyte } & $\begin{array}{c}\text { Linear } \\
\text { Regression } \\
\text { Equation } \\
\mathbf{y}=\mathbf{m} \mathbf{x}+\mathbf{b}\end{array}$ & $\mathbf{R}^{2}$ & $\begin{array}{c}\text { LOD } \\
(\mathbf{n g} / \mathbf{m L})\end{array}$ & $\begin{array}{c}\text { Average } \\
\text { Elution Time } \\
(\mathbf{m i n})\end{array}$ \\
\hline Amphetamine & $0.1816,0.9583$ & 0.9216 & 5.3 & $6.6 \pm 0.044$ \\
\hline Methamphetamine & $0.1140,0.1414$ & 0.9973 & 480 & $6.4 \pm 0.031$ \\
\hline Norephedrine & $0.1667,-0.4596$ & 0.9167 & 110 & $6.9 \pm 0.012$ \\
\hline Ephedrine & $0.6939,-3.425$ & 0.9557 & 22 & $6.9 \pm 0.010$ \\
\hline MDMA & $0.2186,1.287$ & 0.9171 & 1.4 & $6.5 \pm 0.026$ \\
\hline
\end{tabular}




\subsection{Inline Derivatization of Phenethylamines}

The present chapter discusses the modification of the pre-capillary derivatization to permit the utilization of the fluorescent dye, 5-DTAF, in an inline derivatization method. The effect of reagent concentration and electrokinetic mixing parameters were examined to define the optimal parameters for maximizing labeling efficiency without sacrificing peak resolution In the previous stage of method development, the optimal separation buffer was determined to be $50 \mathrm{mM}$ sodium borate, $\mathrm{pH} 9.5,15 \mathrm{mM} \beta-\mathrm{CD}, 10 \mathrm{mg} / \mathrm{mL}$ DM$\beta-\mathrm{CD}$, and $15 \%$ acetonitrile (by volume). The derivatization method used was adapted from the work done by Molina [57] utilizing previously developed buffers and separation parameters. A schematic of the inline derivatization method is given below in figure 37 .

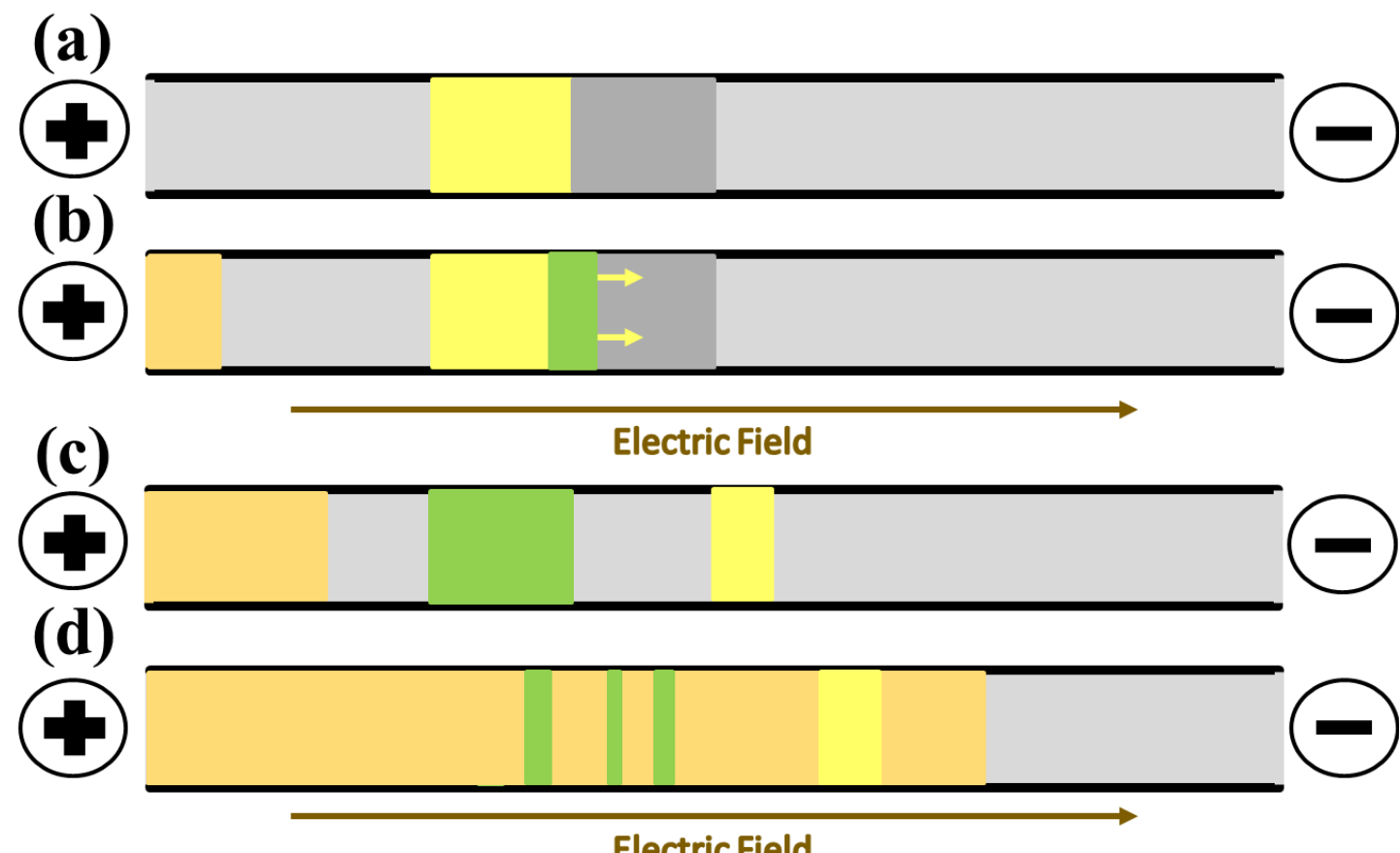

Electric Field

Figure 37: Schematic representation of inline derivatization method. (a) Plugs of sample, 5-DTAF, and background electrolyte (BGE) are injected into capillary filled with more BGE. (b) Voltage is applied generating small electric 
field for a short time. (c) Capillary is allowed to stand for set time frame with no electric field. (d) Separation potential is applied and fluorescent derivatives separate as they approach the detector window.

In order to perform the in-line derivatization separate sample and fluorescent label vials were designated and prepared. The sample vial was comprised of a $180 \mu \mathrm{L}$ aliquot of a $100 \mu \mathrm{g} / \mathrm{mL}$ mixture of amphetamine, methamphetamine, norephedrine, ephedrine, and MDMA, and $20 \mu \mathrm{L}$ of the derivatization buffer $\left(0.5 \mathrm{M} \mathrm{NaHCO} / \mathrm{Na}_{2} \mathrm{CO}_{3}, \mathrm{pH} 9.5\right)$. The fluorescent label vial also contained $20 \mu \mathrm{L}$ of the derivatization buffer as well as, $20 \mu \mathrm{L}$ of 5.0mM 5-DTAF, and $160 \mu \mathrm{L}$ of distilled water. An aliquot from both the sample and fluorescent label vials, as well as the background electrolyte $(50 \mathrm{mM}$ borate, $\mathrm{pH} 9.5)$ vials were injected sequentially into a capillary which had already been filled with the same background electrolyte using 0.5 psi for 5,5 , and 35 seconds respectively. The actual volume of each injection was $6.12 \mathrm{~nL}, 6.12 \mathrm{~nL}$, and $42.84 \mathrm{~nL}$ for each vial further highlighting how little sample and reagent is consumed utilizing this method. These values are based on the internal diameter of the capillary, the buffer viscosity, temperature, injection pressure, and injection length.

The terminal injection of the background electrolyte serves as a spacer between the reagents and the running buffer. This helps to prevent reactions occurring between the modifiers present in the run buffer and the fluorescent derivatizing agent. A low potential $(5 \mathrm{kV})$ is next applied in order to induce electrokinetic mixing, and then the reagents are allowed to sit and react for $10 \mathrm{~min}$. A separation potential of $20 \mathrm{kV}$ was then applied, generating EOF and inducing separation of the analytes. The analysis program method shown in table 3 was utilized and typical results are given in figure 38. 


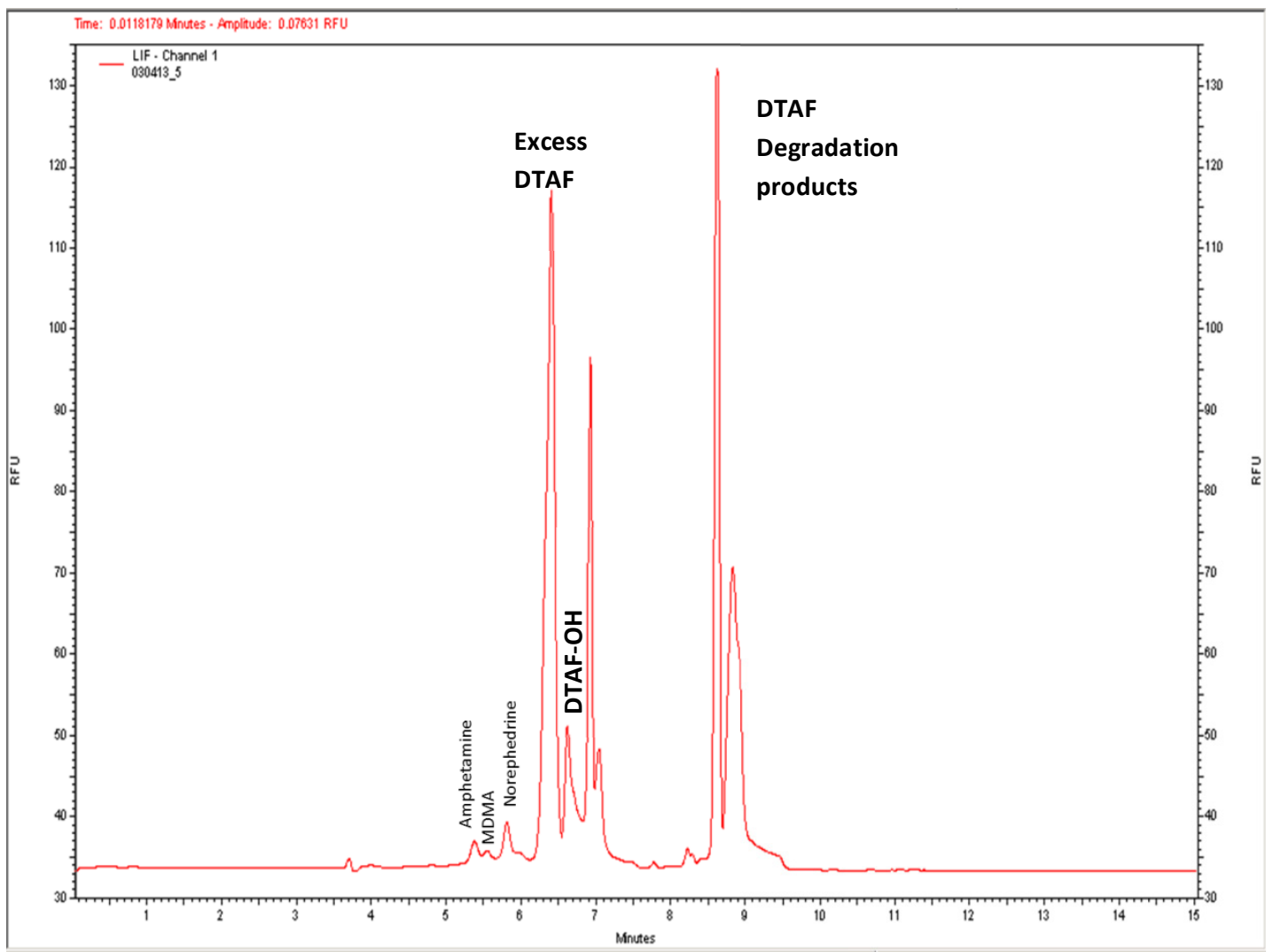

Figure 38: Typical electropherogram of $100 \mathrm{ug} / \mathrm{mL}$ mixture of five phenethylamines labeled via inline electrokinetic mixing with $20 \mu \mathrm{L}$ of $5.0 \mathrm{mM}$ 5-DTAF. Conditions: Fused silica capillary, $50 \mu \mathrm{m}$ I.D., $60 \mathrm{~cm}$ length, $50 \mathrm{~cm}$ effective length; capillary temperature, $35^{\circ} \mathrm{C}$; buffer, $50 \mathrm{mM}$ sodium borate, $\mathrm{pH} 9.5 / 15 \mathrm{mM} \beta-\mathrm{CD} / 10 \mathrm{mg} / \mathrm{mL}$ DM- $\beta-\mathrm{CD} / 15 \%$ acetonitrile. All other conditions same as table 3.

Experiments were done varying the volume of dye in the reagent vial in order to increase the overall molar ratio of analyte versus label. By doing so, theoretically the labeling efficiency would increase. This permits an increasing in overall concentration without problems of precipitation. At the conclusion of this experiment it was determined that $40 \mu \mathrm{L}$ of 5.0mM 5-DTAF gave the best overall labeling efficiency as seen in figure 39. It increased the intensity of the peaks while maintaining resolution despite a large background. 


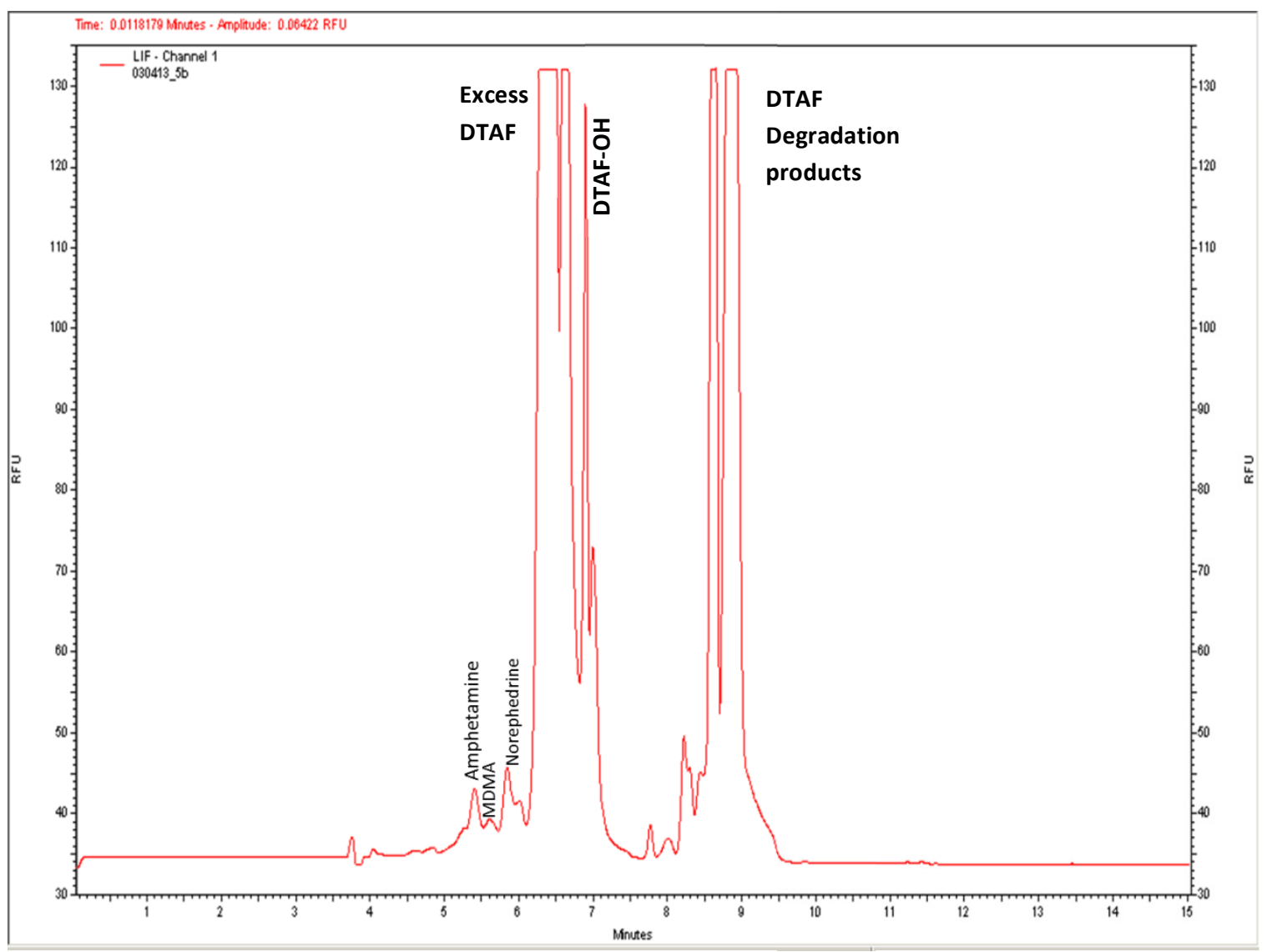

Figure 39: Typical electropherogram of $100 \mathrm{ug} / \mathrm{mL}$ mixture of five phenethylamines labeled via inline electrokinetic mixing with $40 \mu \mathrm{L}$ of $5.0 \mathrm{mM}$ 5-DTAF. Conditions: Fused silica capillary, $50 \mu \mathrm{m}$ I.D., $60 \mathrm{~cm}$ length, $50 \mathrm{~cm}$ effective length; capillary temperature, $35^{\circ} \mathrm{C}$; buffer, $50 \mathrm{mM}$ sodium borate, $\mathrm{pH} 9.5 / 15 \mathrm{mM} \beta-\mathrm{CD} / 10 \mathrm{mg} / \mathrm{mL} \mathrm{DM}-\beta-\mathrm{CD} / 15 \%$ acetonitrile. All other conditions same as table 3.

To confirm the suitability of the injection sequence, the order and number of injections (single versus multiple) was assessed. In the first experiment, a plug of 5DTAF was sandwiched between two plugs of analyte via a sequential injection. While the analytes were successfully labeled, their intensity was very low with the largest peak, norephedrine, having an intensity of less than 5 RFU. 


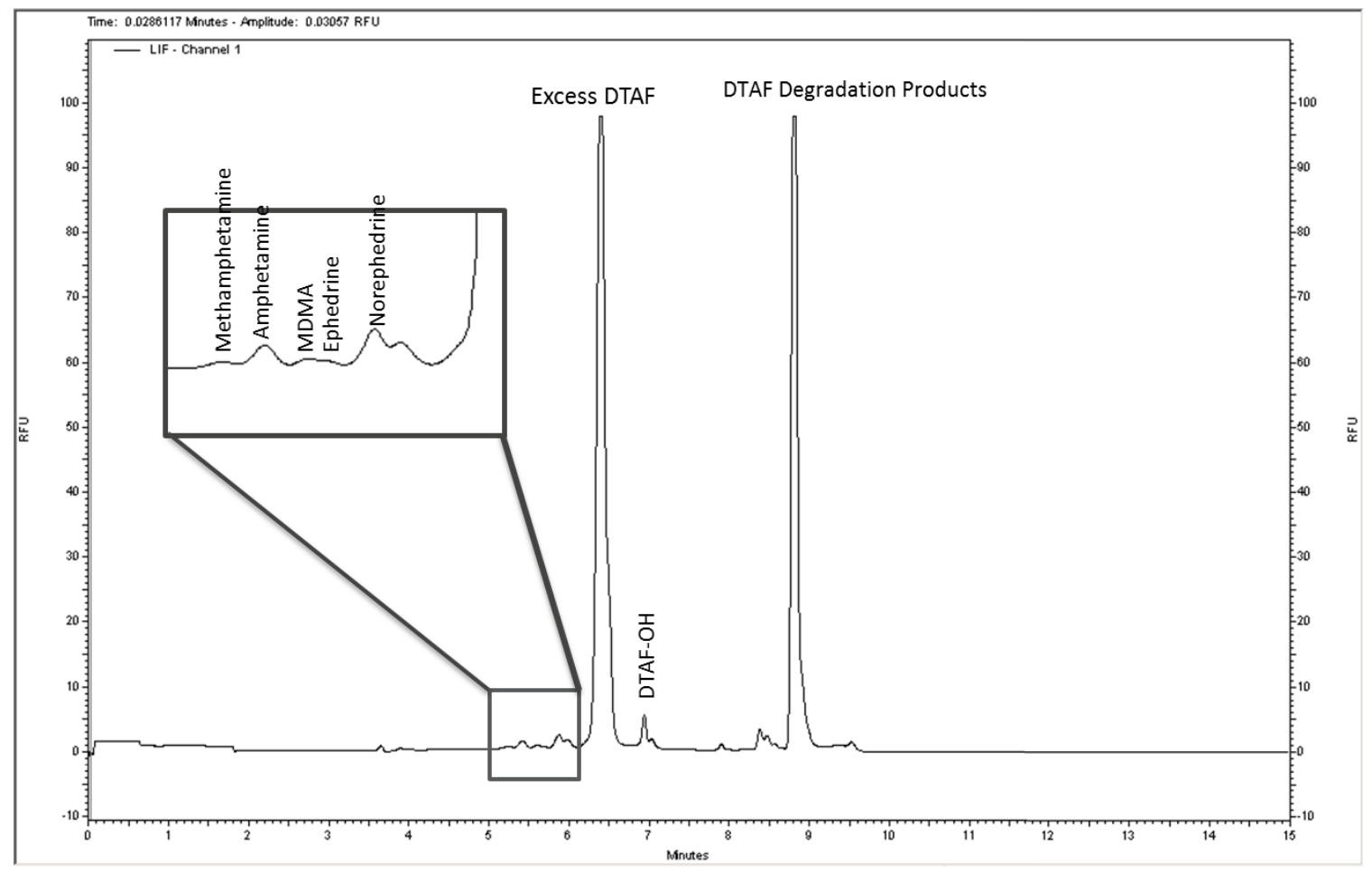

Figure 40: Typical electropherogram of $100 \mathrm{ug} / \mathrm{mL}$ mixture of five phenethylamines labeled via inline electrokinetic mixing with $40 \mu \mathrm{L}$ of $5.0 \mathrm{mM} 5$-DTAF. Conditions: Fused silica capillary, $50 \mu \mathrm{m}$ I.D., $60 \mathrm{~cm}$ length, $50 \mathrm{~cm}$ effective length; capillary temperature, $35^{\circ} \mathrm{C}$; buffer, $50 \mathrm{mM}$ sodium borate, $\mathrm{pH} 9.5 / 15 \mathrm{mM} \beta-\mathrm{CD} / 10 \mathrm{mg} / \mathrm{mL}$ DM- $\beta-\mathrm{CD} / 15 \%$ acetonitrile. Injection order, (5 sec at $0.5 \mathrm{psi}$ ) analyte, tag, analyte; all other conditions same as table 3.

By reversing the order of the sandwich injection sequence so that the analyte is flanked by fluorescent tag it was found that peak intensity increased by an order of magnitude (from 4.0 RFU to 44 RFU for norephedrine) as seen in figure 41. However, the electropherogram peaks were not fully resolved (between amphetamine and MDMA resolution was 0.768 ) and the signal for ephedrine was completely obscured. Next, single injections of reagents in alternating order were assessed. In figure 42 analyte is injected followed by 5-DTAF prior to electrokinetic mixing. While the intensity of the peaks produced are somewhat significant, ranging from 10 to $45 \mathrm{RFU}$, as with figure 41, the there is no base-line resolution and the electropherogram suffers from peak loss. In this 
case, the peaks representing ephedrine, and methamphetamine, could not be distinguished.

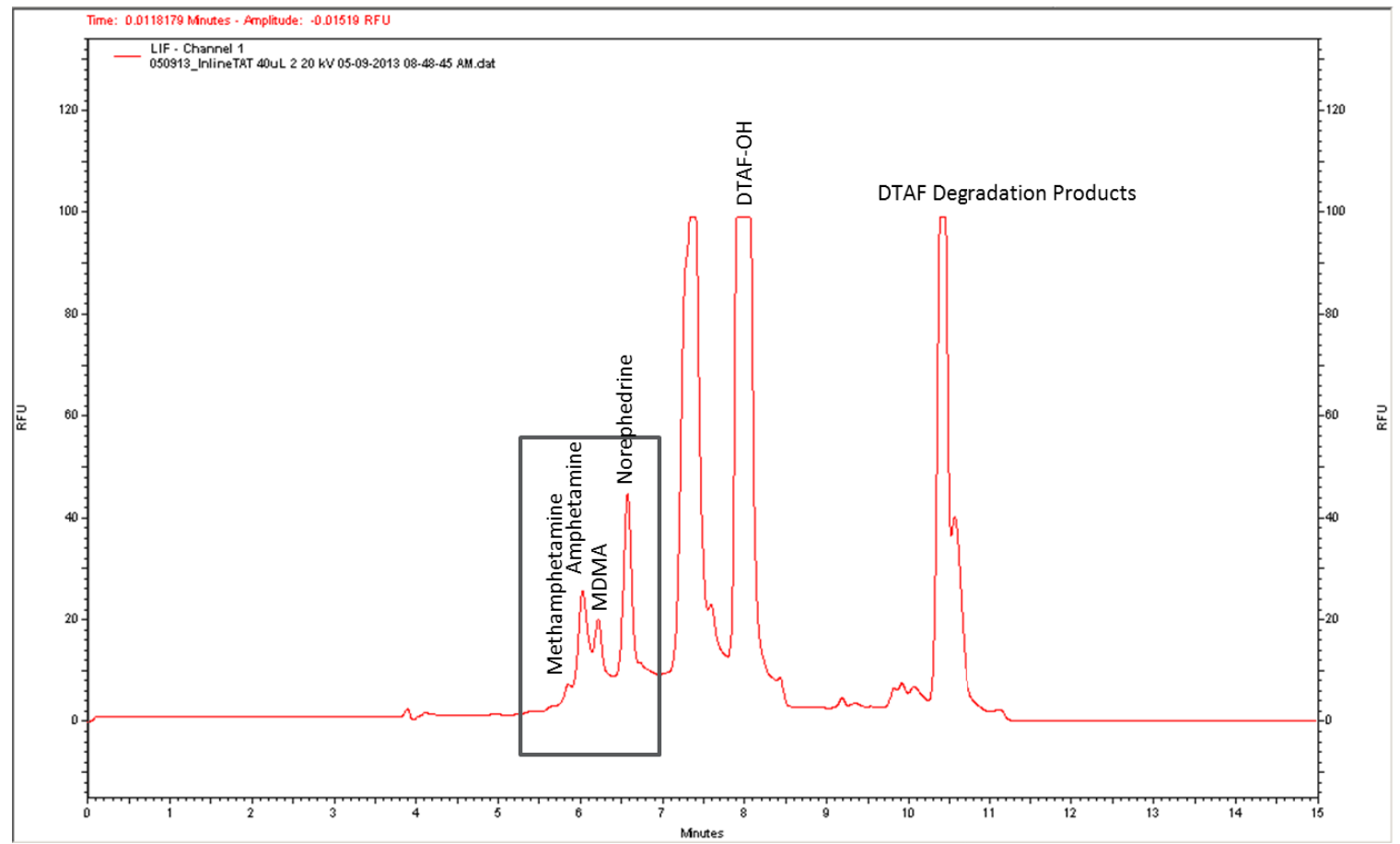

Figure 41: Electropherogram of $100 \mathrm{ug} / \mathrm{mL}$ mixture of five phenethylamines labeled via inline electrokinetic mixing with $40 \mu \mathrm{L}$ of $5.0 \mathrm{mM}$ 5-DTAF. Conditions: Fused silica capillary, $50 \mu \mathrm{m}$ I.D., $60 \mathrm{~cm}$ length, $50 \mathrm{~cm}$ effective length; capillary temperature, $35^{\circ} \mathrm{C}$; buffer, $50 \mathrm{mM}$ sodium borate, $\mathrm{pH} 9.5 / 15 \mathrm{mM} \beta-\mathrm{CD} / 10 \mathrm{mg} / \mathrm{mL}$ DM- $\beta-\mathrm{CD} / 15 \%$ acetonitrile. Injection order, (5 sec at $0.5 \mathrm{psi})$ tag, analyte, tag; all other conditions same as table 3 . 


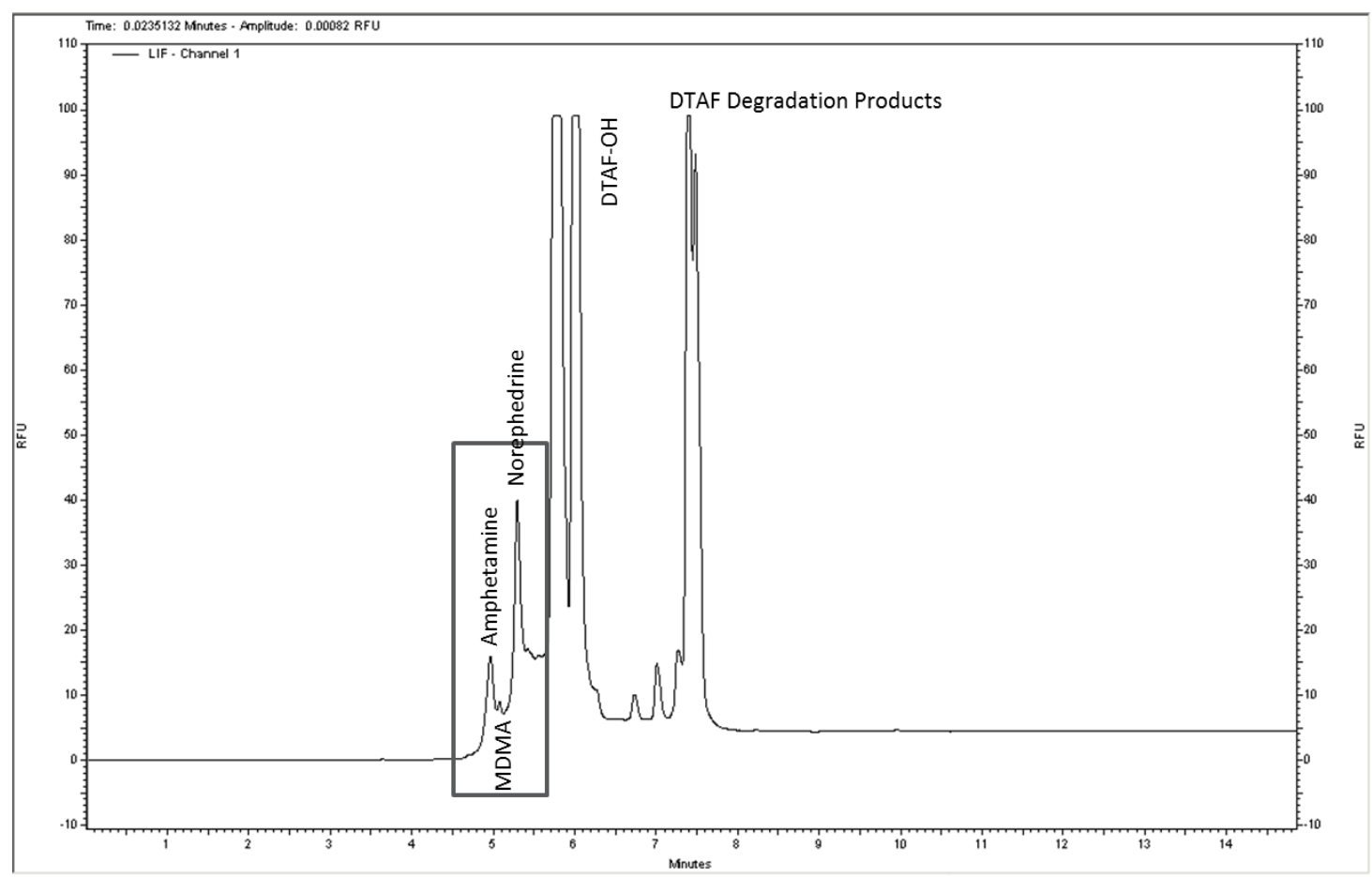

Figure 42: Electropherogram of $100 \mathrm{ug} / \mathrm{mL}$ mixture of five phenethylamines labeled via inline electrokinetic mixing with $40 \mu \mathrm{L}$ of $5.0 \mathrm{mM}$ 5-DTAF. Conditions: Fused silica capillary, $50 \mu \mathrm{m}$ I.D., $60 \mathrm{~cm}$ length, $50 \mathrm{~cm}$ effective length; capillary temperature, $35^{\circ} \mathrm{C}$; buffer, $50 \mathrm{mM}$ sodium borate, $\mathrm{pH} 9.5 / 15 \mathrm{mM} \beta-\mathrm{CD} / 10 \mathrm{mg} / \mathrm{mL} \mathrm{DM}-\beta-\mathrm{CD} / 15 \%$ acetonitrile. Injection order, (5 sec at $0.5 \mathrm{psi}$ ) analyte, tag; all other conditions same as table 3 .

Finally, the effect of sequential injection of the fluorescent label followed by the sample was assessed. This injection sequence resulted in distinct peaks for each analyte present in the mixture with good intensity as seen in figure 43 . The observed increase in labeling efficiency is likely because of the maintenance of the derivatizing reagent in its dianion form at $\mathrm{pH}(9.5)$. Under these conditions, the mobility of the reagent is opposite that of the EOF. As a result there is a longer interaction between analyte and reagent and more efficient mixing within the capillary. 


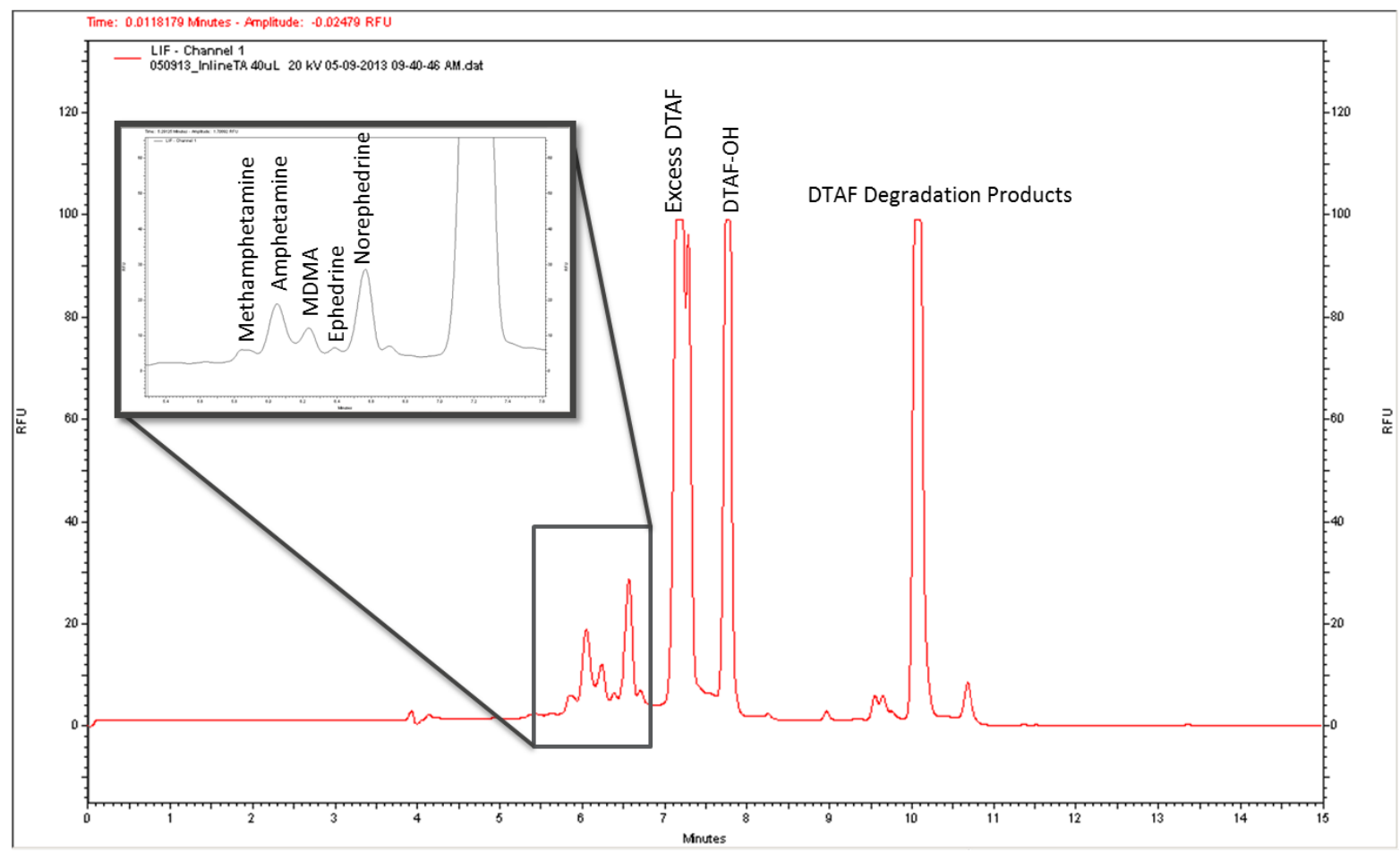

Figure 43: Typical electropherogram of $100 \mathrm{ug} / \mathrm{mL}$ mixture of five phenethylamines labeled via inline electrokinetic mixing with $40 \mu \mathrm{L}$ of $5.0 \mathrm{mM}$ 5-DTAF. Conditions: Fused silica capillary, $50 \mu \mathrm{m}$ I.D., $60 \mathrm{~cm}$ length, $50 \mathrm{~cm}$ effective length; capillary temperature, $35^{\circ} \mathrm{C}$; buffer, $50 \mathrm{mM}$ sodium borate, $\mathrm{pH} 9.5 / 15 \mathrm{mM} \beta-\mathrm{CD} / 10 \mathrm{mg} / \mathrm{mL} \mathrm{DM}-\beta-\mathrm{CD} / 15 \%$ acetonitrile. Injection order, (5 sec at $0.5 \mathrm{psi})$ tag, analyte; all other conditions same as table 3 .

\subsubsection{Optimization of Inline Derivatization Method}

To establish optimal electrokinetic mixing conditions the statistical software, Nemrodw, was utilized to assess which combination of the three parameters (mixing voltage, mixing time, wait time) would produce optimal labeling efficiency. Typically in the preliminary stages of optimization first order models, such as Plackett-Burman, are used [27]. These are done in order to determine which experimental factors are most influential. However, when attempting to optimize an experimental process, second order models are more useful than the preliminary first order models. Commonly used experimental design models use a symmetrical, spherical experiment domain and a 
minimum of two factor levels. The Doehlert matrix is one such surface response design $[31]$.

The Doehlert matrix is comprised of a uniform, spherical shell design which stresses uniformity in space filling within the experimental region. With such a model, the influence of different parameters can be predicted with much greater accuracy. Depending on how many factors are being assessed, the number of levels of each factor may vary as will the total number of experiments. For this work three parameters of the electrokinetic mixing for the inline derivatization method were assessed; mixing voltage, mixing time, and wait time. For the Doehlert matrix, the number of experiments $(N)$ is determined using the following equation where $k$ is the number of variables and $\mathrm{C}_{0}$ is the number of center points [27].

$$
N=k^{2}+k+C_{0}
$$

When three variables are utilized with a single center point, the number of experiments calculated is thirteen. The coded matrix for our particular experiment is outlined in table 4.

\begin{tabular}{|c|c|c|}
\hline \multicolumn{3}{|c|}{ Table 6: Coded matrix for Doehlert optimization of } \\
electrokinetic mixing parameters. \\
\hline Mix Voltage & Mix Time & Wait Time \\
\hline 1 & 0 & 0 \\
\hline-1 & 0 & 0 \\
\hline 0.5 & 0.86603 & 0 \\
\hline-0.5 & -0.86603 & 0 \\
\hline
\end{tabular}




\begin{tabular}{|c|c|c|}
\hline 0.5 & -0.86603 & 0 \\
\hline-0.5 & 0.86603 & 0 \\
\hline 0.5 & 0.28868 & 0.8165 \\
\hline-0.5 & -0.28868 & -0.8165 \\
\hline 0.5 & -0.28868 & -0.8165 \\
\hline 0 & 0.57735 & -0.8165 \\
\hline-0.5 & 0.28868 & 0.8165 \\
\hline 0 & -0.57735 & 0.8165 \\
\hline 0 & 0 & 0 \\
\hline
\end{tabular}

In order to convert the coded matrix values to real experiment values, each must be assessed using the following equation where $C_{i}$ is the coded value for the level of the factor, $i . X_{i}$ is the real value in the experiment, $X^{0}{ }_{i}$ is the real value at the center of the experimental domain, and $\Delta X_{i}$ is the step of variation of the real value. The coded value limit for each factor is represented by $\alpha$.

$$
\begin{gathered}
C_{i}=\left\{\frac{X_{i}-X_{i}^{0}}{\Delta X_{i}}\right\} \alpha \\
X_{i}^{0}=\frac{X_{i, \max }+X_{i, \min }}{2} \\
\Delta X_{i}=\frac{X_{i, \max }-X_{i, \min }}{2}
\end{gathered}
$$

For this experiment, the range for mixing voltage was 2 to $10 \mathrm{kV}$, mixing time was 30 to 75 minutes, and wait time was 3 to 15 minutes. For example, the first cell of the mixing voltage factor has the following corresponding values; $C_{i}=1, X^{0}{ }_{i}=6, \Delta X_{i}=4$, and $\alpha=1$. Using these values, the calculated experimental value is $10 \mathrm{kV}$ as shown in 
table 5. This was repeated for all of the parameters at every level to give the uncoded matrix as seen in table 5.

\begin{tabular}{|c|c|c|}
\hline \multicolumn{3}{|c|}{$\begin{array}{l}\text { Table 7: Uncoded matrix for Doehlert optimization of } \\
\text { electrokinetic mixing parameters. }\end{array}$} \\
\hline Mix Voltage & Mix Time & Wait Time \\
\hline$(\mathbf{k V})$ & $(\mathrm{sec})$ & $(\min )$ \\
\hline 10 & 52.5 & 9 \\
\hline 2 & 52.5 & 9 \\
\hline 8 & 71.99 & 9 \\
\hline 4 & 33.01 & 9 \\
\hline 8 & 33.01 & 9 \\
\hline 4 & 71.99 & 9 \\
\hline 8 & 59 & 13.9 \\
\hline 4 & 46 & 4.1 \\
\hline 8 & 46 & 4.1 \\
\hline 6 & 65.49 & 4.1 \\
\hline 4 & 59 & 13.9 \\
\hline 6 & 39.51 & 13.9 \\
\hline 6 & 52.5 & 9 \\
\hline
\end{tabular}

Samples comprised of a $100 \mu \mathrm{g} / \mathrm{mL}$ mixture of amphetamine, methamphetamine, norephedrine, ephedrine, and MDMA were run in triplicate and the responses for each identified analyte were entered into the Nemrodw software for analysis to calculate the 
coefficients for the polynomial model designed and generate contour plots as seen in figures 44-46.

$$
\begin{gathered}
Y=b_{0}+b_{1} X_{1}+b_{2} X_{2}+b_{3} X_{3}+\left(b_{1}-1\right) X_{1}^{2}+\left(b_{2}-2\right) X_{2}^{2}+\left(b_{3}-3\right) X_{3}^{2} \\
+\left(b_{1}-2\right) X_{1} X_{2}+\left(b_{1}-3\right) X_{1} X_{3}+\left(b_{2}-3\right) X_{2} X_{3}
\end{gathered}
$$

The contour plots graphically show changes in signal intensity which can be used to interpret the most efficient parameters for the method of interest.

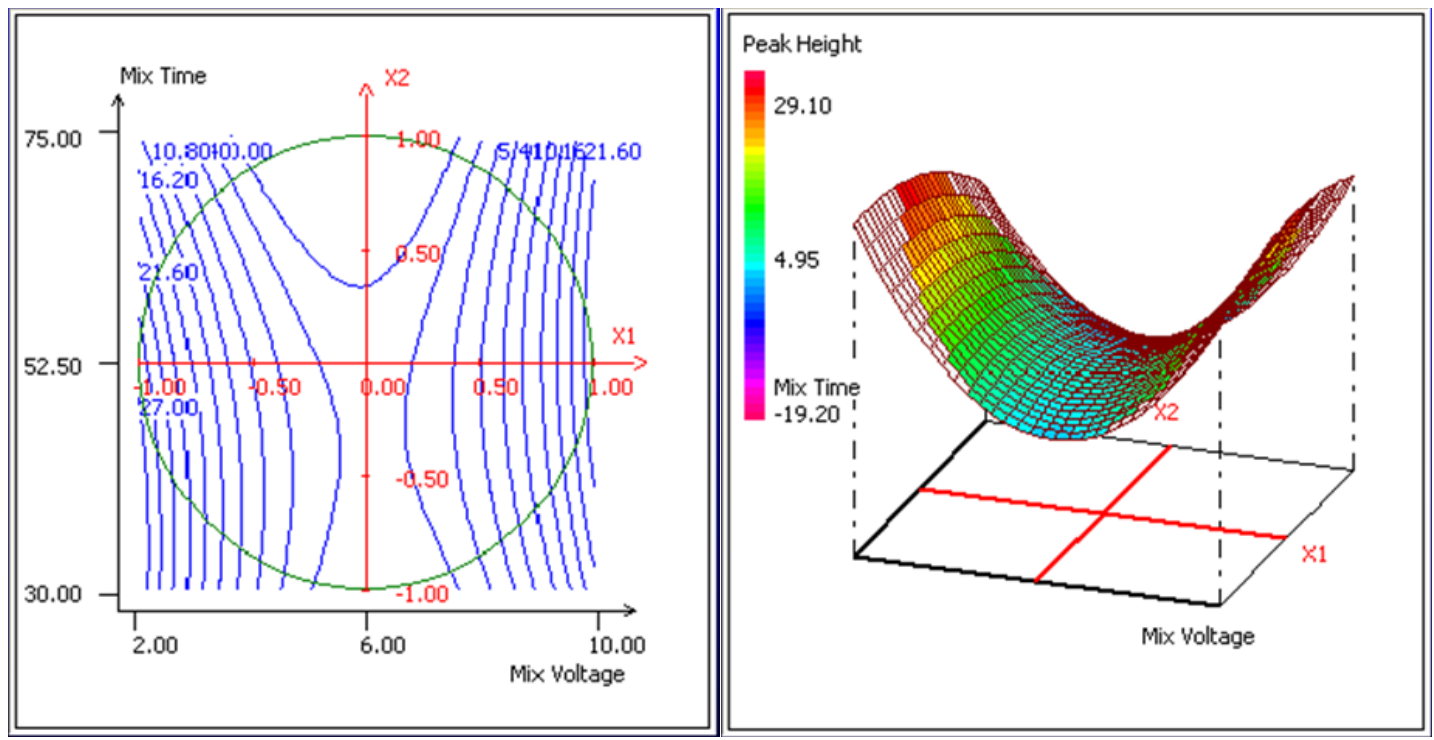

Figure 44: Two-dimensional and three-dimensional contour plots for amphetamine peak in $100 \mathrm{ug} / \mathrm{mL}$ mixture of five phenethylamines labeled via inline electrokinetic mixing with $40 \mu \mathrm{L}$ of 5.0mM 5-DTAF. Conditions: Fused silica capillary, $50 \mu \mathrm{m}$ I.D., $60 \mathrm{~cm}$ length, $50 \mathrm{~cm}$ effective length; capillary temperature, $35^{\circ} \mathrm{C}$; buffer, $50 \mathrm{mM}$ sodium borate, $\mathrm{pH} 9.5 / 15 \mathrm{mM} \beta-\mathrm{CD} / 10 \mathrm{mg} / \mathrm{mL}$ DM- $\beta-\mathrm{CD} / 15 \%$ acetonitrile. Injection order, (5 sec at $0.5 \mathrm{psi})$ tag, analyte; all other conditions same as table 3 . Varying mix voltage and mix time values were plotted while holding wait time constant at $9.00 \mathrm{~min}$. The saddle shape generated indicates maximum labeling efficiency at the extremes of the mixing voltage range $(2-10 \mathrm{kV})$ particularly at the median mixing time value $(52.5 \mathrm{sec})$.

In figure 44 the magnitude of the mixing voltage and the length of the mixing time were plotted in relation to one another with the wait time being held constant. This created a saddle-shaped three-dimensional plot where best results were achieved at the extremes of the mix voltage experimental range. 


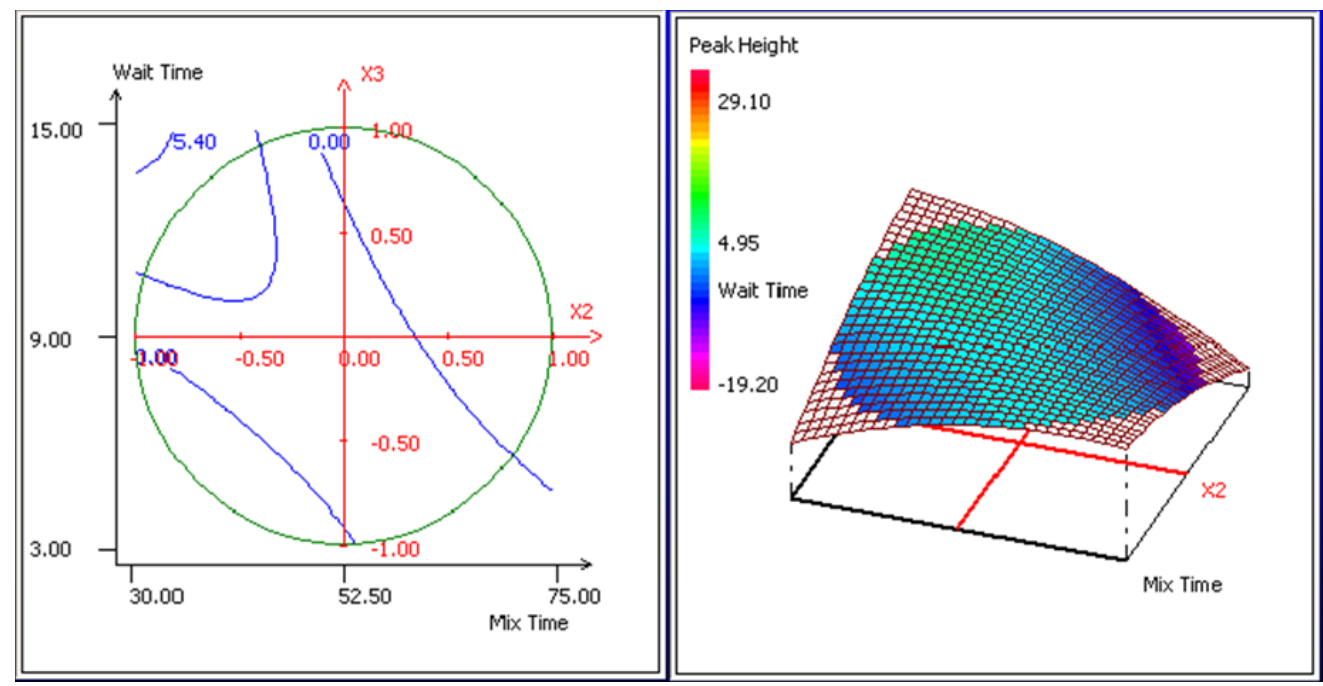

Figure 45: Two-dimensional and three-dimensional contour plots for amphetamine peak in 100ug/mL mixture of five phenethylamines labeled via inline electrokinetic mixing with $40 \mu \mathrm{L}$ of 5.0mM 5-DTAF. Conditions: Fused silica capillary, $50 \mu \mathrm{m}$ I.D., $60 \mathrm{~cm}$ length, $50 \mathrm{~cm}$ effective length; capillary temperature, $35^{\circ} \mathrm{C}$; buffer, $50 \mathrm{mM}$ sodium borate, $\mathrm{pH} 9.5 / 15 \mathrm{mM} \beta-\mathrm{CD} / 10 \mathrm{mg} / \mathrm{mL}$ DM- $\beta-\mathrm{CD} / 15 \%$ acetonitrile. Injection order, (5 sec at $0.5 \mathrm{psi})$ tag, analyte; all other conditions same as table 3 . Varying mix time and wait time values were plotted while holding mix voltage constant at $6.00 \mathrm{kV}$. The bowl shape generated indicates maximum labeling efficiency at the wait time upper extreme value $(15.0 \mathrm{~min})$ and the mixing time lower extreme value $(30.0 \mathrm{sec})$.

For figure 45, mixing time and wait time were plotted while holding the mixing voltage constant. This produced a shape similar to an inverted bowl where the apex runs diagonally across the shape. Based on this it can observed that there is an inverse relationship between these two factors with maximum efficiency when longer wait times are coupled with shorter mixing times. 

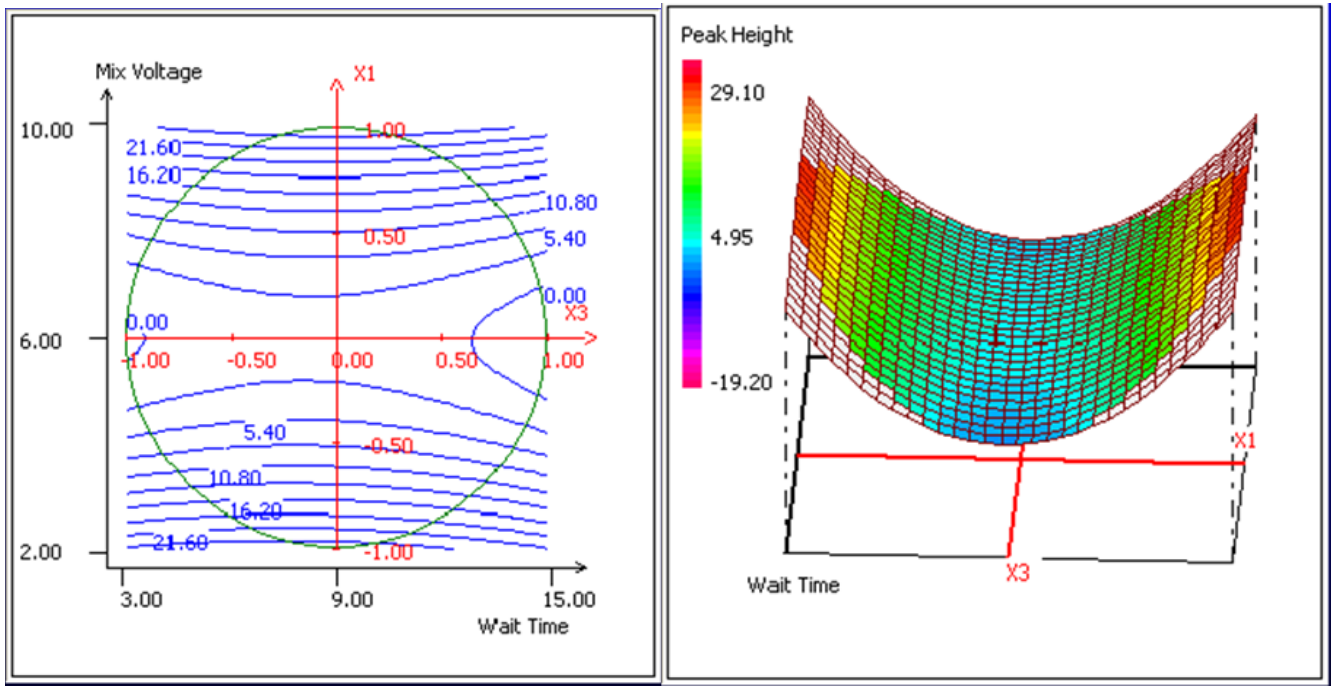

Figure 46: Two-dimensional and three-dimensional contour plots for amphetamine peak in $100 \mathrm{ug} / \mathrm{mL} \mathrm{mixture} \mathrm{of}$ five phenethylamines labeled via inline electrokinetic mixing with $40 \mu \mathrm{L}$ of 5.0mM 5-DTAF. Conditions: Fused silica capillary, $50 \mu \mathrm{m}$ I.D., $60 \mathrm{~cm}$ length, $50 \mathrm{~cm}$ effective length; capillary temperature, $35^{\circ} \mathrm{C}$; buffer, $50 \mathrm{mM}$ sodium borate, pH 9.5/15mM $\beta-C D / 10 \mathrm{mg} / \mathrm{mL}$ DM- $\beta-\mathrm{CD} / 15 \%$ acetonitrile. Injection order, (5 sec at $0.5 \mathrm{psi}$ ) tag, analyte; all other conditions same as table 3 . Varying mix voltage and wait time values were plotted while holding mix time constant at $52.50 \mathrm{sec}$. The saddle shape generated indicates maximum labeling efficiency at the extremes of the mixing voltage range $(2-10 \mathrm{kV})$ particularly at the median wait time value $(9.00 \mathrm{~min})$.

In figure 46, the saddle shape is again produced when varying mixing voltage and wait time are plotted while holding the mixing time constant. These contour plots generated once again suggests that optimal mixing voltage values are at the higher and lower ends of the range regardless of the length of the wait time.

Using the contour plots generated for each analyte in the five drug mixture, the optimal parameters for the electrokinetic mixing of each drug was determined as is summarized in table 7 below. 


\begin{tabular}{|c|c|c|c|c|c|}
\hline \multicolumn{6}{|c|}{ Table 8: Optimal parameter conditions for inline derivatization of each analyte in a mixture. } \\
\hline Parameter & Amphetamine & Methamphetamine & Norephedrine & Ephedrine & MDMA \\
\hline $\begin{array}{c}\text { Mixing } \\
\text { Voltage } \\
\text { (kV) }\end{array}$ & 9 & 10 & 10 & 9 & $9(10)$ \\
\hline $\begin{array}{c}\text { Mixing Time } \\
\text { (sec) }\end{array}$ & 41.25 & $41.25(52.5)$ & 52.5 & 41.25 & $41.25(52.5)$ \\
\hline $\begin{array}{c}\text { Wait Time } \\
\text { (min) }\end{array}$ & 9 & 9 & 11 & 9 & 9 \\
\hline
\end{tabular}

Based on these observations, the overall optimal mixing conditions were determined to be $9.5 \mathrm{kV}$ for $46.875 \mathrm{sec}$, and 9 minutes of wait time. However, under these conditions there was excessive signal produced by the excess 5-DTAF leading peaks being obscured. In order to avoid this, mixing conditions of $8 \mathrm{kV}$ for $33 \mathrm{sec}$, and 9 minutes of wait time were utilized instead. This is illustrated in figure 47 below. 


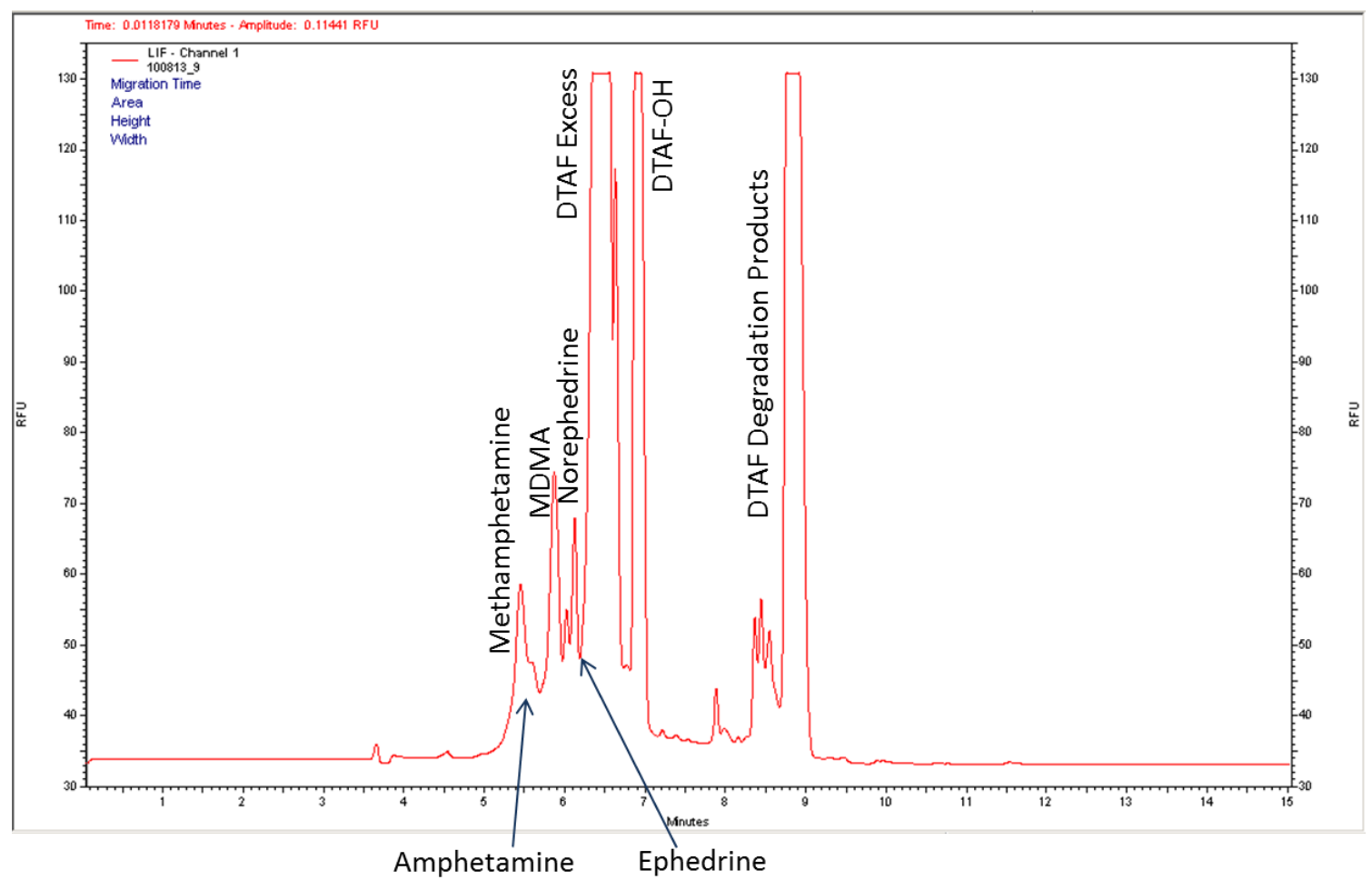

Figure 47: Separation of $100 \mathrm{~g} / \mathrm{mL}$ mixture of five analytes derivatized on-capillary by 1.0mM 5-DTAF. Conditions: Fused silica capillary, $50 \mu \mathrm{m}$ I.D., $60 \mathrm{~cm}$ length, $50 \mathrm{~cm}$ effective length; capillary temperature, $35^{\circ} \mathrm{C} ;$ buffer, $50 \mathrm{mM}$ sodium borate, $\mathrm{pH} 9.5 / 15 \mathrm{mM} \beta-\mathrm{CD} / 10 \mathrm{mg} / \mathrm{mL} D M-\beta-C D / 15 \%$ acetonitrile; mixing voltage, $8 \mathrm{kV}$; mixing time, $33 \mathrm{sec}$; wait time, $9 \mathrm{~min}$; injection order, ( $5 \mathrm{sec}$ at $0.5 \mathrm{psi}$ ) tag, analyte; all other conditions same as table 3.

\begin{tabular}{|c|c|c|c|}
\hline Analyte & $\begin{array}{c}\text { Linear } \\
\text { Regression } \\
\text { Equation } \\
\mathbf{y}=\mathbf{m x}+\mathbf{b}\end{array}$ & $\begin{array}{c}\text { LOD } \\
(\mu \mathrm{g} / \mathrm{mL})\end{array}$ & $\begin{array}{c}\text { Elution Time } \\
\text { (min) }\end{array}$ \\
\hline Amphetamine & $0.4910,15.37$ & 6.1 & $6.5 \pm 0.074$ \\
\hline Methamphetamine & $0.4232,-1.397$ & 7.1 & $6.3 \pm 0.26$ \\
\hline Norephedrine & $0.3970,35.45$ & 7.6 & $6.5 \pm 0.25$ \\
\hline Ephedrine & $0.3773,6.828$ & 8.0 & $5.7 \pm 0.17$ \\
\hline MDMA & $0.7035,7.3989$ & 4.3 & $6.3 \pm 0.23$ \\
\hline
\end{tabular}




\section{CHAPTER 5: CONCLUSIONS}

\subsection{Conclusions}

This research project demonstrates the usefulness of 5-(4,6dichlorotriazinyl)aminofluorescein in the analysis of amphetamine-type stimulants as well as the viability of an inline derivatization method for fluorescence detection in capillary electrophoresis. The reactivity of the 5-DTAF with the analytes of interest made it an excellent reagent for this work despite the complexity of the electropherograms produced as a result of it being a natively fluorescent label. It was determined that efficient inline derivatization of multiple phenethylamines could be achieved using a 5.0mM 5-DTAF solution in ethanol/1,2-dichloroethane (9:1). By injecting the fluorescent tag prior to the analyte, the electrokinetic mixing of the two zones produced higher yields of the DTAF-derivatives. These fluorescent derivatives eluted first due to their faster mobility in comparison to the excess reagent and derivative byproducts. As a result a novel technique for the fast, inline derivatization and separation of multiple phenethylamines was successfully developed.

The work completed also demonstrates the importance of modifiers such as $\beta$ cyclodextrins and organic solvents on separation efficiency. Given how closely related in size and structure these analytes are prior to and after derivatization, traditional zone electrophoresis is not capable of separating these compounds. It is only after the introduction of $\beta$-cyclodextrins (which form inclusion complexes to varying degrees with the different derivatives) and acetonitrile (which reduces the electroosmotic flow to allow the analyte zones to spread out more) that separation of individual compounds from a 
mixture is obtained. The behavior of these compounds in the running buffer was discussed with particular attention paid to the type and concentration of the $\beta$-CDs utilized as well as the amount of organic solvent added.

This resulted in the adoption of a $50 \mathrm{mM}$ sodium borate, $\mathrm{pH} 9.5 / 15 \mathrm{mM} \beta-$ $\mathrm{CD} / 10 \mathrm{mg} / \mathrm{mL} \mathrm{DM}-\beta-\mathrm{CD} / 15 \%$ acetonitrile running buffer. The modifiers utilized and their concentrations were determined through a systematic analysis of their effects on the baseline resolution between analyte peaks. It was found that cyclodextrin concentrations surpassing the optimal levels determined had greatly diminished solubility in the run buffer solution. Due to this, heat dissipation along the length of the capillary was reduced leading to the cyclodextrins precipitating and creating blockages. It was also found that as the concentration of acetonitrile increased, so did the degree of peak separation. However, it was observed that this trend reached its apex at 15\% after which point the resolution experienced a downturn. This portion of this work further highlighted the significant effect optimization of the run buffer composition can on sensitivity and selectively.

An efficient way of predicting the effect of changes in different parameters and optimal conditions is through the usage of predictive modeling software. These software suites allow users to choose the type of statistical model used (Doehlert, Box-Behnken, etc.), the variables being assessed, and the experimental region they will be applied to. In this work the experimental design program, Nemrodw, was utilized to determine the optimal conditions for the inline derivatization method developed by assessing 
electrokinetic mixing voltage, length of time for the mixing step, and length of the standby time (for longitudinal diffusion to take place).

\subsection{Future Work}

The development of an inline derivatization with laser-induced fluorescence detection marks a significant step in the development of truly complete portable electrophoretic systems. In the work done by Lloyd et al [47], the Agilent Bioanalyzer lab-on-a-chip system, which was developed for DNA and protein analysis, was used for the analysis of ATS using fluorescein isothiocyanate (FITC) as the label and a borate/SDS buffer. The labeling in this was done prior to injection in foil-lined tubes. If this could all be done in the chip, this method would be very useful in a forensic setting as it could be completely automated.

Other microfluidic systems such as the M150 by Cascade Microtech utilize both commercially available glass electrophoretic chips and custom-designed polymer-based chips. The ability to integrate an online derivatization method into these existing systems either as they are or via the attachment of nanoports (increasing sample well sizes) would assist in the development of a fully automated and portable analytical method for presumptive testing of seized samples. This would be especially useful given the rapid proliferation of designer phenethylamine-based compounds.

Also, the incorporation of a demethylation method for tertiary amines, such as the one utilized by Alnajjar et al [3], would greatly extend the usefulness of the method by allowing the analysis of other drugs of abuse such as cocaine and heroin. This is 
particularly of interest as many seized samples which are purported to be phenethylamines are often cut or contaminated with other substances. Being able to identify all the components of a seized pill can make determining if toxic interactions play a role in drug-related sudden death cases. 


\section{REFERENCES}

1. Abdel-Hay, K. M.; Awad, T.; DeRuiter, J.; Clark, C. R. Differentiation of methylenedioxybenzylpiperazines (MDBPs) and methoxymethylbenzylpiperazines (MMBPs) By GC-IRD and GC-MS. Forensic Sci. Int. 2011, 210, 122-128.

2. Allen, A.; Cantrell, T.S. Synthetic Reductions in Clandestine Amphetamine and Methamphetamine Laboratories - A Review. Forensic Sci. Int. 1989, 42, 183199.

3. Al Najjar, A. O. Enhancement of Sensitivity in Capillary Electrophoresis: Forensic and Pharmaceutical Applications, Ohio University, Athens, Ohio, 2004.

4. Anastos, N.; Barnett, N. W.; Lewis, S. W. Capillary electrophoresis for forensic drug analysis: A review. Talanta 2005, 67, 269-279.

5. Aoyama, C.; Santa, T.; Tsunoda, M.; Fukushima, T.; Kitada, C.; Imai, K. A fully automated amino acid analyzer using NBD-F as a fluorescent derivatization reagent. Biomedical Chromatography, Biomed. Chromatogr 2004, 18, 630.

6. Araujo, P. W.; Brereton, R. G. Experimental design II. Optimization. TrAC, Trends Anal. Chem. 1996, 15, 63-70.

7. Araujo, P.; Janagap, S. Doehlert uniform shell designs and chromatography. Journal of Chromatography B 2012, 910, 14-21.

8. Aubrey, A.D.; Chalmers, J.H.; Bada, J.L.; Grunthaner, F.J.; et al. The Urey Instrument: An Advanced In Situ Organic and Oxidant Detector for Mars Exploration. Astrobiology 2008, 8, 1-13.

9. Bishop, S. C.; Lerch, Margaret; McCord, B. R. Micellar electrokinetic chromatographic screening method for common sexual assault drugs administered in beverages. Forensic Science International 2004, 141, 7.

10. Bishop, S. C.; McCord, B. R.; Gratz, S. R.; Loeliger, J. R.; Witkowski, M. R. Simultaneous Separation of Different Types of Amphetamine and Piperazine Designer Drugs by Capillary Electrophoresis with a Chiral Selector. Journal of Forensic Sciences, J Forensic Sci 2005, 50, 1.

11. Boulos, S.; Cabrices, O.; Blas, M.; McCord, B. R. Development of an entangled polymer solution for improved resolution in DNA typing by CE. Electrophoresis 2008, 29, 4695-4703.

12. Brettell, T.A.; Butler, J.M.; Almirall, J.R. Forensic Science. Analytical Chemistry 2007, 79, 4365 . 
13. Brettell, T.A.; Butler, J.M.; Almirall, J.R. Forensic Science. Analytical Chemistry 2009, 81, 4695 .

14. Brunton, L.L.; Lazo, J.S.; Parker, K.L. Gilman's and Goodman's the pharmacological basis of therapeutics; MacMillan: New York [u.a., 1985.

15. Casarett, L.J.; Doull, J.; Klaassen, C.D. Casarett and Doull's toxicology: the basic science of poisons; McGraw-Hill: New York [u.a.], 2001.

16. Chen, B.; Liu, J.; Chen, W.; Chen, H.; Lin, C. A general approach to the screening and confirmation of tryptamines and phenethylamines by mass spectral fragmentation. Talanta 2008, 74, 512-517.

17. Chen, M. L.; Suo, L. L.; Gao, Q.; Feng, Y. Q. Determination of eight illegal drugs in human urine by combination of magnetic solid-phase extraction with capillary zone electrophoresis. Electrophoresis 2011, 32, 2099-2106.

18. Concheiro, M.; dos Santos Sadler Simoes, S.M.; Quintela, O.; de Castro, A.; et al. Fast LC-MS/MS method for the determination of amphetamine, methamphetamine, MDA, MDMA, MDEA, MBDB and PMA in urine. Forensic Science International 2006, 171, 44-51.

19. Deng, Y.; Zhang, H.; Du, X.; Wang, H. Quantitation of biogenic amines in human plasma base on the derivatization with N-hydroxysuccinamidyl fluorescein-Oacetate by high-performance liquid chromatography. J Sep Sci 2008, 31, 990-998.

20. Drake, S. J.; Morrison, C.; Smith, F. Simultaneous chiral separation of methylamphetamine and common precursors using gas chromatography/mass spectrometry. Chirality 2011, 23, 593-601.

21. Drummer, O. H.; Odell, M. The Forensic Pharmacology of Drugs of Abuse; Arnold: Great Britain, 2001.

22. Elie, L.; Baron, M.; Croxton, R.; Elie, M. Microcrystalline identification of selected designer drugs. Forensic Sci. Int. 2012, 214, 182-188.

23. Fanali, S.; Aturki, Z.; Desiderio, C. New strategies for chiral analysis of drugs by capillary electrophoresis. Forensic Sci. Int. 1998, 92, 137-155.

24. Fanali, S.; Cristalli, M.; Vespalec, R.; Bocek, P. Chiral separations in capillary electrophoresis. Adv. Electrophor. 1994, 7, 1-86.

25. Fanali, S.; Desiderio, C.; Aturki, Z. Enantiomeric resolution study by capillary electrophoresis. Selection of the appropriate chiral selector. J. Chromatogr. A 1997, 772, 185-194. 
26. Ferrance, J.; Landers, J. P. Exploiting sensitive laser-induced fluorescence detection on electrophoretic microchips for executing rapid clinical diagnostics. Luminescence 2001, 16, 79-88.

27. Ferreira, S. L. C.; Dos Santos, W. N. L.; Quintella, C. M.; Neto, B. B.; BosqueSendra, J. M. Doehlert matrix: a chemometric tool for analytical chemistryreview. Talanta 2004, 63, 1061-1067.

28. Furlanetto, S.; Orlandini, S.; La Porta, E.; Coran, S.; Pinzauti, S. Optimization and validation of a CZE method for rufloxacin hydrochloride determination in coated tablets. J. Pharm. Biomed. Anal. 2002, 28, 1161-1171.

29. Gübitz, G.; Schmid, M. G. Chiral separation by capillary electromigration techniques. Journal of Chromatography A 2008, 1204, 140-156.

30. Habrdova, V.; Peters, F.T.; Theobald, D.S.; Maurer, H.H. Screening for and validated quantification of phenethylamine-type designer drugs and mescaline in human blood plasma by gas chromatography/mass spectrometry. Journal of Mass Spectrometry, 2005, 40, 785 .

31. Hibbert, D. B. Experimental design in chromatography: A tutorial review. Journal of Chromatography B 2012, 910, 2-13.

32. Higashi, Y.; Nakamura, S.; Matsumura, H.; Fujii, Y. Simultaneous liquid chromatographic assay of amantadine and its four related compounds in phosphate-buffered saline using 4-fluoro-7-nitro-2,1,3-benzoxadiazole as a fluorescent derivatization agent. Biomedical Chromatography 2006, $20,423$.

33. Johnson, I.; Spence, M.T.Z., Ed.; Molecular Probes Handbook, A Guide to Fluorescent Probes and Labeling Technologies, $11^{\text {th }}$ Edition; Invitrogen, 2010.

34. Jouyban-Gharamaleki, A.; Khaledi, M. G.; Clark, B. J. Calculation of electrophoretic mobilities in water-organic modifier mixtures in capillary electrophoresis. J. Chromatogr. A 2000, 868, 277-284.

35. Kato, M.; Gyoten, Y.; Sakai-Kato, K.; Toyo'oka, T. Rapid analysis of amino acids in Japanese green tea by microchip electrophoresis using plastic microchip and fluorescence detection. J Chromatogr A 2003, 1013, 183-189.

36. Khalaf, H.; Steinert, J. Determination of secondary amines as highly fluorescent formamidines by high-performance liquid chromatography. Analytica Chimica Acta 1996, 334, 45.

37. Kuroda, N.; Nomura, R.; Al-Dirbashi, O.; Akiyama, S.; Nakashima, K. Determination of methamphetamine and related compounds by capillary electrophoresis with UV and laser-induced fluorescence detection. J Chromatogr A 1998, 798, 325-334. 
38. Lacroix, M.; Poinsot, V.; Fournier, C.; Couderc, F. Laser-induced fluorescence detection schemes for the analysis of proteins and peptides using capillary electrophoresis. Electrophoresis 2005, 26, 2608-2621.

39. Laing, R. R., Ed.; Siegel, J. A., Ed.; Hallucinogens: A Forensic Drug Handbook; Academic Press: San Diego, CA, USA, 2003.

40. Landers, J. P., Ed.; Handbook of Capillary and Microchip Electrophoresis and Associated Microtechniques; CRC Press: Boca Raton, FL, USA, 2008.

41. Landers, J. P. Handbook of capillary electrophoresis; CRC Press: Boca Raton, FL, USA, 1997.

42. Leardi, R. Experimental design in chemistry: A tutorial. Anal. Chim. Acta 2009, $652,161-172$.

43. Lemos, N. P.; Bortolotti, F.; Manetto, G.; Anderson, R. A.; Cittadini, F.; Tagliaro, F. Capillary electrophoresis: a new tool in forensic medicine and science. Sci. Justice 2001, 41, 203-210.

44. Levine, B. Principles of forensic toxicology; American Association for Clinical Chemistry: [Washington, D.C.], 1999; .

45. Li, S. F. Y. Capillary Electrophoresis: Principles, Practice and Applications; Journal of Chromatography Library; Elsevier Science: Amsterdam, The Netherlands, 1992; Vol. 52, pp 582.

46. Liu, L.; Zheng, Z.; Lin, J. Application of dimethyl-beta-cyclodextrin as a chiral selector in capillary electrophoresis for enantiomer separation of ephedrine and related compounds in some drugs. Biomedical Chromatography 2005, 19, 447.

47. Lloyd, A.; Blanes, L.; Beavis, A.; Roux, C.; Doble, P. A rapid method for the infield analysis of amphetamines employing the Agilent Bioanalyzer. Analytical Methods, 2011, 3, 1535.

48. Lomsadze, K.; Dominguez Vega, E.; Salgado, A.; Crego, A. L.; Scriba, G. K. E.; Marina, M. L.; Chankvetadze, B. Separation of enantiomers of norephedrine by capillary electrophoresis using cyclodextrins as chiral selectors: Comparative CE and NMR studies. Electrophoresis 2012, 33, 1637.

49. Lurie, Ira S. Capillary electrophoresis of illicit drug seizures. Forensic Science International 1998, 92, 125.

50. Lurie, I. S.; Bozenko Jr., J. S.; Li, L.; Miller, E. E.; Greenfield, S. J. Separation of Methamphetamine and Related Compounds using Capillary Electrophoresis with Dynamically Coated Capillaries. Microgram Journal , 8, 24. 
51. Mandrioli, R.; Mercolini, L.; Raggi, M. A. Chiral analysis of amphetamines, methadone and metabolites in biological samples by electrodriven methods. Electrophoresis 2011, 32, 2629-2639.

52. Mateus, L.; Cherkaoui, S.; Christen, P.; Veuthey, J. Use of a Doehlert design in optimizing the analysis of selected tropane alkaloids by micellar electrokinetic capillary chromatography. J. Chromatogr. A 1998, 829, 317-325.

53. McCord, B. R.; Turner, C.; Blas, M.; Bishop, S. C.; Lerch, M.; Dehere, S.; Pannepucci, R. Development of Microfluidic Devices for the Rapid Isolation and Detection of Drugs of Abuse. National Institute of Justice, 2004-WG-BX-K077.

54. Meng, L.; Wang, B.; Luo, F.; Shen, G.; Wang, Z.; Guo, M. Application of dispersive liquid-liquid microextraction and CE with UV detection for the chiral separation and determination of the multiple illicit drugs on forensic samples. Forensic Sci. Int. 2011, 209, 42-47.

55. Meng, P.; Fang, N.; Wang, M.; Liu, H.; Chen, D. D. Y. Analysis of amphetamine, methamphetamine and methylenedioxy-methamphetamine by micellar capillary electrophoresis using cation-selective exhaustive injection. Electrophoresis 2006, 27, 3210-3217.

56. Mohr, S.; Pilaj, S.; Schmid, M. G. Chiral separation of cathinone derivatives used as recreational drugs by cyclodextrin-modified capillary electrophoresis. Electrophoresis 2012, 33, 1624.

57. Molina, M.; Silva, M. In-capillary derivatization and analysis of amino acids, amino phosphonic acid-herbicides and biogenic amines by capillary electrophoresis with laser-induced fluorescence detection. Electrophoresis 2002, 23, 2333-2340.

58. Morrison, C.; Smith, F. J.; Tomaszewski, T.; Stawiarska, K.; Biziuk, M. Chiral gas chromatography as a tool for investigations into illicitly manufactured methylamphetamine. Chirality 2011, 23, 519-522.

59. Negrusz, Adam., Cooper,Gail Audrey Ann., Clarke's analytical forensic toxicology; Pharmaceutical Press: London, 2013; .

60. Okhonin, V.; Liu, X.; Krylov, S. N. Transverse Diffusion of Laminar Flow Profiles to Produce Capillary Nanoreactors. Anal. Chem. 2005, 77, 5925.

61. Paez, Ximena; Hernandez, Luis. Biomedical Applications of Capillary Electrophoresis with Laser-Induced Fluorescence Detection. Biopharmaceutics \& Drug Disposition 2001, 22, 273. 
62. Pascali, J. P.; Bortolotti, F.; Tagliaro, F. Recent advances in the application of CE to forensic sciences, an update over years 2009-2011. Electrophoresis 2012, 33, 117-126.

63. Paugam, L.; Menard, R.; Larue, J. -.; Thouvenot, D. Optimization of glucosinolate separation by micellar electrokinetic capillary chromatography using a Doehlert's experimental design. J. Chromatogr. A 1999, 864, 155-162.

64. Ramseier, A.; von Heeren, F.; Thormann, W. Analysis of fluorescein isothiocyanate derivatized amphetamine and analogs in human urine by capillary electrophoresis in chip-based and fused-silica capillary instrumentation. Electrophoresis 1998, 19, 2967-2975.

65. Riekkola, M.; Jussila, M.; Porras, S. P.; Valko, I. E. Non-aqueous capillary electrophoresis. J. Chromatogr. A 2000, 892, 155-170.

66. Romao, W.; Lalli, P. M.; Franco, M. F.; Sanvido, G.; Schwab, N. V.; Lanaro, R.; Costa, J. L.; Sabino, B. D.; Bueno, M. I. M. S.; de Sa, G. F.; Daroda, R. J.; de Souza, V.; Eberlin, M. N. Chemical profile of meta-chlorophenylpiperazine (m$\mathrm{CPP}$ ) in ecstasy tablets by easy ambient sonic-spray ionization, X-ray fluorescence, ion mobility mass spectrometry and NMR. Anal. Bioanal. Chem. 2011, 400, 3053-3064.

67. Ruppel, T. D. Drugs of Abuse in Urine by GC/MS Following SAMHSA (NIDA) Procedures. PerkinElmer Application Note 2008.

68. Russell, M. J.; Bogun, B. New "party pill" components in New Zealand: The synthesis and analysis of some $\hat{\mathrm{I}}^{2}$-ketone analogues of 3,4methylenedioxymethamphetamine (MDMA) including $\hat{\mathrm{I}}^{2} \mathrm{k}-\mathrm{DMBDB}\left(\hat{\mathrm{I}}^{2}\right.$-ketoneN,N-dimethyl-1-(1,3-benzodioxol-5-yl)-2-butanamine). Forensic Sci. Int. 2011, 210, 174-181.

69. Ruyters, H.; van der Wal, S. Enantiomeric Analysis of Primary and Secondary Amines by Fully Automated Derivatization on a P/ACE System with LIF Detection. Beckman Coulter Application Information: Amino Acids 1993, A-1754, $1-4$.

70. Sanchez-Hernandez, L.; Castro-Puyana, M.; Marina, M. L.; Crego, A. L. Recent approaches in sensitive enantioseparations by CE. Electrophoresis 2012, 33, 228242.

71. Santagati, N. A.; Ferrara, G.; Marrazzo, A.; Ronsisvalle, G. Simultaneous determination of amphetamine and one of its metabolites by HPLC with electrochemical detection. J. Pharm. Biomed. Anal. 2002, 30, 247-255. 
72. Sarmini, K.; Kenndler, E. Influence of organic solvents on the separation selectivity in capillary electrophoresis. J. Chromatogr. A 1997, 792, 3-11.

73. Skoog, D.A.; Holler, F.J.; Nieman, T.A. Principles of Instrumental Analysis $5^{\text {th }}$ Ed. Harcourt Brace.: Philidelphia, PA, USA, 1998.

74. Steiner, F.; Hassel, M. Influence of solvent properties on separation and detection performance in non-aqueous capillary electrophoresis-mass spectrometry of basic analytes. J. Chromatogr. A 2005, 1068, 131-142.

75. Stojanovska, N.; Fu, S.; Tahtouh, M.; Kelly, T.; Beavis, A.; Kirkbride, K. P. A review of impurity profiling and synthetic route of manufacture of methylamphetamine, 3,4-methylenedioxymethylamphetamine, amphetamine, dimethylamphetamine and p-methoxyamphetamine. Forensic Science International 2013, 224, 8 .

76. Suzuki, S.; Shimotsu, N.; Honda, S.; Arai, A.; Nakanishi, H. Rapid analysis of amino sugars by microchip electrophoresis with laser-induced fluorescence detection. Electrophoresis 2001, 22, 4023.

77. Taga, A.; Honda, S. Derivatization at capillary inlet in high-performance capillary electrophoresis Its reliability in quantification. J Chromatogr A 1996, 742, 243.

78. Taga, A.; Nishino, A.; Honda, S. Characteristic features of the throughoutcapillary technique of in-capillary derivatization in capillary electrophoresis. $J$ Chromatogr A 1998, 822, 271.

79. Taga, A.; Sugimura, M.; Honda, S. Derivatization of amino acids in a moving zone of o-phthalaldehyde in the middle of a capillary for amino acid analysis by capillary electrophoresis. J Chromatogr A 1998, 802, 243-248.

80. Tagliaro, F.; Bortolotti, F. Recent advances in the applications of CE to forensic sciences (2005-2007). Electrophoresis 2008, 29, 260-268.

81. Tagliaro, F.; Bortolotti, F. Recent advances in the applications of CE to forensic sciences (2001-2004). Electrophoresis 2006, 27, 231-243.

82. Tagliaro, F.; Bortolotti, F.; Pascali, J. P. Current role of capillary electrophoretic/electrokinetic techniques in forensic toxicology. Anal. Bioanal. Chem. 2007, 388, 1359-1364.

83. Tagliaro, F.; Pascali, J.; Fanigliulo, A.; Bortolotti, F. Recent advances in the application of CE to forensic sciences: A update over years 2007-2009. Electrophoresis 2010, 31, 251-259.

84. Tagliaro, F.; Turrina, S.; Pisi, P.; Smith, F. P.; Marigo, M. Determination of illicit and/or abused drugs and compounds of forensic interest in biosamples by 
capillary electrophoretic/electrokinetic methods. J. Chromatogr. B: Biomed. Sci. Appl. 1998, 713, 27-49.

85. Taylor, R.B.; Low, A.S.; Reid, R.G. Determination of opiates in urine by capillary electrophoresis. Journal of Chromatography B 1996, 675, 213.

86. Thormann, W.; Aebi, Y.; Lanz, M.; Caslavska, J. Capillary electrophoresis in clinical toxicology. Forensic Sci. Int. 1998, 92, 157-183.

87. Toyo'oka, T.; Mantani, T.; Kato, M. Characterization of labelling and de-labelling reagents for detection and recovery of tyrosine residue in peptide. Biomedical Chromatography 2003, 17, 133.

88. Trabelsi, S.; Oturan, N.; Bellakhal, N.; Oturan, M. A. Application of Doehlert matrix to determine the optimal conditions for landfill leachate treatment by electro-Fenton process. J. Mater. Environ. Sci. 2012, 3, 426-433.

89. Trenerry, V. C.; Robertson, J.; Wells, R. J. Analysis of illicit amphetamine seizures by capillary electrophoresis. Journal of Chromatography A 1995, 708, 169.

90. Tsunoda, M.; Kato, M.; Fukushima, T.; Santa, T.; Homma, H.; Yanai, H.; Soga, T.; Imai, K. Determination of aspartic acid enantiomers in bio-samples by capillary electrophoresis. Biomedical Chromatography 1999, 13, 335.

91. UNIDCP Rapid Testing Methods of Drugs of Abuse. United Nations publication 1994.

92. UNODC World Drug Report 2013. United Nations publication 2013.

93. UNODC Recommended Methods for the Identification and Analysis of Amphetamine, Methamphetamine and their Ring-substituted Analogues in Seized Materials. United Nations publication 2006.

94. Vega, E. D.; Lomsadze, K.; Chankvetadze, L.; Salgado, A.; Scriba, G. K. E.; Calvo, E.; Lopez, J. A.; Crego, A. L.; Marina, M. L.; Chankvetadze, B. Separation of enantiomers of ephedrine by capillary electrophoresis using cyclodextrins as chiral selectors: Comparative CE, NMR and high resolution MS studies. Electrophoresis 2011, 32, 2640.

95. Veledo, M. T.; de Frutos, M.; Diez-Masa, J. C. Amino acid determination using capillary electrophoresis with on-capillary derivatization and laser-induced fluorescence detection. J Chromatogr A 2005, 1079, 335-343.

96. Verpoote, E. Microfluidic chips for clinical and forensic analysis. Electrophoresis 2002, 23, 677-712. 
97. Wallenborg, S. R.; Lurie, I. S.; Arnold, D. W.; Balley, C. G. On-chip chiral and achiral separation of amphetamine and related compounds labeled with 4-fluoro7-nitrobenzofurazane. Electrophoresis 2000, 21, 3257.

98. Wang, H.; Lu, M.; Mei, N.; Lee, J.; Weinfeld, M.; Le, X. C. Immunoassays using capillary electrophoresis laser induced fluorescence detection for DNA adducts. Anal Chim Acta 2003, 500, 13-20.

99. Waterval, J. C. M.; Lingeman, H.; Bult, A.; Underberg, W. J. M. Derivatization trends in capillary electrophoresis. Electrophoresis 2000, 21, 4029-4045.

100. Weinberger, R.; Lurie, I. S. Micellar Electrokinetic Capillary Chromatography of Illicit Drug Substances. Anal. Chem. 1991, 63, 823.

101. Westphal, F.; Junge, T.; Girreser, U.; Stobbe, S.; Perez, S. B. Structure elucidation of a new designer benzylpiperazine: 4-Bromo-2,5dimethoxybenzylpiperazine. Forensic Sci. Int. 2009, 187, 87-96.

102. White, M. FSS Report on Methylamphetamine: Chemistry, Seizure Statistics, Analysis, Synthetic Routes and History of Illicit Manufacutre in the UK and the USA for the ACMD Working Group on Methylamphetamine. The Forensic Science Service 2004, 63.

103. Wicks, D. A.; Li, P. C. H. Separation of fluorescent derivatives of hydroxylcontaining small molecules on a microfluidic chip. Anal Chim Acta 2004, 507, 107-114.

104. Wong, E.; Okhonin, V.; Berezovski, M. V.; Nozaki, T.; Waldmann, H.; Alexandrov, K.; Krylov, S. N. "Inject-Mix-React-Separate-and-Quantitate" (IMReSQ) Method for Screening Enzyme Inhibitors. Journal of the American Chemical Society 2008, 130, 11862.

105. Yassine, O.; Morin, P.; Dispagne, O.; Renaud, L.; Denoroy, L.; Kleimann, P.; Faure, K.; Rocca, J. L.; Ouaini, N.; Ferrigno, R. Electrophoresis PDMS/glass chips with continuous on-chip derivatization and analysis of amino acids using naphthalene-2,3-dicarboxaldehyde as fluorogenic agent. Anal Chim Acta 2008, $609,215-222$.

106. Zhang, H.; Le Potier, I.; Smadja, C.; Zhang, J.; Taverna, M. Fluorescent detection of peptides and amino acids for capillary electrophoresis via on-line derivatization with 4-fluoro-7-nitro-2,1,3-benzoxadiazole. Anal Bioanaly Chem 2006, 386, 1387-1394.

107. Zhang, L.; Wang, R.; Yu, Y.; Zhang, Y. Capillary electrophoresis with laserinduced fluorescence and pre-column derivatization for the analysis of illicit drugs. J Chromatogr B 2007, 857, 130-135. 
108. Zhao, S.; Feng, Y.; LeBlanc, M. H.; Piletz, J. E.; Liu, Y. Quantitation of agmatine by liquid chromatography with laser-induced fluorescence detection. Analytica Chimica Acta 2002, 470, 155.

109. Zhou, L.; Luo, Z.; Wang, S.; Hui, Y.; Hu, Z.; Chen, X. In-capillary derivatization and laser-induced fluorescence detection for the analysis of organophosphorus pesticides by micellar electrokinetic chromatography. Journal of Chromatography A 2007, 1149, 377.

110. Zhu, X.; Shaw, P. N.; Barrett, D. A. Catecholamines derivatized with 4-fluoro-7nitro-2,1,3-benzoxadiazole: characterization of chemical structure and fluorescence properties. Analytica Chimica Acta, 2003, 478, 259. 


\section{APPENDICES}

1. Structures and substituent positions of various phenethylamines of interest.

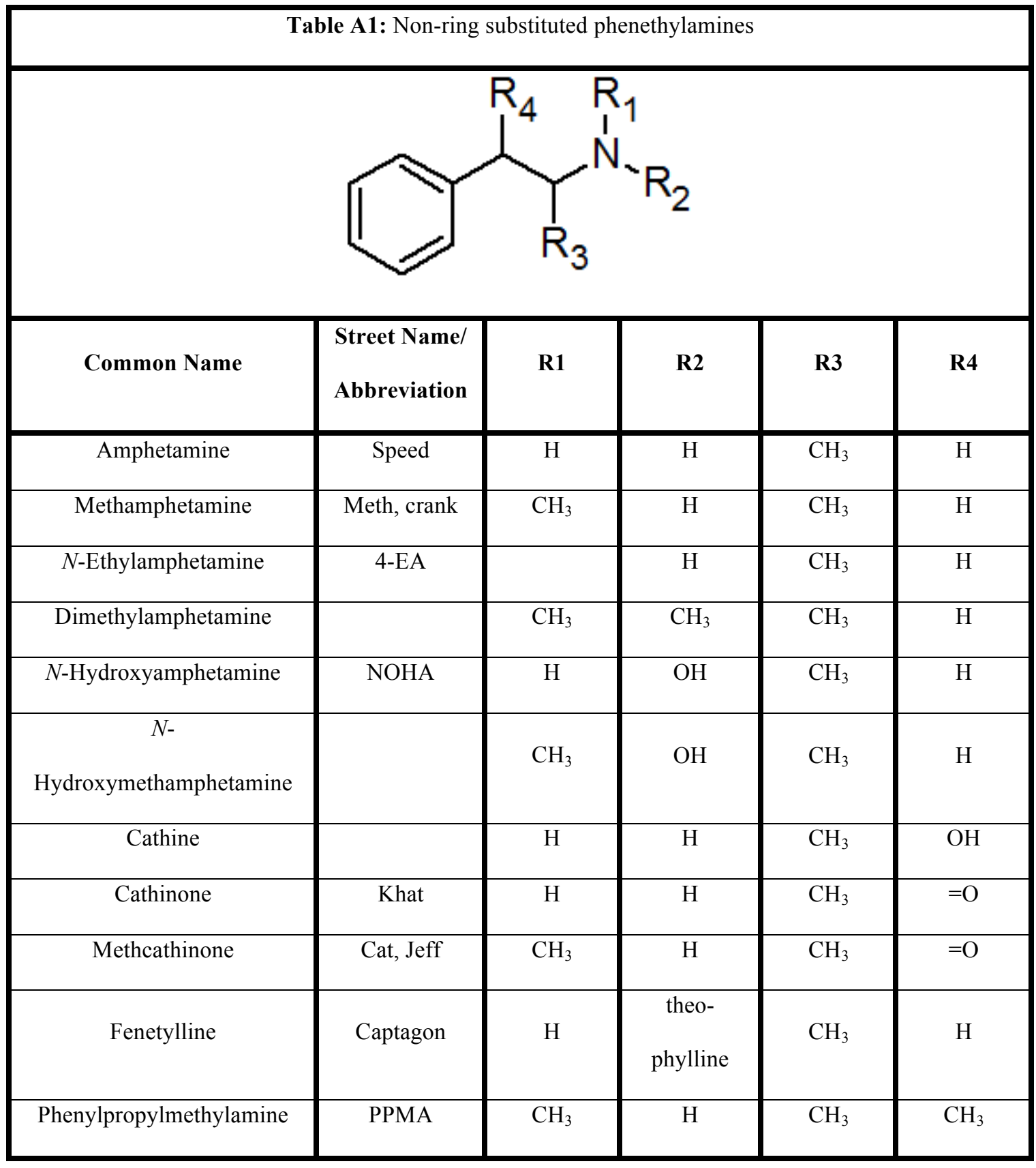




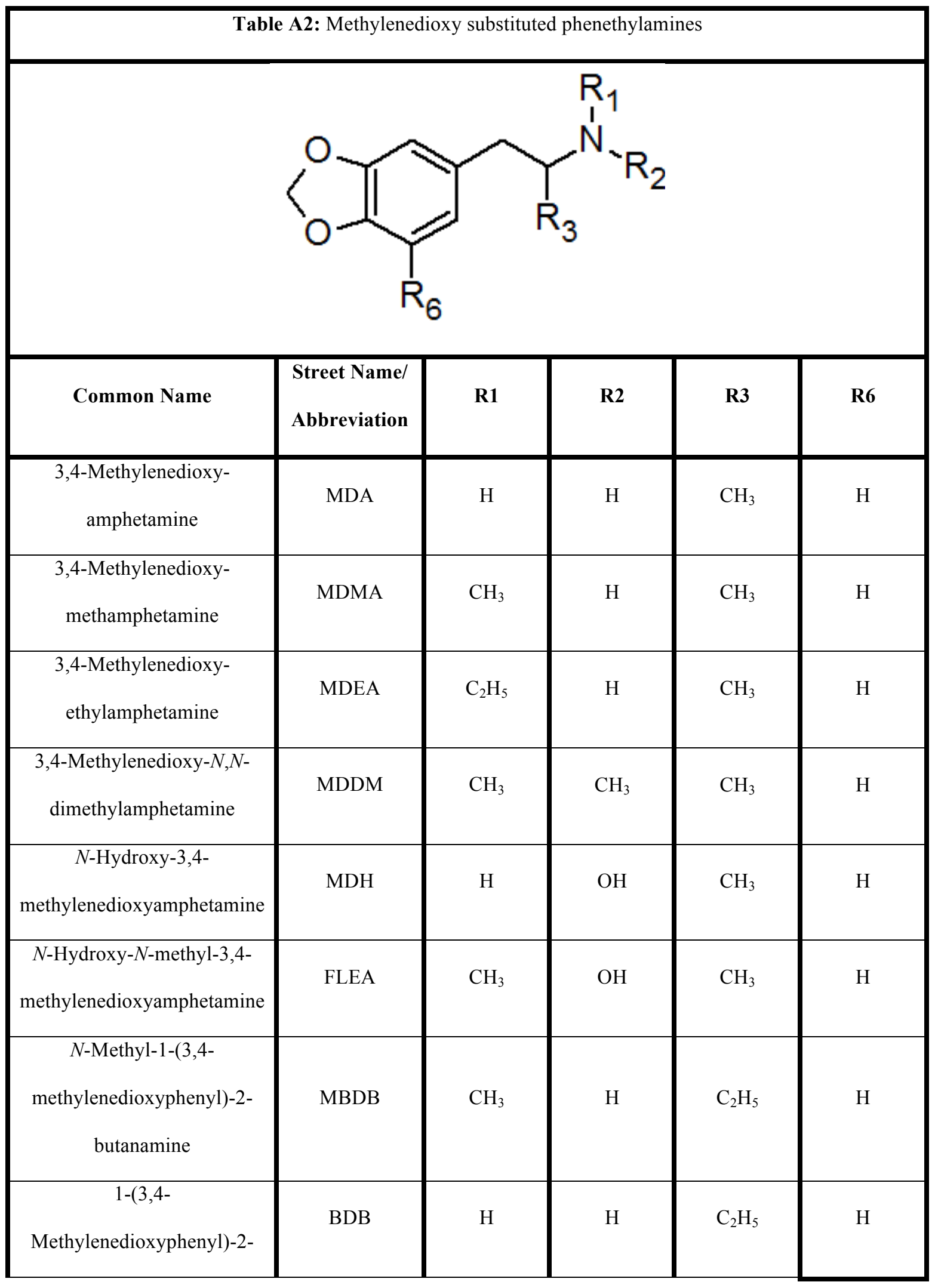




\begin{tabular}{|c|c|c|c|c|c|}
\hline butanamine & & & & \\
\hline $\begin{array}{c}\text { 5-Methoxy-3,4- } \\
\text { methylenedioxyamphetamine }\end{array}$ & MMDA & $\mathrm{H}$ & $\mathrm{H}$ & $\mathrm{CH}_{3}$ & $\mathrm{OCH}_{3}$ \\
\hline
\end{tabular}




\begin{tabular}{|c|c|c|c|c|c|c|c|}
\hline \multicolumn{8}{|c|}{ Table A3: Other ring substituted phenethylamines } \\
\hline & & & & -1 & & & \\
\hline Common Name & $\begin{array}{l}\text { Street Name/ } \\
\text { Abbreviation }\end{array}$ & R1 & $\mathbf{R 3}$ & R5 & R6 & R7 & $\mathbf{R 8}$ \\
\hline \multicolumn{8}{|c|}{ 2,4,5-Ring substituted phenethylamines } \\
\hline $\begin{array}{c}\text { 4-Bromo-2,5- } \\
\text { dimethoxyphenethylamine }\end{array}$ & $2 \mathrm{C}-\mathrm{B}$ & $\mathrm{H}$ & $\mathrm{H}$ & $\mathrm{OCH}_{3}$ & $\mathrm{H}$ & $\mathrm{Br}$ & $\mathrm{OCH}_{3}$ \\
\hline $\begin{array}{c}\text { 4-Methylthio-2,5- } \\
\text { dimethoxyphenethylamine }\end{array}$ & $2 \mathrm{C}-\mathrm{T}$ & $\mathrm{H}$ & $\mathrm{H}$ & $\mathrm{OCH}_{3}$ & $\mathrm{H}$ & $\mathrm{SCH}_{3}$ & $\mathrm{OCH}_{3}$ \\
\hline $\begin{array}{c}\text { 4-Ethylthio-2,5- } \\
\text { dimethoxyphenethylamine }\end{array}$ & $2 \mathrm{C}-\mathrm{T}-2$ & $\mathrm{H}$ & $\mathrm{H}$ & $\mathrm{OCH}_{3}$ & $\mathrm{H}$ & $\mathrm{SC}_{2} \mathrm{H}_{5}$ & $\mathrm{OCH}_{3}$ \\
\hline $\begin{array}{c}\text { 4-Propylthio-2,5- } \\
\text { dimethoxyphenethylamine }\end{array}$ & $2 \mathrm{C}-\mathrm{T}-7$ & $\mathrm{H}$ & $\mathrm{H}$ & $\mathrm{OCH}_{3}$ & $\mathrm{H}$ & $\mathrm{SC}_{3} \mathrm{H}_{7}$ & $\mathrm{OCH}_{3}$ \\
\hline $\begin{array}{c}\text { 4-Chloro-2,5- } \\
\text { dimethoxyphenethylamine }\end{array}$ & $2 \mathrm{C}-\mathrm{C}$ & $\mathrm{H}$ & $\mathrm{H}$ & $\mathrm{OCH}_{3}$ & $\mathrm{H}$ & $\mathrm{Cl}$ & $\mathrm{OCH}_{3}$ \\
\hline $\begin{array}{c}\text { 4-Iodo-2,5- } \\
\text { dimethoxyphenethylamine }\end{array}$ & $2 \mathrm{C}-\mathrm{I}$ & $\mathrm{H}$ & $\mathrm{H}$ & $\mathrm{OCH}_{3}$ & $\mathrm{H}$ & I & $\mathrm{OCH}_{3}$ \\
\hline \multicolumn{8}{|c|}{ 2,4,5-Ring substituted phenethylamines } \\
\hline $\begin{array}{c}2,4,5- \\
\text { Trimethoxyamphetamine }\end{array}$ & TMA-2 & $\mathrm{H}$ & $\mathrm{CH}_{3}$ & $\mathrm{OCH}_{3}$ & $\mathrm{H}$ & $\mathrm{OCH}_{3}$ & $\mathrm{OCH}_{3}$ \\
\hline 4-Methyl-2,5- & DOM & $\mathrm{H}$ & $\mathrm{CH}_{3}$ & $\mathrm{OCH}_{3}$ & $\mathrm{H}$ & $\mathrm{CH}_{3}$ & $\mathrm{OCH}_{3}$ \\
\hline
\end{tabular}




\begin{tabular}{|c|c|c|c|c|c|c|c|}
\hline dimethoxyamphetamine & & & & & & & \\
\hline $\begin{array}{c}\text { 4-Bromo-2,5- } \\
\text { dimethoxyamphetamine }\end{array}$ & DOB & $\mathrm{H}$ & $\mathrm{CH}_{3}$ & $\mathrm{OCH}_{3}$ & $\mathrm{H}$ & $\mathrm{Br}$ & $\mathrm{OCH}_{3}$ \\
\hline $\begin{array}{c}\text { 4-Chloro-2,5- } \\
\text { dimethoxyamphetamine }\end{array}$ & $\mathrm{DOC}$ & $\mathrm{H}$ & $\mathrm{CH}_{3}$ & $\mathrm{OCH}_{3}$ & $\mathrm{H}$ & $\mathrm{Cl}$ & $\mathrm{OCH}_{3}$ \\
\hline $\begin{array}{c}\text { 4-Iodo-2,5- } \\
\text { dimethoxyamphetamine }\end{array}$ & DOI & $\mathrm{H}$ & $\mathrm{CH}_{3}$ & $\mathrm{OCH}_{3}$ & $\mathrm{H}$ & I & $\mathrm{OCH}_{3}$ \\
\hline $\begin{array}{c}\text { 4-Ethyl-2,5- } \\
\text { dimethoxyamphetamine }\end{array}$ & DOET & $\mathrm{H}$ & $\mathrm{CH}_{3}$ & $\mathrm{OCH}_{3}$ & $\mathrm{H}$ & $\mathrm{C}_{2} \mathrm{H}_{5}$ & $\mathrm{OCH}_{3}$ \\
\hline \multicolumn{8}{|c|}{ Other ring substitution patterns } \\
\hline $\begin{array}{l}\text { 3,4,5-Trimethoxy- } \\
\text { phenethylamine }\end{array}$ & Mescaline & $\mathrm{H}$ & $\mathrm{H}$ & $\mathrm{H}$ & $\mathrm{OCH}_{3}$ & $\mathrm{OCH}_{3}$ & $\mathrm{OCH}_{3}$ \\
\hline $\begin{array}{c}\text { para- } \\
\text { Methoxyamphetamine }\end{array}$ & PMA & $\mathrm{H}$ & $\mathrm{CH}_{3}$ & $\mathrm{H}$ & $\mathrm{H}$ & $\mathrm{OCH}_{3}$ & $\mathrm{H}$ \\
\hline $\begin{array}{l}\text { para-Methoxy- } \\
\text { methamphetamine }\end{array}$ & PMMA & $\mathrm{CH}_{3}$ & $\mathrm{CH}_{3}$ & $\mathrm{H}$ & $\mathrm{H}$ & $\mathrm{OCH}_{3}$ & $\mathrm{H}$ \\
\hline $\begin{array}{c}2,5- \\
\text { Dimethoxyamphetamine }\end{array}$ & DMA & $\mathrm{H}$ & $\mathrm{CH}_{3}$ & $\mathrm{OCH}_{3}$ & $\mathrm{H}$ & $\mathrm{H}$ & $\mathrm{OCH}_{3}$ \\
\hline $\begin{array}{l}\text { 3,4,5-Trimethoxy- } \\
\text { amphetamine }\end{array}$ & TMA & $\mathrm{H}$ & $\mathrm{CH}_{3}$ & $\mathrm{H}$ & $\mathrm{OCH}_{3}$ & $\mathrm{OCH}_{3}$ & $\mathrm{OCH}_{3}$ \\
\hline 4-Methylthioamphetamine & 4-MTA & $\mathrm{H}$ & $\mathrm{CH}_{3}$ & $\mathrm{H}$ & $\mathrm{H}$ & $\mathrm{SCH}_{3}$ & $\mathrm{H}$ \\
\hline
\end{tabular}


2. Instructional guidelines for the usage of the Perkin Elmer Thermo Cycler 480.

- Flip power switch into ON position.

- Press File button.

○ Select file number 1, "soak".

- Press, Step

- Adjust temperature to desired setting.

○ Press Enter

- Open instrument lid.

- Insert capped microvials in desired wells.

○ Close lid

- Press Start 
3. Instructional guidelines for the usage of the Beckman P/ACE MDQ system with laser-induced fluorescence detection.

\section{- Creating a method}

- Go to the menu bar. Select File.

- Select Method.

- Select New.

○ A dialog window has opened. Select Initial Conditions tab.

- Select auxiliary data channels that will be recorded and maximum values (voltage, current, pressure, etc.).

- Set cartridge temperature.

- Select peak detection parameters (width and threshold).

- Select LIF Detector Initial Conditions tab.

- Enable data acquisition channels.

- Set dynamic range (in RFU).

- Set filter settings.

- Select signal type (direct or indirect).

- Input laser/filter descriptions.

- Set data acquisition rate.

- Select Time Program tab. In each row define the action to be taken, magnitude, length of duration, and electrode positions.

- Capillary - sets capillary temperature for duration of method.

- Laser - alerts the detector to whether the external laser is on.

- Rinse - flushes capillary at high pressure from selected vial. 
- Injection - injects aliquot from vial into capillary. Can be done kinetically (by voltage) or hydrodynamically (by low pressure).

- Wait - sets capillary to wait in specific location.

- Separate - can be done via voltage, pressure, or vacuum.

- Autozero - sets baseline to zero as separation progresses.

- Running a method.

- Turn on laser from external power supply.

- Go to the menu bar. Select File.

- Select Method.

- Select Open.

- Choose the correct method file.

○ Go to the menu bar. Select Control.

- Select Direct Control.

- Select Load.

○ Open instrument lid.

- Place vials in the appropriate position.

- Close instrument lid.

- Select Run... 
4. Instructional guidelines for the usage of the Nemrodw experimental design software.

\section{- Creating a Doehlert matrix}

○ New Study - input desired filename and title of study

- Once a title has been given, options will become available for the type of study.

- Screening - Study of a large number of factors

- Main effects \& interactions - Study effects

- Response Surface - Study in experimental region

- Mixture - Study of mixtures

- Study in two disconnected experimental regions

- Principal composants analysis

- Select response surface.

- Design selection parameters

- Number of factors

- Region shape (spherical or cuboidal)

- Type of model (linear, quadratic, special)

- For Doehlert select spherical and quadratic.

- Press OK

- Classes of experimental design

- Standard experimental matrix

- Importation of experimental design

- Hand built experimental matrix 
- Imported or constructed Datasheet

- Product experimental design

- Select "standard experimental matrix"

- Press OK

- Spherical experimental region

- Matrix

- Doehlert

- Composite

- Box-Benhken

- Hybride

- Indicators for each design are shown

- Number of experiments

- Number of levels

○ Select Doehlert

- Characteristics of experimental matrix

- Number of replicates

- Modification of size of domain

- Number of center runs

- Already included

- To be added

- Total number of center runs

- This option is utilized if additional readings at the center of the experimental region are desired. 
- Construction of the experimental matrix

- Addition of another experimental matrix

- End of construction

- Addition of check points

- If satisfied with current design, press OK.

- Coded matrix is produced in Datasheet.

- Go to experimental matrix tab

- Select copy

- Paste into Excel

- Press OK

- Description of quantitative factors

- Name of factor

- Units

- Center of domain (center point of experimental range)

- Step of variation (distance between center and ends of experimental range)

- Number of decimals

- After entering data, press ok.

- $\quad$ Repeat for every factor being assessed.

- Uncoded matrix is produced (gives actual experimental values for each factor in each experiment).

- Select randomization if desired.

○ Go to experimental matrix tab 
- Select copy

- Paste into Excel

- Press OK

○ Press close

- Inputting responses to the Doehlert matrix

- Response dialog box has three categories.

- Investigation editing

- Design evaluation

- Treatment

○ Investigation editing

- Study summary

- Number of factors

- Number of experiments

- Number of model coefficients

- Number of responses

- Model (quadratic equation)

- Experimental region

- Experimental matrix

- Factor descriptions

- Datasheet

○ Design evaluation

- Information and dispersion matrices

- Design summary 
- Correlation matrix

- Eigenvalues and eigenvectors

- Model matrix

- Isovariance curves (2 or 3-dimensional contour plots)

- Alias matrix

- Statistics of variables (box plot)

○ Treatment

- Modify/enter responses

- Modification/addition of experiments to experimental matrix

- Modification/addition of experiments to the Datasheet

- Deactivation of some experiments (check points)

- Modification/addition of responses to the experimental matrix

○ Select and input responses

- Modification/addition of responses to the Datasheet

- Model modification (removing coefficients)

- Special matrix

- After responses are inputted, two more options become available.

- Calculate coefficients of model

- Desireability

- Select "calculate coefficients" 
- Based on response selected, two groups of analytical options are provided.

- Multilinear regression

- Analysis of variance

- $\quad$ Fit summary

- Residuals

- Diagnostic plot of residuals

- Tools for interpretation

- Graphical study

- Canonical analysis

- Study of optimal path

- Study of sensitivity

- Special studies 
BRITT E. TURNQUEST

Born, Nassau, New Providence, Bahamas

2001-2003

AA Chemistry (incomplete)

College of the Bahamas

Nassau, New Providence, Bahamas

2003-2006

BSc Chemistry

Acadia University

Wolfville, Nova Scotia, Canada

2007-2013

Teaching Assistant

Florida International University

Miami, Florida

Doctoral Candidate

Florida International University

Miami, Florida

LACC Fellow

Florida International University

Miami, Florida

\section{PUBLICATIONS AND PRESENTATIONS}

Turnquest, B.E., McCord, B.R. (2010). Inline Derivatization and Detection of Primary and Secondary Amine Containing Drugs via CE-LIF. Poster presented at the American Academy of Forensic Sciences Annual Meeting, Seattle, Washington; Florida International University Annual Scholarly Forum, Miami, Florida.

Turnquest, B.E., McCord, B.R. (2012). Electrophoretic Separation of Drugs of Abuse Using Laser-Induced Fluorescence Detection. Poster presented at the American Academy of Forensic Sciences Annual Meeting, Atlanta, Georgia; Florida International University Annual Scholarly Forum, Miami, Florida; International Forensic Research Institute Forensic Science Symposium, Miami, Florida.

Turnquest, B.E., McCord, B.R. (2013). Effect of Organic Modifiers on Separation of Fluorescently Labeled Phenethylamines in Capillary Electrophoresis. Poster presented at the American Academy of Forensic Sciences Annual Meeting, Washington, DC; Florida 
International University Annual Scholarly Forum, Miami, Florida; International Forensic Research Institute Forensic Science Symposium, Miami, Florida. 